\title{
Technology, work and organisation : a study of the nursing process in intensive care units
}

Citation for published version (APA):

Groen, M. A. H. (1995). Technology, work and organisation : a study of the nursing process in intensive care units. [Doctoral Thesis, Maastricht University]. Datawyse / Universitaire Pers Maastricht. https://doi.org/10.26481/dis.19951005mg

Document status and date:

Published: 01/01/1995

DOI:

10.26481/dis.19951005mg

Document Version:

Publisher's PDF, also known as Version of record

\section{Please check the document version of this publication:}

- A submitted manuscript is the version of the article upon submission and before peer-review. There can be important differences between the submitted version and the official published version of record.

People interested in the research are advised to contact the author for the final version of the publication, or visit the DOI to the publisher's website.

- The final author version and the galley proof are versions of the publication after peer review.

- The final published version features the final layout of the paper including the volume, issue and page numbers.

Link to publication

\footnotetext{
General rights rights.

- You may freely distribute the URL identifying the publication in the public portal. please follow below link for the End User Agreement:

www.umlib.nl/taverne-license

Take down policy

If you believe that this document breaches copyright please contact us at:

repository@maastrichtuniversity.nl

providing details and we will investigate your claim.
}

Copyright and moral rights for the publications made accessible in the public portal are retained by the authors and/or other copyright owners and it is a condition of accessing publications that users recognise and abide by the legal requirements associated with these

- Users may download and print one copy of any publication from the public portal for the purpose of private study or research.

- You may not further distribute the material or use it for any profit-making activity or commercial gain

If the publication is distributed under the terms of Article $25 \mathrm{fa}$ of the Dutch Copyright Act, indicated by the "Taverne" license above, 


\section{Technology, work and organisation}

a study of the nursing process in intensive care units

\section{PROEFSCHRIFT}

ter verkrijging van de graad van doctor aan de Rijksuniversiteit Limburg te Maastricht, op gezag van de Rector Magnificus, Prof. mr. M.J. Cohen, volgens het besluit van het College van Dekanen, in het openbaar te verdedigen op donderdag 5 oktober 1995 om 14.00 uur

door

Margaretha Anna Hendrika Groen 


\section{Promotor:}

Prof. dr. J.F. den Hertog

\section{Leden van de beoordelingscommissie:}

Prof. dr. W.E. Steinmueller (voorzitter)

Prof. dr. ir. W.E. Bijker

Prof. dr. W. van Rossum (Rijksuniversiteit Groningen)

Prof. dr. A. van Witteloostuijn

\section{CIP-GEGEVENS KONINKLIJKE BIBLIOTHEEK, DEN HAAG}

Groen, Margaretha Anna Hend rika

Technology, work and organisation: a study of

the nursing process in intensive care units /

Margaretha Anna Hendrika Groen. - Maastricht:

Universitaire Pers Maastricht. - Ill.

Proefschrift Maastricht. - met lit. opg. - met samenvatting in het Nederlands. ISBN 90-9008671-4

trefw.: medische technologie / ziekenhuisorganisatie / verpleegkundigen

(C) 1995, M.A.H. Groen, Maastricht 
Voor mijn moeder, ter nagedachtenis aan mijn vader 



\section{Contents}

Foreword

Chapter 1 Introduction 1

1.1 Automation at the bedside 2

1.2 Methods and outlook of the study 3

1.3 Intensive care in the Netherlands 4

1.4 Structure of the thesis 9

Chapter 2 Technology in health care 11

2.1 Technological change in health care 11

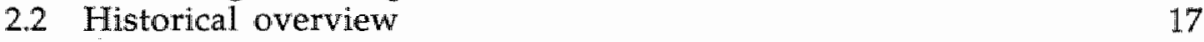

2.3 Ethics 21

2.4 Economics 22

2.5 Psychological studies $\quad 24$

2.6 Sociological studies $\quad 30$

2.7 Man-machine interaction 36

2.8 Conclusions $\quad 39$

$\begin{array}{lll}\text { Chapter } 3 & \text { Research methodology } & 43\end{array}$

3.1 Conceptual framework and research questions in qualitative research

3.2 The case study strategy in exploratory research 47

3.3 Methods of investigation 50

3.4 Grounded theory as method of analysis 53

3.5 Chronology of the research process 54

3.6 Reflections $\quad 59$

3.7 Conclusions 64

Chapter 4 Careers in nursing 65

4.1 Method and sample 65

4.2 Going into nursing $\quad 69$

4.3 Specialising in intensive care $\quad 70$

4.4 Working in intensive care $\quad 74$

4.5 Perspectives on differences between types of ICU

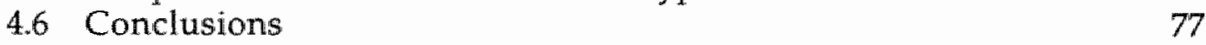


Chapter 5 A model of the work process

5.1 Complex care and the functions of technology

5.2 Life on the ward 81

5.3 Activities 86

5.4 Overview of the model 90

$\begin{array}{ll}5.5 \text { Hands-on routine } & 92\end{array}$

5.6 Hands-on emergency 94

5.7 Hands off 96

5.8 Vigilance 97

$\begin{array}{ll}5.9 \text { Conclusions } & 100\end{array}$

Chapter 6 Working and learning 101

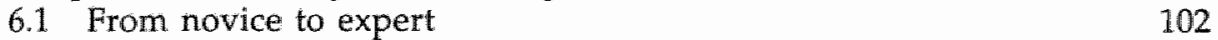

6.2 Single-loop and double-loop models of decision-making 105

6.3 Information handling and learning 106

6.4 Roles of technology 111

6.5 Teamwork in patient care $\quad 115$

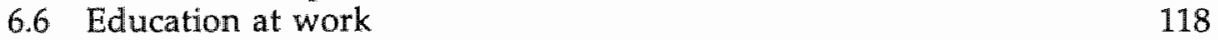

$\begin{array}{lll}6.7 \text { Condusions } & 124\end{array}$

$\begin{array}{lll}\text { Chapter } 7 \text { Discussion } & 127\end{array}$

$\begin{array}{ll}7.1 \text { Work and technology } & 127\end{array}$

$\begin{array}{ll}7.2 \text { Gender issues } & 129\end{array}$

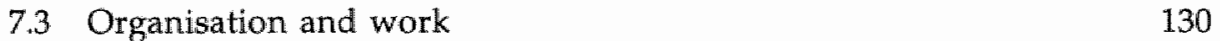

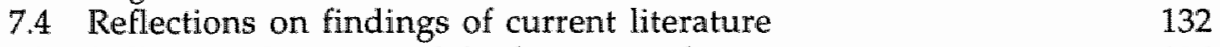

7.5 Policy conclusions and further research 136

$\begin{array}{lr}\text { Bibliography } & 139\end{array}$

Samenvatting (Summary in Dutch) $\quad 147$

Curriculum vitae 151 


\section{Foreword}

Medical technology fascinates me. During my undergraduate studies in health care administration I was introduced to the fields of innovation studies and technology assessment in health care. I wrote my thesis on the organisational aspects of the Dutch heart-transplantation programme, a high-profile innovation at the time, and decided to go and study Science and Technology Policy in Manchester. I finished this course with a thesis on the automation of clinical chemistry laboratories that was supervised by Dr K. Green and Professor John V. Pickstone.

While looking for a way to use this knowledge in further research I came across a vacancy for PhD student at the Faculty of Economics of the University of Limburg to investigate new information technologies and women's employment. It was agreed that I could bring my own research interests to bear on this project and I decided to explore the medical sector for issues of gender and technology. Within health care I decided to focus on hospitals as these are places where medical technology is concentrated.

I interpreted 'information technology' in a broad sense, including all equipment that is used for handling data by means of micro-electronics. This allowed me to study diagnostic and monitoring equipment that is used in patient care and is thus unique to the primary process of the hospital organisation. Finding women who work with technology in hospitals is, perhaps surprisingly, easy. Clinical chemistry and radiology are two areas where the equipment is mainly operated by women. Intensive care appealed to me because it combines bedside care with high technology. Unlike clinical chemistry and radiology, intensive care is a specialisation within nursing. Thus, in intensive care, people who are qualified as nurses have to acquire the skills to handle complex technology.

With respect to the gender aspect of intensive care nursing, I found that between types of intensive care units (ICUs) the relative numbers of men and women vary considerably. Whereas the nursing population in general contains $15 \%$ men, most general ICUs employ around $50 \%$ male nurses. In ICUs for children (paediatric ICUs) and for newborn babies (neonatal ICUs) the percentage of male nurses is often less than $10 \%$. It was decided to look at career patterns of intensive care nurses and at the practice of nursing in the three types of ICUs to gain some understanding of why male and female nurses differ in their choices.

Undertaking $\mathrm{PhD}$ research is fraught with uncertainties and requires professional guidance. Il am very grateful to my supervisor, Professor Friso den Hertog, for the way in which he managed this project. As a true expert he intuitively knows where the problem lies. Friso understands that I learn by doing and he has created the ideal learning conditions by providing involved advice at crucial times. His encouragement has helped me to deal with the open-ended nature of scientific research and his keen interest in methodological issues stimulated me to explore new research methods. 
Although I was employed by the Faculty of Economics, my work place was at MERIT, because of the relations that my work has with the research that is conducted there. There, and in other faculties, I have met people who made useful suggestions for my research as well as people who have become dear friends. In particular, I wish to thank Thera Tolner and the participants of two discussion groups that I joined: IVO, where approaches to gender studies are discussed as well as ways to create a structural place for gender studies in the university, and BOTS, chaired by Professor W. Bijker, where the debates concern research on technology and society.

During my field work I have met many people who have been very friendly and helpful. It was very inspiring to talk to nurses and doctors who are enthusiastic about their work and it was fascinating to follow them around. I am deeply grateful to the following medical heads of departments who welcomed me on their wards: Professor C. Blanco and Dr G. Vos in Maastricht, Professor J. Koppe and Dr R. de Leeuw in Amsterdam, Professor P. Sauer, Professor D. Tibboel, Dr E. van der Voort and Dr B. van den Berg in Rotterdam.

I want to thank the following head nurses for their cooperation: Janine Mouthaan, Jean-Pierre Gielen, Hans Nelissen, Christien ten Brink, Wil de Groot, Wout Alers, Cock Ouwens and Jeanne de Vetter as well as the Director of Nursing at the teaching hospital in Rotterdam, Ms. C. Breugem. Special thanks are due to Harry Topman for the interest he showed in this project and for the comments he made on some of the draft chapters. Interviews with Corrie Suijkerbuijk and Fons de Jonge, members of the nursing section of the Nederlandse Vereniging voor Intensive Care, were also very helpful at the early stages of this project.

I am grateful to Kenneth Gilbert, whose thorough comments and proof-reading of the manuscript have made a big difference in its readability. I also gratefully acknowledge the extensive and helpful remarks that Professor W.E. Steinmueller made on the previous version of this text.

I thank my mother for showing a great deal of interest in my work and for the valuable insights and practical advice she has offered on many occasions. Finally, I would like to thank James Small, my husband, for his continuous support. We had fruitful discussions troughout the project, he read the drafts and made valuable recommendations to improve the text. Above all, he is a great partner to live with. 


\section{Chapter 1}

\section{Introduction}

"The landscape of modern health care is filled with machines. Its features are marked by their angles and metallic surfaces and enveloped by an atmosphere of mechanical bleeps and clicks, which denote a vital presence at the same time reassuring and distracting."

Reiser and Anbar (1984) The machine at the bedside, p. 3

Ten years after Reiser and Anbar published their book on the use of technology in patient care, the landscape of modern health care is indeed filled with machines. If anything has changed, it is that there are more machines at the bedside and that they are more complex. This is particularly true of intensive care units (ICUs), where the sheer number of machines at the bedside is at the same time reassuring and distracting, their mechanical bleeps and clicks being ever present. ICUs are units where the technology is highly visible, and at a first glance they appear to fit the image of a work place where automation has progressed to the extent that essential tasks are carried out by machines. Yet, while the role of technology in patient care is clearly important, the present study argues that the provision of care remains in essence a human activity and constitutes a service that can only be realised by people for other people. The present study explores how technology at the bedside is given a role in the process of patient care on ICUs, and focuses on the work of nurses who are the main providers of this care.

The study adopts a gender studies perspective as it addresses the careers, motivations and actions of male and femalle nurses. Intensive care nursing is an exceptional area of nursing as it attracts a relatively large number of male nurses, and this raises two issues with regard to the role of technology. Firstly, it has been suggested that men are attracted to the ICU because of the technology, and secondly that in the work process men pay more attention to the technology than women do. These points are elaborated below. In this chapter the nature and extent of bedside automation are discussed and an outline is presented of the perspective that is adopted in this study. This is followed by an overview of the organisation of intensive care in the Netherlands, both at the national level and at the level of the ward. The chapter is concluded with an outline of the structure of the thesis. 


\subsection{Automation at the bedside}

The increased rate of application of computers and other automated equipment to the work process after World War II intensified the 'automation debate'. The prospect of the automated work place was associated on the one hand with the loss of those jobs that would be taken over by the machines, and on the other hand it was expected that the remaining jobs would require fewer skills. With regard to the practice of medicine, Reiser (1978) argues in his book Medicine and the reign of technology that the relationship between the doctor and the patient is changing as the use of machines becomes more widespread. On the basis of a historical analysis of the techniques that doctors use to gather information about the patient, Reiser argues that as the data-gathering technique changes, so does the relationship between the doctor and the patient. He distinguishes three stages in this process, starting in the nineteenth century. Initially, the doctor used verbal techniques to discover what the patient experienced. This was followed by a stage in which techniques of physical examination became more important. Both these stages only involve the doctor and the patient and are characterised by direct contact. The third stage, according to Reiser, is characterised by an indirect connection of the doctor with the experiences and the body of his or her patient, namely through machines and technical experts who operate these machines. The reason why medicine has turned to machines to provide diagnostic information about the patient, stems from a desire to make medical evidence standardised and reproducible. Yet, this has resulted in a one-sided perspective on the patient's problems, as is argued by Reiser in the following quotation:

"Machines inexorably direct the attention of both doctor and patient to the measurable aspects of illness, but away from the 'human' factors that are at least equally important. Insofar as technological evidence occupies the time and commands the chief allegiance of both doctor and patient, it diminishes the possibility that a close personal relationship will develop between the two. So, without realising what has happened, the physician in the last two centuries has gradually relinquished his unsatisfactory attachment to subjective evidence - what the patient says - only to substitute a devotion to technological evidence - what the machine says."

Reiser (1978) Medicine and the reign of technology, pp. 229-230

Not only is machine-generated information partial as it deals exclusively with the measurable aspects of illness, it is in addition not objective or flawless because the results are inevitably influenced by the technical experts who operate the machines and those who evaluate the outcomes. Thus, too much faith in the objective nature of these data is misplaced. Yet, the real danger of the movement towards greater reliance on technological evidence lies, according to Reiser, in the fact that the skills in using the old, direct techniques have declined. Reiser argues that the new techniques require different skills and that these skills substitute the old ones that were relevant to the old techniques. Social pressure within the profession would ensure that new skills were valued more than old ones, thus accelerating the acceptance of the new techniques. Thus, in Reiser's view, some skills are substituted by other skills, but eventually some of the human skills become obsolete as they are replaced by machines. This mechanism of substitution is explored in the present study. Although we do not wish to take issue with Reiser's excellent and inspiring historical analysis, we do suggest that at the 
present time the use of technology requires accumulation of skills rather than substitution, at least within the specific environment of ICUs. This finding is based on the research that is presented in this thesis and therefore reflects the situation with regard to the care process as it is carried out by the nurses. As Reiser (1978) has indicated, many medical technologies are not operated by doctors but instead by nurses and other allied health workers. Doctors are thus relieved of a number of tasks, while the responsibilities of nurses and others are increased. This is certainly true of the practice of intensive care where nurses are responsible for continuously monitoring the condition of the patient with the use of a wide variety of medical equipment. Thus, in order to explore how technology is used in patient care, it is essential to study the work process of nurses.

The perspective that is adopted in the present study, then, incorporates the following aspects. It perceives the relations between technology and work as far more complex than mere substitution. Although technology has automated specific medical tasks, the use of technology has not diminished the role of expert knowledge in the assessment and provision of high-quality care by either doctors or nurses. Developments in medical technology have greatly contributed to the expansion of the possibilities for diagnosis and treatment by adding new functions to the existing range, but patients can only benefit from these advances if skilful hands and watchful minds are applied to them. Further, technology must be given a role in the work process, and this requires negotiation. The partial nature of the machine-generated information was mentioned before, and part of the negotiations are therefore aimed at the construction of an image of the patient in which several sources of information are integrated. Another element in the negotiations deals with the unreliability of machine-generated information. A picture thus emerges of medical technology as an additional source of information that simultaneously introduces additional uncertainties in the work process. How nurses cope with this information and with these uncertainties in addition to the information and uncertainties that normally surround the work, is the main question of this study.

\subsection{Methods and outlook of the study}

In this study the work process is investigated by means of participant observations and interviews on eight ICUs in four hospitals. The methods allow the researcher direct access to practice, and this enables us to explore what nurses actually do as well as what they think about what they are doing. Thus, the work process is observed as it takes place and the researcher is in a position to ask nurses to explain what is happening, and therefore to clarify the situation. Being there, and staying in the setting for a number of weeks, also gives the researcher an opportunity to invite the nurses to reflect on their work and careers. By moving the research to a new setting, the researcher becomes more sensitive with regard to whether particular findings are specific to a particular location or whether they have implications for a general theory. A further elaboration of the methodological considerations as well as a detailed description of the research design and the research process can be found in Chapter 3. The choice of direct methods of investigation is in line with the general outlook of this study in which the work process is the central topic. This approach also pertains to the gender 
issues that are addressed in this study. The chief concern with regard to this issue is if and how gender differences are borne out in the practice of intensive care nursing. We supplement this with an analysis of the careers and motivations of male and female nurses. Thus, the study primarily seeks to establish if male and female nurses contribute to the work process in different ways, against the background of their views on nursing. Surveys have shown that intensive care is an area of nursing in which relatively large numbers of male nurses want to work and in fact do work. Since nursing has traditionally been a female-dominated profession, it is of interest to see that the small minority of male nurses has concentrated in a few areas, including intensive care. However, as is shown in this study, there are different types of ICU and these attract various levels of male nurses. The general ICUs, where mainly adults are treated, have disproportionately high numbers of male nurses, whereas the paediatric and neonatal ICUs are staffed predominantly by female nurses. This difference is explored in the present study through analysis of the career paths of male and female nurses and is reported in Chapter 4. An outline of the types of ICUs and their characteristics is provided in Section 1.3 below. Since we exclusively study those nurses who were working on an ICU at the time of the data collection, the results should be interpreted accordingly and cannot explain the larger issues of gender differences in nursing.

\subsection{Intensive care in the Netherlands}

Before we turn to an overview of the organisation of intensive care in the Netherlands, some key figures are provided for the Dutch health care sector and the hospital sector in particular. The health care sector as a whole employs 650,000 persons, or $11 \%$ of the national workforce in the Netherlands (Source: FOZ 1995). A considerable number of these persons do not have a full-time job, since there are 450,000 full-time positions that are filled by 650,000 persons. Moreover, $81 \%$ of those persons working in health care are women, whereas nationally, across all sectors, only $36 \%$ of the workforce are women. Total spending on health care in the Netherlands has remained stable over the past decade at around $10 \%$ of GNP. However, expenditure in real terms increased from 32.9 billion guilders in 1980 to 57.4 billion guilders in 1993. Wages form a considerable part of health care expenditure, with general hospitals spending $57.4 \%$ of their budgets on wages and teaching hospitals $65.1 \%$.

There are 113 general hospitals with a total of 50,537 beds in the Netherlands and 9 teaching hospitals with a total of 7,599 beds. Practically all of the inhabitants of the Netherlands are insured for the costs of health, care and hospital treatment is free at the point of delivery. Over $95 \%$ of the general hospitals have an ICU, while the teaching hospitals and other large hospitals usually have several specialised ICUs, such as surgical, medical, neurological or neurosurgical units. The number of ICU beds per hospital is related to the size of the hospital, and ranges from $3.5 \mathrm{ICU}$ bed on average in a general hospital with fewer than 150 beds to 26 ICU beds in general hospitals with more than 600 beds. All teaching hospitals have more than 600 beds and an average number of $43.7 \mathrm{ICU}$ beds (Source: NZI, 1992). 
Intensive care is for those patients who need, and can benefit from, more specialised attention than is available in the standard wards of a hospital. In order to establish what intensive care consists of, we provide the following definition:

"An intensive care unit is a special care unit in a designated area of a hospital, which supplies specially trained medical, nursing and other personnel and diagnostic, monitoring and therapy equipment in order that seriously ill patients may be provided with close observation, intensive care, and with immediate recognition of potentially life-threatening complications and prompt institution of indicated treatment."

Skillman (1975) Intensive care, p. 569

This study deals with units for intensive care as described above. Thus, a number of specialised units for special care are outside the scope of this study, namely the cardiac care units and dialysis units, where generally no respiratory support is available, and the neurological, neurosurgical, cardio-surgical and other ICUs that are specialised in one particular group of medical conditions. Within the study three types of ICU are distinguished: general ICUs where mainly adults are treated, paediatric ICUs where children up to the age of 16 are treated, and neonatal ICUs where newborn babies are treated. We will use the abbreviations GICU, PICU and NICU respectively to refer to these types of intensive care units. Each type of ICU is discussed briefly below. Then follows an outline of the Dutch system of nursing education and some remarks about the employment situation for intensive care nurses. The section concludes with a description of some organisational features of Dutch ICUs.

\section{General intensive care units}

The majority of intensive care beds in the Netherlands are on GICUs. The nursing staff on GICUs consists of intensive care nurses and nurses in training for intensive care. Medical staff are mostly consultants of medicine, surgery or anaesthesiology, and in a few places there are consultants of intensive care, the 'intensivists'. In addition to the consultants there are junior doctors who have just finished theoretical training at medical school ('co-assistenten'), and qualified doctors ('assistenten') who are usually doing a specialisation. Those specialists who are working towards a qualification as intensivists, are called 'fellows'.

\section{Paediatric intensive care units}

Paediatric intensive care is a relatively new area that was established through pioneering work in paediatric hospitals. There are PICUs in six teaching hospitals in the Netherlands. The nursing staff consists of paediatric nurses, paediatric intensive care nurses and paediatric nurses in training for paediatric intensive care. The medical staff consists of paediatricians, doctors in training for paediatrics, and paediatricians in training for paediatric intensive care. Since 1982 there have been consultants who specialise in paediatric intensive care, the 'paediatric intensivists". This is still a very small group: by December 1993 there were only 11 paediatric intensivists practising in the Netherlands.

\section{Neonatal intensive care units}

The NICU exclusively treats newborn babies that are often born prematurely or suffer from birth defects or congenital diseases. Neonatal intensive care is also a small area with 12 units in the country: one in each teaching hospital and three in 
general hospitals. Since 1983 neonatal intensive care facilities have been subject to special government regulation according to Article 18 of the Wet Ziekenhuisvoorzieningen (Hospital Provisions Act). The Wet Ziekenhuisvoorzieningen is an important instrument in the planning of health care facilities, and has the aim of ensuring quality of service, geographic accessibility and efficient use of resources. Article 18 governs the permission for hospitals to purchase and exploit expensive medical treatment facilities. Thus, some hospitalls are appointed to offer one or more of these facilities, such as magnetic resonance imaging (MRI), in vitro fertilisation (IVF), heart transplants and liver transplants or neonatal intensive care, while other hospitals are not allowed to offer these facilities. The number of NICU beds has increased from 124 in 1987 to 187 in 1991. The nursing staff consists of neonatology nurses and paediatric nurses in training for neonatology. In some NICUs training is provided for qualified intensive care nurses who do not have a paediatric certificate. Medical staff are neonatologists (consultants), paediatricians in training for neonatology (fellows), doctors in training for paediatrics (assistants).

\section{Nursing education and employment}

The Dutch system for nursing education offers two ways into nursing: education 'in-service' by a combination of working and learning, or education in a school of 'higher vocational training'. In each case the duration of the education is approximately four years. The in-service system offers a general diploma for those who train in a general or teaching hospital, or specialised diplomas in mental health or psychiatry. These students are at the same time employees and pupils in the hospital. The school education is aimed at a general nursing training that is more theoretical and pays attention to analytical and communication skills. It includes work-place visits during which the students can experience the work but are not put into positions of responsibility. These visits take the students to various fields in health care, so that they get a comprehensive picture of areas they may work in. Although they are trained for nursing, many are attracted to administrative and middle management functions. In order to become a practising nurse one has to follow one of the two paths outlined above. Both groups receive the general or 'A-diploma', which is nationally recognised. University degrees in nursing can only be obtained through an undergraduate course in nursing science. The first course in nursing science was offered in 1980. Initially, it was a prerequisite for prospective students to have obtained a diploma in nursing. Recently, this condition has been lifted. The degree does not, however, entitle the graduate to practice nursing.

\section{Specialisation}

There are two ways to specialise in one area of nursing after the general diploma: for some areas there are nationally recognised certificates, and for other specialisations the hospitals offer their own courses. Specialist certificates in community nursing, obstetric nursing, paediatric nursing and intensive care nursing are nationally recognised, and a national register is kept of the nurses who obtain the certificates. There are guidelines for the duration of each course, the subjects that should be covered, the amount of time that should be spent on each subject, the skills that should be developed and the areas that should be tested by examination. Whereas most of these specialisations have been recognised for a long time, intensive care nursing was only recognised in April 1992. The courses 
that are not nationally recognised or registered, are generally referred to as "house educations". These courses are organised or commissioned by the hospital to provide nurses with specific skills and theoretical knowledge that the nurses need to work in a particular area. This system applies to paediatric intensive care, neonatal intensive care and other fields such as dialysis and oncology.

\section{Employment in general intensive care}

The employment situation for nurses is characterised by peaks and troughs. Although it is recognised that some hospitals and even wards within hospitals experience greater difficulties in attracting and keeping staff, there are national patterns. For general nursing the troughs are periods in which nurses receive their diploma and their dismissal notice from the hospital at the same time. At peak times the new graduates can pick and choose where they want to work. Because there are many specialisations in nursing, staff shortages in one area are not necessarily representative of the profession as a whole. The labour market for intensive care nurses has traditionally been characterised by a shortage of nurses. Qualified intensive care nurses used to be certain of finding work in an ICU, either in the hospital of their training or elsewhere. ICUs experienced rapid staff turnover and this meant that there was always demand for intensive care nurses. Yet, this situation began to change in 1992 as the salaries for intensive care nurses rose, staff turnover declined and the increase in the number of IC beds came to a halt. Trainees for intensive care nursing could no longer expect to be placed on an ICU once they completed their training. Depending on the kind of contractual arrangements these trainees had with the training hospital, this meant that some of these nurses were dismissed, while others were placed on wards experiencing a shortage of qualified nurses. This situation continues.

\section{Employment in paediatric and neonatal intensioe care}

In paediatric intensive care and neonatal intensive care the situation is different. Traditionally, there has been little exchange of staff among PICUs, among NICUs or between the two. There is only a small number of units in the country, and consequently there are few qualified nurses. "The units attempt to be self-sufficient, in that they train the number of nurses that they need in order to counterbalance the need for new staff as a result of staff turnover and/or expansion of the unit. Thus, recruitment of qualified neonatal or paediatric intensive care nurses is practically always indirect. The requirement that candidates must have specialised in paediatric nursing before they can enter the paediatric or neonatal intensive care training reduces the potential population from which candidates can be recruited. In particular those units that are expanding have difficulties attracting enough candidates. Therefore, some units are recruiting intensive care nurses as well as paediatric nurses.

\section{Ward organisation}

Generally speaking, the ward management consists of a head nurse and one or more 'team leaders', the number depending on the size of the ward. The head nurse and the team leaders work office hours and five-day weeks. The team leaders have usually taken middle management training and are responsible for the daily activities on their unit. They spend a part of their time performing patient care, for example one day per week. The head nurse is further removed 
from direct patient care and has responsibilities in management, administration and planning. The nursing staff is usually not further divided into hierarchical levels. All bedside nurses work shifts, whether they have part-time or full-time contracts. There are three shifts that generally follow the pattern that is outlined here: early: 7.30-16.00, late: $15.30-23.30$, night: $23.15-8.00$. Nurses on ICUs have some freedom to organise their own working times by submitting their preferred shifts for a four-week period.

The qualified intensive care nurses on the ward operate as a team that is responsible for patient care. They are also responsible for supervision and instruction of the trainees who are working on the ward as part of their training for a certificate of specialisation. Occasionally there are visiting nurses on the ward from other departments, or nurses who work on the ward as part of the preparation for a specialisation course, the 'pre-workers'. Visiting nurses and preworkers have few responsibilities on the ward, and trainees are given more complex situations to deal with as they gain more experience. For the planning of staffing levels for each shift, this means that both a quantitative and a qualitative assessment has to be made.

On Dutch ICUs the medical and nursing staff are the two main groups responsible for patient care. Following the instructions of the doctors, most of the work on and around the patient is carried out by the nurses. This includes the handling of the bedside equipment that is used in the treatment of the patient, such as intravenous drips, cardiac pace-makers, Swan-Ganz catheters, ventilators, vital-signs monitors, defibrillation pads and in some hospitals continuous arterial-venous haemodialysis (CAVHD) or extra-corporal membrane oxygenation (ECMO). For tasks away from direct patient care, most wards employ a secretary and a household assistant. Every ward has an arrangement for technical support with the technical maintenance department of the hospital. Many wards have a technician on site during the day and on call at other times. The operation of diagnostic equipment such as $X$-ray, ultrasound and EEG is done by staff of the relevant department, who are called in by the doctors and usually bring their own equipment. Physiotherapists and dieticians are generally not employed by the ward either and are called in when nescessary.

\section{Two ways to divide the work: patient assignment and task assignment}

There are two principal ways to divide the nurses' work. One way is to assign each nurse a task, and the other way is to assign each nurse a patient. In the system of task assignment a nurse will perform one task for all the patients and then go on to the next task. Therefore, the tasks are divided at the start of the shift and are assigned to the nurses: nurse $A$ takes the temperature, nurse $B$ distributes the medication, and so on. The patient sees many nurses during the shift, and they all come to perform their own task. In the system of patient assignment the organising principle for the work of the nurse is the patient or patients to whom the nurse is assigned during the shift. This means that the nursing tasks that need to be performed for the patient are all performed by the same nurse. In the patientoriented system one could say that the patients are allocated at the beginning of the shift: nurse $A$ looks after patient $X$ and nurse $B$ looks after patient $Y$. In Dutch hospitals there has been a move away from the former to the latter form of horizontal differentiation. Extreme forms of the task assignment system are disappearing, but elements of it can still be found in many places. The extreme 
form of patient assignment is also rare, and work organisation usually contains elements of both systems.

On ICUs the nurses decide at the beginning of the shift how patients will be allocated. Each nurse assumes the responsibility for one or more patients. If the nurse is still in training, he or she will be assigned to a patient on the basis of the skills that are required in the care of that patient. On the one hand the patient should not be 'too difficult', and on the other hand there should be enough 'learning points' in the case. The qualified nurses do not use the argument of skill in their choice of a patient. Elements of task assignment on these units are to be found in the arrangements that are made for the preparation and distribution of medication, restocking of general supplies on the unit, emptying the bins and checking on the state of the emergency equipment. Some of these tasks are not directly related to the care of an individual patient and are therefore done by a nurse who has some time on his or her hands. There are differences between wards, as in some general intensive care units each nurse prepares the medication he or she needs for the patient. In paediatric and neonatal intensive care it is sometimes considered more efficient to assign the preparation of medication to one nurse, because then the whole batch can be checked by another nurse who distributes it. Before giving the medication to the patient, it is checked again by the nurse who is responsible for the patient.

The work organisation on Dutch ICUs is further explored in this thesis. The dual responsibilities of the team, on the one hand the quality of patient care and on the other hand the education of trainees, are discussed at length in Chapter 6, after an analysis of the structure of the work process in Chapter 5 .

\subsection{Structure of the thesis}

The main body of the thesis is divided into two parts. The first part contains Chapters 1, 2 and 3 in which the contextual and methodological background to the study is presented. The second part consists of Chapters 4,5 and 6 and is concerned with the results of the empirical study of the nursing process in ICUs. This is followed by a concluding chapter in which the findings of the study are summarised and conclusions for practice and further research are drawn.

Chapter 2 reviews the literature on technology in health care and adopts a multidisciplinary perspective. After a discussion of models of technological change in health care there follow six sections that outline the findings of research on a variety of aspects of intensive care. These sections are organised by discipline and are concerned with history, ethics, economics, psychology, sociology and philosophy of technology respectively. A concluding section summarises these findings and relates them to the research interests of the present study.

Chapter 3 is concerned with the methodological basis of the study. After consideration of the conceptual framework and the research questions of the present study, the relevant methods are discussed. Methodological issues concerning the research strategy, the methods of data collection and the methods of analysis are addressed with reference to the current literature. The present study adopts a case-study strategy, using participant observation and interviews for the collection of data and grounded theory methods for the analysis of the data. This is supplemented by a small-scale survey of intensive care nurses. An account is 
provided of the chronology of the research process, and an assessment of the validity and reliability of the present study is made on the basis of current methodological insights.

Chapter 4 presents the outcomes of a small-scale survey that was conducted during the periods of observation on eight intensive care units. The survey offers information regarding the career paths of 83 male and female intensive care nurses, their decisions to opt for a career in nursing, their motivation to specialise in intensive care nursing, and the perceptions they hold regarding the different types of ICUs.

Chapter 5 sets out to analyse the nursing process in ICUs. The theory presented in this chapter has been constructed during the research process from the material that was gathered mainly through observations and interviews. The resulting model reflects the dynamics of the nursing process by taking the observable actions of the nurses as its starting point. These actions are grouped into seven basic categories, referred to as 'activities'. On the basis of these activities four phases in the work process are identified and each phase is characterised by a particular pattern of activities. It is found that two recurring themes are crucial to the work process: nurses need skills in information handling, and teamwork is indispensable. These themes are explored further in Chapter 6 where the learning process of individual nurses and the coordination of the collective process of nursing are analysed. With regard to the individual learning process we use the five-stage model of skill acquisition as developed by Dreyfus and Dreyfus (1986), and the single-loop and double-loop models of decision-making of Argyris (1976). We combine these models into a model of learning which applies to skills in information handling and which is particularly suitable for the analysis of the role of technology in intensive care nursing. The second theme that we pursue in Chapter 6 is that of the nature of teamwork in intensive care. We perceive teamwork to be an enabling activity in the work process as it pertains to two central responsibilities of the team: assuring the quality of patient care and providing education for trainee nurses and junior doctors. Teamwork and the quality of patient care are discussed with regard to the coordination mechanisms that underlie teamwork, and it is concluded that two of the mechanisms as defined by Mintzberg (1979) are relevant: mutual adjustment and standardisation of skills. It is argued that standardisation of skills in the case of intensive care requires continuous learning, and this is illustrated for the skills that are taught to learners by experienced nurses and for the introduction of new technologies that require the entire team to acquire new skills.

Chapter 7 concludes the thesis by providing an overview of the findings and a discussion of the contribution this study makes to existing literatures on the relationships between technology, work and organisation. Three issues are addressed in this discussion: the relations between work and technology, gender issues, and the relations between organisation and work. These issues are discussed with respect to the findings of the present study. A comparison is made with the outcomes of the literature review that we present in Chapter 2 , and the discussion is concluded with recommendations for policy and suggestions for further research. 


\section{Chapter 2}

\section{Technology in health care}

Technology in health care is not the exclusive domain of one research discipline, but instead has proven to be an area that attracts researchers from a wide variety of disciplines. Hence, a review of the literature on technology in health care revealed contributions from the disciplines of history, economics, philosophy, sociology, ethics and psychology as well as research that originated in the fields of technological change and policy research. Since each study approached the area of technology in health care with the questions and methods of its own discipline, the findings of the review are diverse and the current state of knowledge can best be described as fragmented. In order to structure the presentation of the findings in this chapter, a number of questions have been formulated that summarise the main issues covered in the research to date. These questions are grouped into sections according to their disciplinary origins. A separation is however made between those questions that address the wider area of technological change in health care (Section 2.1) and those questions that deal with aspects of technology and work in intensive care (Sections 2.2 to 2.7 ). In the concluding section (2.8) an overview is given of the answers to these questions, and the findings of this review are discussed with respect to the issues of work and technology in intensive care which the present study seeks to explore.

\subsection{Technological change in health care}

Studies of technological change are often conducted with the aim of influencing the course of the change process and are thus concerned with technology policy. In health care in particular, studies known as technology assessments (TAs) have been carried out to provide pollicy information regarding the likely effects of the introduction of new technologies. However, there are also studies of technological change that are less concerned with policy but rather attempt to describe the patterns of change in order to form a theory. This section begins with the description of a simple model of technological change. This model distinguishes between the process of innovation or development and the process of diffusion. With regard to medical technologies a number of special characteristics of these processes are identified and discussed. An alternative theory of technological. change is then described. This theory is less concerned with the different stages of 
the process but instead focuses on the actors that are involved. The discussion then moves on to two methods of policy research each of which incorporates a theory of technological change. Both methods are used in the study of medical technologies: technology assessment (TA) and constructive technology assessment (CTA). This section is concluded with some reflections on the influence of technological change on medical practice, both at the level of the medical practitioners and at the level of the health care system as a whole.

What are the characteristics of innovation and diffusion of health care technologies and which models are used to study this process?

In economic analyses the process of technological change is usually, for analytical purposes, split into two stages: innovation or development and diffusion (Coombs et al, 1987; OTA, 1976; Banta and Luce, 1993). Each stage can be divided into a number of steps. In Figure 2.1 below, the development stage consists of basic research, applied research and targeted development, and the diffusion stage includes manufacturing and marketing, adoption and use. A similar model of technological change in health care was described by OTA in 1976 and is still used (eg. in Banta and Luce, 1993). This model distinguishes basic research, applied research, targeted development and first human use in the development stage, followed by clinical trials, early adopters, late adopters and accepted practice or disuse in the diffusion stage.

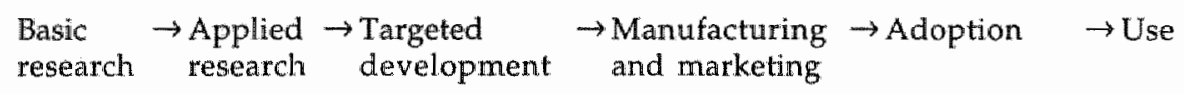

Figure 2.1 A linear model of technological change, after Gelijns and Rosenberg (1994)

According to this linear model, technological change starts with basic research at the level of biophysical and other fundamental processes in research laboratories and universities. Some of the outcomes of basic research are used by companies to perform applied research and targeted development aimed at making a new product. According to Banta and Luce (1993), diffusion begins when the technology is used on people. They locate the moment of innovation after the first human use. This is followed by clinical trials after that the innovation can be manufactured and marketed. Diffusion takes place through early adopters, followed by late adopters, and finally the innovation becomes part of accepted practice or it falls into disuse.

The chief weakness of this linear model of technological change is that it is static and it suggests that one step is necessarily followed by another. Such models obfuscate the real complexities of the patterns of technological change. They ignore alternatives and portray the dynamics of technological change as a sequence of well-defined, logical and rational steps from basic research to successful product. The model is particularly problematic for the study of technological change in health care as it overlooks some essential characteristics of technological change in medicine. According to Gelijns and Rosenberg (1994) new technologies in medicine are characterised by a high degree of uncertainty after their initial 
adoption. This uncertainty applies not only to the technical specifications of the innovation, but also to the range of medical problems for which the innovation can be used. During its lifetime, a medical technology may undergo many changes that originate from users" experience with the technology in the clinical setting. A related characteristic of technological change in medicine is that a close interaction between developers and users is crucial to the successful development of new medical technologies (Gelijns and Rosenberg, 1994; Shaw, 1991; Groen, 1988). The users of medical technologies are often medical professionals who are in a position to outline the specifications of the kind of equipment they need (Shaw, 1991). Some of these users design their own solution or they discuss with a manufacturer what their specific needs are. To a greater or lesser extent, the users are involved in the innovation process. These "user-dominated" innovation processes often result in commercially successful products (von Hippel, 1976), and networks of users, manufacturers and intermediaries have proven to be effective innovators in the health care sector (Shaw, 1991; Groen, 1988).

The diffusion of innovations in health care is further complicated by legislation, rules and budgets that limit the freedom of the users to purchase equipment. With the ever-increasing costs of health care, questions have been asked about the additional benefits of money spent on new technologies (Russell, 1979). In the next section we will discuss technology assessment (TA) as a method of policy research that has been used to investigate effects of new technology. In the Netherlands, TAs were conducted on heart transplants, liver transplants and in vitro fertilisation. The outcomes were used to specify at the national level which hospitals were given permission to offer these treatments and how many treatments were allowed per year. These decisions were laid down in the so-called 'Article $18^{\prime}$ (of the Hospital Provisions Act). This regulation also applies to neonatal intensive care. The national government thus directs and controls the diffusion of medical technologies. Government policies provide the framework within which hospitals and doctors can make decisions about the adoption or development of new technologies. In a study of the adoption of medical technologies by hospitals, Greer (1985) proposes that it is useful to distinguish between three decision systems in the hospital: the medical-individualistic system for tools, the fiscal-management system for expensive equipment, and the strategic-institutional system for decisions about innovations that imply substantial changes in the nature or future of the hospital. Each decision system involves a different set of actors, considerations and procedures, related to the costs involved and the impact that the adoption of the new technology will have on the hospital organisation. Romano (1990) notes that this categorisation only applies to purchase decisions for medical equipment, and it does not address what happens afterwards. He makes a distinction between adoption and use of technology and argues that the purchase of a new technology is only the first step, which does not automatically lead to proper use of the technology and to incorporation in the working practices. Problems can be expected in particular when the purchase decision is made by one discipline in the hospital while in fact another discipline has to use the technology.

Thus, criticisms of the simple linear model generally refer to its static and inflexible nature which renders the model unrealistic. An alternative model of technological change is provided by the Social Construction of Technology (SCOT) approach (see Bijker et al., 1987). Technological change is not seen as a linear 
process but as a multidirectional process, which involves many relevant social groups. The central concepts in this theory are 'interpretative flexibility', which indicates that there are multiple ways to interpret a particular technological development, and 'closure' or 'stabilisation', which denotes the situation where controversies regarding a particular development are resolved. In a sense, there is not one process of technological change: there are several. Since, according to SCOT, every relevant social group has its own perception of the problems concerning a particular development and generates several solutions for each problem, the process of technological change will be experienced differently in each group. Also, the process does not have a fixed structure or a predictable direction. Technological change is inherently unpredictable since it is constructed in the interaction of social groups. The SCOT approach thus offers fewer certainties than the linear model, but it appears more realistic in its assumptions about the nature of technological change. Attempts have been made to incorporate the SCOT insights into a policy research method that is referred to as constructive technology assessment (CTA).

The complex and continuous nature of the process of technological change in health care involves close cooperation of suppliers and users. This suggests that a focus on social and multidirectional processes is well suited to capture the unpredictable and interactive course of events. This is explored further in the next question.

Which methods and assumptions are applied in policy research on technology in health care?

Two methods are discussed here: technology assessment (TA) and constructive technology assessment (CTA). TA is the older of the two and was pioneered by the US Office of Technology Assessment (OTA) in the 1970s. OTA defined the method as follows:

"Technology assessment is a comprehensive form of policy research that examines the short- and long-term social consequences (e.g. societal, economic, ethical, legal) of the application or use of technology. It is an analysis of social rather than technical issues, and it is especially concerned with unintended, indirect, or delayed social impacts."

OTA (1976) Development of medical technology, p. 45

This definition was adopted by the Dutch government and provided the basis for the commissioning of three TAs in health care in the early 1980s. The three medical technologies under evaluation were: heart transplants, liver transplants and in vitro fertilisation. These studies, in turn, were evaluated by an independent researcher. Van Rossum $(1989,1990)$ notes that the health care TAs were undertaken for one specific reason: to provide an analysis of three technologies in order to assist decision-making about the inclusion of these technologies in the National Health Insurance policy. Not surprisingly, the studies focused on economic issues and can be characterised as extended cost-effectiveness studies. The TAs were commissioned with the expectation that the results of the studies would make the decision-making process more rational. Therefore, all parameters that were taken into account had been turned into quantitative, and presumably objective, measurements. A number of parameters were left out of the 
assessment altogether $r_{f}$ most notably the organisational aspects and questions about the management of technical change (van Rossum, 1989, 1990). Van Rossum concludes that the three TAs provided useful information for decision makers, but notes that this kind of TA is done after the fact, when the development of the technologies has been stabilised.

Constructive technology assessment (CTA) provides an alternative approach as it is concerned with the direction of technological change, particularly in the early stages of the process. It attempts to assess medical technologies during their development, so that ideas about the possible consequences can be incorporated into the design of the technology. Moreover, CTA involves discussions among the relevant actors regarding the desirability of particular developments. So far, no CTAs have been conducted in the Netherlands. The Dutch Office of Technology Assessment (formerly known as NOTA, now as the Rathenau Institute) has studied the feasibility of a CTA, using neonatology as an example (Vrolijk et al., 1991). A Danish experiment which involved a consensus conference on the future of neonatology was analysed by NOTA researchers, and it was found that the selection of relevant actors presented a problem (Straten and Weijers, 1991). The theoretical basis for CTA is 'technology dynamics' (van Boxsel, 1992) and it draws heavily on the ideas developed in the Social Construction of Technology (SCOT) movement. As the name indicates, SCOT perceives the construction of technologies as a social process, and not an exclusively technical process. In this view, technology is not solely developed by scientists and engineers in the isolated world of their laboratories, but is shaped by a wide range of actors and the combination and interaction of social, political, economic and technical factors (see MacKenzie and Wajcman, 1985; Bijker et al., 1987; constructivist ideas are used by MacKenzie, 1990; Cowan, 1989; Cockburn and Ormrod, 1994; Blume, 1992). From this perspective, actors are seen to have specific interests and thus wish to influence the course of developments. The dynamics of this process can be seen when choices are made that favour one technology but lead to other viable alternatives being discarded. CTA can be regarded as an attempt to involve more groups in the design process. To this end, CTA uses the concept of a 'social map' of 'technological' and 'societal' actors (Vrolijk et al., 1991). The social map thus provides an overview of the individuals, groups, organisations and institutions that have been or will be involved in the development of the technology because they invest in the technology (technological actors) or because they have an interest in the effects of the technology (societal actors). A central concern in CTA is for the actors to reach consensus regarding desirable directions for the development of the technology. Such consensus does not have to be limited to the development of one particular application of a technology.

To summarise, we have seen that TA and CTA as methods of policy research are based on different assumptions regarding the nature of technological change. The aims of the methods and the techniques employed in the analysis are therefore also different. Table 2.1 below shows the differences between TA and CTA as summarised by Vrolijk et al. (1991). 
TA and Cost-Benefit Analysis

Operational pollicies

Can we afford this technology?

Cost and effectiveness of technology

One application of technology

\section{CTA}

Strategic policies

Which technologies do we want?

Influence on developments.

Range of potentiall applications

Table 2.1 TA and CTA compared

Thus, TA is based on a linear model of technological change and deals with the impact of new technologies, using techniques to establish the cost-effectiveness of a new technology that is assumed to be stable. CTA is based on a social constructivist perspective of technology and deals with the development of technologies, using techniques to make explicit the expectations and preferences regarding the direction of this development. Alternatively, the role of technology in medical practice can be addressed without specific reference to policy formulation. This is illustrated below as we address the following question.

\section{How does technological change influence medical practice?}

The influence of technological change on the practice of medicine concerns the relationship between the doctor and the patient as well as the overall system of health care. As we have seen in Chapter 1, it has been argued that technology may get out of our control. Reiser (1984) summarised this fear as follows: "[Machines] can make us forget the hands and minds behind their creation; they can make us forget ourselves." (p. 18). Reiser argued in 1978 that a shift had occurred away from the patient"s story and towards the measurements of technology as the prime source of information for the physician. He does not believe that as a result of the use of medical equipment the doctor will take more time for his patients. Reiser discards this idea as a myth and urges the doctor to

"(...) regard [technologies] (...) with detachment, as mere tools, to be chosen as necessary for a particular task. He must accept the patient as a human being, and regain and reassert his faith in his own medical judgment."

Reiser (1978) Medicine and the reign of technology, p. 231

An important comment is made by Bergsma (1979) who argues that it is more appropriate to discuss specific technologies rather than technology in general. He argues that it is necessary to spell out the assumptions that underlie investigations into relationships between technologies and patients. Although patients and health care professionals in general rely more and more on the use of technologies, this does not mean that they are controlled by technology. The actors remain responsible for the way in which they deal with the available technology. Yet, patients, doctors, nurses and other actors in health care function within the context of increasing availability and use of medical technology. According to Strauss et al. (1985), an interesting paradox exists since, while much of the modern technology is aimed at acute situations, this technology is of limited use to the increasing number of patients with chronic diseases, most of whom also live for much longer. Against this background, Strauss and his colleagues carried out a 
project that investigated work in health care. They found that the patient is one of the many actors involved in the work (Strauss et al., 1985; Strauss, 1985).

The research shows up the complexities involved in increasing specialisation and the growing use of technology. This is illustrated in a case study of the intensive care nursery (Wiener et al., 1979) by the same research team. Growing complexities are accompanied by 'extended birth trajectories', so that care is initiated earlier and involves more specialists and more machines, while the complications, side-effects and interactions of treatments become potentially more serious and uncertainties about long-term consequences increase. These long-term. consequences often present themselves as chronic illnesses so that according to Strauss and his research team, a vicious circle is created in which medical technology contributes to the emergence of diseases that cannot be treated successfully with more technology.

Thomas (1974) refers to these technically advanced technologies collectively as 'halfway technology'. He provides the following description:

"[Halfway technology] represents the kinds of things that must be done after the fact, in efforts to compensate for the incapacitating effects of certain diseases whose course one is unable to do very much about. It is a technology designed to make up for disease, or to postpone death."

Thomas (1974) The lives of a cell, p. 37

Thomas also notes that it is this kind of technology that requires ever more funding and facilities, and he mentions organ transplants and artificial organs as examples. His analysis of the technology of medicine also includes 'nontechnology', which refers to caring and supportive activities, and "high technology', which, according to Thomas, "comes as the result of a genuine understanding of disease mechanisms". In this last category Thomas (1974) puts immunisation against various diseases, antibiotics and hormone-substitution therapies. Although Thomas published this classification twenty years ago, it is still applicable to health care in the $1990 \mathrm{~s}$, as developments have continued in the direction of more halfway technologies. The picture of modern health care that thus emerges is one in which mostly halfway technology and nontechnology is used in the treatment of patients who increasingly have to live with chronic diseases for which no high-technology fix is available. This results in partial solutions for the patient and ever-increasing costs for society.

Although the exisiting literature offers some perspectives on the influence of technological change on medical practice, we have argued that in order to do justice to the complexity of this process, detailed analyses are required of specific technologies and the contexts in which they are developed and used. The present study fulfils this requirement, by exploring the use of technology in the specific context of the ICU. In the following sections the literature regarding ICUs is reviewed as part of this exploration.

\subsection{Historical overview}

This historical overview addresses developments in intensive care nursing and highlights the changing role of technology in the history of ICUs, covering 
developments in general ICUs and in neonatal ICUs. This section is thus concerned with the following question.

\section{How has the relationship developed between nursing and technollogy?}

\section{General intensive care}

Intensive care units were first set up in the United States in the 1950s. The number of ICUs has increased to the extent that practically every hospital now has an ICU. Over time, many technologies have been adopted in intensive care medicine, thus increasing the possibilities for treatment and causing a shift in the patient population. Fairman (1992) points out that, although most historicall studies of intensive care have focused on machines and doctors, the development of ICUs in the 1950s was strongly influenced by nursing practices. "Nursing is what is intensive about intensive care units", she argues. According to Fairman, two nursing practices have traditionally been used in the care for critically ill patients: intense observation by assigning a single nurse to one patient, and triage by grouping patients together according to their physical stability. For this kind of intensive care no complex technology was used other than what was also used on general wards. In other words, there often were no heart monitors or dialysis machines available. Fairman $(1992$, p. 57) calls these machines "incidental to the development of ICUs" and quotes a nurse as saying:

"We didn't have monitors, they didn't exist when we opened up those little units. So the nursing staff had to look at some other indicators of the patients. (...) The nurse had to be the watcher of something exceeding an acceptable parameter. They [nurses] had to monitor it. They were the alarm."

Since the early 1950 s experiments have been carried out to develop machines that could continuously monitor body functions (Reiser, 1978). The enormous amount of data that was gathered in this way could not be handled in clinical practice. When these machines were linked to computers in the 1960 s and automated alarms were built in, the monitors became very popular. Continuous monitoring also met with considerable criticism in those years. The constant sounds of the equipment disturbed patients and "nurses and other medical personnell tended to focus on supervising the machines more than caring for the patient" (Reiser, 1978, p. 220). The medical equipment that was used for interventions and treatment in the ICUs in the 1960 s and 1970 s was initially the exclusive domain of the physicians, but increasingly responsibilities in this area were delegated to nurses or paramedical staff.

During the polio epidemic of 1952 in Copenhagen manual positive pressure ventilation was for the first time demonstrated to be an effective replacement for natural breathing. Some 5000 patients who suffered temporary parallysis which prevented them from breathing independently, were kept alive through the efforts of an estimated 1400 medical students who manually ventilated them. Manual positive pressure ventilation requires that the patient has a tube inserted in the windpipe and that through this tube air is delivered to the lungs. For this purpose the tube is connected to a bag which is filled with air from a gas outlet. When the bag is squeezed the air is pushed into the lungs by positive pressure so that exchange of oxygen and 
carbon dioxide can take place. When the pressure is released the patient exhales and thus discharges the carbon dioxide into the surrounding air.

Manual positive pressure ventilation is very labour-intensive. The procedure was mechanised and automated so that continuous ventilation of a constant quality can now be delivered without the immediate need for a person at the bedside. Modern ventilators are computerised and offer a wide range of ventilating options, thus allowing doctors to choose the type of ventilation that suits the needs of the patient best. Manual ventilation is, however, still a crucial procedure in modern ICUs.

Sketch 2.1 Positive pressure ventilation

Gradually the nurses became more involved in the medical side of the care process by accepting tasks that had always been regarded as medical. In the Netherlands, nurses even began to perform actions for which by law only doctors were authorised. For these situations an 'extended arm' construction was developed, according to which the doctor remained legally responsible for the decision-making, but the nurse carried responsibility for the proper performance of the tasks (Topman, 1987 and 1993). This is a questionable practice, since the murse has no legal right to perform the task in the first place, and is dependent on the honesty and cooperation of the physician to take the responsibility if anything goes wrong. In the 1980s a debate took place in the Netherlands about this issue of the 'extended arm' (Dassen et al., 1987), but the construction has survived until the present day. While doctors delegated many tasks to machines and allied health workers, they did not use the extra time with the patients (Reiser, 1978). More technology seemed to lead to more technology, and even the nurses were no longer focused on the patient. As Fairman argues:

"But as the number of intensive care units in the 1960s and 1970s grew, the lessons of the 1950 s were forgotten. Watchful vigilance of patients was obscured by enthusiasm for machines as the ICU became a technological repository. The care of the critically ill patient entered into a realm where data from machines supplanted the intense observation of nurses and their expertise."

Fairman (1992) p. 58

\section{Neonatal intensive care}

Developments in neonatal intensive care followed a similar pattern to those in general intensive care. However, most of the initial technologies in neonatology were miniaturisations of technologies for adults, that were introduced in neonatology some years after they had been introduced in general intensive care. A special aspect of neonatal intensive care is that it deals with babies who are so young and small that they cannot maintain their own body temperature. Various technologies were developed by obstetricians in the early twentieth century to keep the patients warm. Experiments involved the use of heated mattresses in both open and closed cots for one or more babies. An alternative was the "climate room', which was an ordinary ward with several cots in it, that was kept at a constant and high temperature. This technology has not survived, partly because the high temperatures made it difficult for the nurses to function properly, but also because the staff were more prone to infections as a result of the differences in temperature that they experienced when moving between the "climate room" and other parts of the hospital. Moreover, this increased the risk of infections being 
passed on to the babies (Vrolijk et al, 1991). To date, incubators or isolettes are still an indispensable technology in neonatology, and the improvement in insulating capacities of incubators has contributed to the survival of ever smaller and younger patients. The principle of the 'climate room' appears still to be in use, however, as a hot (usually between 28 and 30 degrees Celsius) and humid (80\%) climate is still maintained in modern neonatology units.

A technology that was pioneered in neonatology and later transferred to general interusive care is the transcutaneous oxygen saturation meter. This piece of equipment continuously measures the levels of oxygen saturation in the red blood cells through the skin. It is a non-invasive technology since it does not require a probe to be inserted into the body. This type of saturation meter was a tremendous improvement as it could replace the previous method that involved taking blood samples for analysis in the laboratory and thus was non-continuous and invasive. The transcutaneous oxygen saturation meter is used to monitor the effectiveness of artificial ventilation. In neonatology this monitoring is crucial, since too much or too little oxygen in the blood can lead respectively to permanent damage of the eyes or to neurological problems as a result of brain thaemorrhages.

Sketch 2.2 Transcutaneous saturation meter, after Vrolijk et al. (1991)

The success of neonatal intensive care has been summarised as follows: the chances of survival have improved while the likelihood of surviving with a disability has decreased (Dubbelman and Hermans, 1990, Visser, 1991). More babies survive in a healthy condition. This is even more surprising when we consider how the patient population of neonatal intensive cares has changed over time (Vrolijk et al., 1991). Birth weight and gestational period (duration of pregnancy) have both been used as indicators of the limits of neonatology. In the 1960s the minimum birth weight for a baby to have a chance to survive with special care was 1500 grams (about half the normal weight at birth for a full-term baby). In the 1970 s this lower limit was brought down to 1000 grams or a minimum gestational period of 28 weeks. From the 1980 s the most commonly used indicator is the gestational age. The minimum gestational age is currently set around 25 weeks since by this time the lungs should be developed to an extent that allows the baby to breathe air.

To answer the question how the relationship between intensive care nursing and the use of technology has developed, several aspects have to be taken into account. We have seen that the character of intensive care has changed dramatically over the past decades. Increased availability and use of technology have added to the variety of treatments that can successfully be offered, and this has caused a shift in the patient population. However, the introduction of a new technology does not necessarily lead to the replacement of the existing technology, but rather adds to the diversity of the technologies in use. We noted that nurses thave become increasingly inwolved in the medical aspects of intensive care, and many tasks that require the use of medical technology are now delegated to them. Precisely how this has affected the nurses' work is not clear from the historical overview, but it has been suggested that nursing has become more "technologyoriented' and less 'patient-oriented'. Table 2.2 below illustrates for a number of functions how they were performed formerly, as indicated by the term "old method" and how they are performed in current practice. Complete substitution 
usually does not take place, as the older method is used alongside the technological alternative.

Function

Monitoring

Delivery of medication

Ventilation

Blood pressure

Oxygen levels in blood

Blood sampled for analysis in laboratory

\section{Current practice}

Continuous monitoring by machine and direct observation by nurse

Automated delivery systems and manual delivery nurse

Flexible manual ventilation and inflexible mechanical ventilation

Cuff and mercury gauge for one-off measurement
Flexible and versatile automated and manual ventilation

Direct and continuous measurements in the blood stream as well as noninvasive manual and autonated measurements

Continuous and noninvasive measurement of saturation, backed up by laboratory analyses

Table 2.2 Technological change in intensive care

\subsection{Ethics}

Ethical questions are often approached in a normative and prescriptive manner. The ethicist formulates the principles on which moral decisions should be based, and the application of these principles should lead to good decisions. In this prescriptive tradition many authors have written about the dilemmas in health care. Some authors, however, take another approach and investigate the process of decision-making itself, producing descriptive studies of the ways in which ethical problems are dealt with in practice. We will discuss three such studies, focusing on the following question.

What are typical ethical problems that arise in the practice of intensive care?

Zussman (1992) summarises the relationship between ethics and intensive care as follows.

"Filled with patients and staff who find it terrifying, consuming an enormous share of hospital resources, treating patients whose eventual death is often a foregone conclusion, intensive care is a virtual laboratory for the exploration of some of the most central issues in contemporary medical ethics."

Zussman (1992) Intensive care, p. 23 
These issues are the doctor-patient relationship, decisions to withhold treatment from terminally ill patients, and decisions about who should receive treatment. Based on his field work in intensive care units in two American hospitals in the late 1980s, Zussman describes how and why these decisions are made. Social factors are important in his analysis, and he looks at the roles of doctors, nurses, patients and families in the process. A similar approach was adopted by Frohock (1986) and Anspach (1993), who studied decision-making in neonatology. Frohock captures the special character of neonatology by referring to the fact that the patients are at the beginning of life, so that successful treatment can result in sixty or more extra years of life. "No other type of medicine has a higher payoff for overcoming illness", Frohock claims in the introduction to Special Care. The consequences of failure are also extreme. The child could lose its life, but worse than that, according to Frohock, it may "survive without enough physical resources to recognize anyone or anything" (1986, p. viii).

The ethical dilemmas in intensive care originate from the question of whether what can be done should be done. This question is all the more serious because it is asked in a situation where outcomes are to a large extent unpredictable. As Anspach (1993) points out, the dilemmas in neonatology are not just about saving lives, but involve decisions about the kinds of lives that are worth saving and the kinds of lives that are not worth saving. Anspach uses three examples to illustrate the dilemmas. Firstly, is it right to withhold life-saving surgery from an infant who will be mentally retarded, as in the case of infants with Down's syndrome? Secondly, is it right to withhold surgery from infants with spina bifida, who may be able to lead normal lives, but who also may be paralysed and need numerous operations? Thirdly, is it right to resuscitate very premature infants who may have only a slight chance of normal survival? How does one decide? The authors we have mentioned all agree that the law does not provide clear guidelines, nor do the theoretical books about ethics address the pertinent questions. They argue that in order to resolve the gap that exists between theoretical and practical concerns, it is necessary to understand how ethical decisions are made in practice, in the particular circumstances in which they are made. Again, it should be noted that the literature reviewed here is primarily concerned with the situation in the USA. Dutch research along these lines is in progress (Mesman, 1992).

It appears that the availability of a wide variety of interventions contributes to the complexity of the ethical problems in intensive care. The problems involve questions about providing or withholding treatment in a situation where no certainty exists regarding the outcome and it is recognised that outcomes can be worse than death.

\subsection{Economics}

In economic terms, ICUs can be characterised as extremely capital- and labourintensive. In addition, they are complex and expensive, and their availability is restricted. This raises questions with regard to the number of ICU places that should be available and how these places can be used in the most economical manner. The central question, then, in the study of the economic aspects of intensive care is. 


\section{How can ICUs be used most efficiently?}

Spangenberg et al. (1989, p. 367) note that ICUs in the USA consume $20 \%$ of the hospital budget, or $1 \%$ of GNP, while treating only $5 \%$ of total admissions. Moreover, the researchers argue that "it has not been adequately demonstrated that routine admission to intensive care is associated with an increase in survival rate and a decrease in morbidity". This lack of evidence of the effectiveness of ICUs is partly explained by the diversity of conditions for which patients are admitted to ICUs. "Too many patients are in ICUs who do not need the level of care provided there, either because they are not ill enough to justify it or because they are too ill to benefit from it", according to Jennett (1984, p. 64). Thus, the efficiency of ICUs depends to a certain extent on the composition of the patient population. This is a central consideration in a recent study of efficiency of ICUs in the Netherlands (Spangenberg et al., 1989 and Miranda and Spangenberg, 1992) which analyses the inputs and outputs of ICUs as well as factors that influence the results. This national study concerned a sample of 36 ICUs and used a business-economic model that perceives the ICU as a responsibility centre in which inputs and outputs are monitored. The inputs into ICUs include the size, capacity, design and layout of the unit and logistical aspects. We will return to the description of these inputs in Chapter 4 , where we discuss the organisational characteristics of Dutch ICUs. Output of ICUs was measured in terms of the achieved reduction in mortality and morbidity. The research found that patient turnover is high in ICUs; on average 80.8 admissions took place per bed per year. Mortality on ICUs was generally low at $8.1 \%$, and was lowest for those patients who had been placed in the ICU after surgery. The majority of patients had a reasonable to good quality of life after discharge from the ICU. Factors that were expected to influence the result of ICUs included patient characteristics and decisions about admission and discharge.

The report indicates that the existing ICU places can be used more efficiently. The study used the treatment intensity scoring system (TISS) to determine which interventions were performed on the patient during their period in intensive care. Analysis of the TISS scores showed that on average more interventions were performed on the patients in ICUs of teaching hospicals than on patients in ICUs of general hospitals. Assuming that one nurse can handle a certain number of TISS points per shift, the researchers determined the number of patients that one nurse could look after in one shift. The result was that in teaching hospitals one nurse could look after 1.6 patients, whereas in small hospitals, which generally had lower TISS scores, one nurse could look after 3.2 patients. The analysis also showed that in $10 \%$ of the cases the TISS score was so low that the patient could have been treated outside the ICU. Further analysis disclosed that $5 \%$ of the ICU days were spent on patients who were waiting for transferral to another ward. The researchers suggest that ICUs could be used more efficiently if clear distinctions were made between three levels of care, so that patients requiring less care would be placed in a unit that provides a less intensive level of care. In practical terms, the less intensive units would have more patients per nurse and the more intensive units would have less patients per nurse. The least intensive level of ICU would be comparable with the existing recovery room where patients are monitored after surgery. The research showed that in $95 \%$ of the hospitals the recovery room is only in operation during 8 hours per day. Opening up the 
recovery room for 24 hours per day would allow hospitals to treat surgical patients more efficiently.

Thus, efficiency in ICUs can benefit from clearer admission criteria and from the distinction of severall levels of care. As Jennett points out, there are risks involved as well as costs in the admission or prolonged stay of patients who do not need intensive care.

"In balancing the benefits of remaining in ICU or not, due account should be taken of the hazards associated with such units - of human error and equipment malfunction, of cross-infection from the very ill or the immunologically compromized, and of the psychological effects of such highly abnormal surroundings."

Jennett (1984) High technology medicine, p. 65

\subsection{Psychological studies}

Psychological approaches to the study of work in the ICU have predominantly addressed occupational stress and the ways nurses deall with it. Research has sought to establish which combination of personality characteristics is best compatible with the demanding work situation of the ICU. These studies, reviewed below, have shown that successful intensive care nurses have a combination of masculine and feminine characteristics as measured by standard psychological scales of personality traits. A second kind of psychological study has addressed the influence of new technology on physical and psychological stress. More important than the technology itself are the organisational arrangements within which the work takes place, according to a major European study. A third kind of psychological study has surveyed the attitudes and preferences of male nurses and found that intensive care is one of the most popular areas of nursing with men. This section begins with a discussion of the personality factors that reduce the risk of burnout and continues with a review of the results of a European study of stress in intensive care. Furthermore, findings are presented regarding the position of men in nursing and the career preferences of male nurses.

\section{Which personality factors reduce the risk of burnout in intensive care nurses?}

One particular phenomenon that has been associated with intensive care nursing is burnout. Burnout has been defined as a syndrome of physical, emotional and mental exhaustion, involving the development of a negative self-concept, negative job attitude and lack of concern for clients (see Boyle et al., 1991). It seems plausible that the fast pace of the intensive care unit and the challenge of dealing with the psychological problems of seriously ill patients and their families are factors that induce stress. Yet, some nurses deliberately choose this environment to work in and some of them experience burnout while others do not. Staff turnover has been extremely high in units for intensive care, and shortages of intensive care nurses were common in the 1980s. Consequently, psychologists began to investigate which personality characteristics could be associated with the type of nurse that "would both enjoy the field and remain active in critical care" (Levine et al., 1988). On the basis of surveys with standardised questionnaires, 
psychological profiles were constructed. Levine et al. (1988) focus on three aspects: self-esteem (measured with the Texas Social Behavior Inventory), gender identity (measured with the Personal Attributes Questionnaire) and selected personality characteristics (determined by Cattell's 16 PF Inventory). Outcomes of this study are that nurses who had been working in intensive care for an average of eight years and who enjoyed being a critical care nurse had androgynous or masculine personality characteristics. The self-esteen scores of intensive care nurses were significantly higher than those of the control group. The authors summarise:

"Nurses from this study who perceived themselves as being competitive, mechanical, mathematical, task-oriented, efficient, resourceful, and decision-makers, seemed to work more comfortably in an environment that required all these characteristics to be successful."

Levine et al. (1988) p. 397

Another American study looked at burnout in intensive care nurses and related this to personality hardiness, social support and ways of coping (Boyle et al., 1991). The questionnaire included the Staff Burnout Scale for Health Professionals (1980), parts of the Alienation Test (1979), parts of the California Life Goals Evaluation Schedule (1966), the Ways of Coping Checklist (1984) and the House and Wells Social Support Scale (1981). The authors argue that hardiness, social support and ways of coping should not be addressed individually to establish their relationship with burnout. The combined approach in this study has resulted in the conclusion that social support, both work-related and non-work-related, is very important to intensive care nurses, and it is recommended that fostering a supportive social environment should be a priority for the nurse manager.

Thus, in addition to personality factors there are social factors that help to reduce the risk of burnout in intensive care nurses. The personality factors that are found to match the requirements of the ICU include a task-oriented and competitive attitude and decision-making capacities. Social factors and in particular social support were found to have a positive effect on the prevention of burnout. A further question that is addressed by psychological research pertains to the role of technology in relation to stress.

\section{Does new technology increase stress?}

One European project has specifically addressed the impact of new technology on physical and psychological stress (Fitter, 1986). The project was entitled "The impact of new technology on workers and patients in the health services" and was commissioned by the European Foundation for the Improvement of Living and Working Conditions. For the project, case studies were carried out in six countries: Denmark, Ireland, Italy, the United Kingdom, the Netherlands and the Federal Republic of Germany. Across these cases, five characteristics of nursing work have been found that are commonly occurring stressors (Fitter, 1986, p. vi):

- a high work pace and frequent overload

- rapid decision-making and a high level of responsibility

- cumulative work pressure, combined with shift work, that results in fatigue

- the difficulties of relating to seriously ill or dying patients and their relatives working with inexperienced staff who cannot assume equal responsibility. 
Factors directly relating to the use of new technology were:

- enhanced cognitive demands required by complex equipment

- poor design standards and equipment failures resulting in high levels of false alarms

- lack of adequate training for nursing staff in the use of technology

- ethical dilemmas concerning the use and non-use of life-maintaining technologies.

A general conclusion about the impact of new (micro-electronic-based) technologies is that they increase the workload for nurses. One aspect of this phenomenon is that more diagnostic and therapeutic procedures are possible, so that nurses are involved in more work. A related aspect is the policy of minimising the duration of the patient's stay in hospital, because this intensifies the nurses' workload. Yet, the stress in intensive care is largely offset by positive job characteristics:

- high job quality in terms of a high degree of meaningfulness, responsibility, independence, variety and scope for development in the work; a job held in high esteem by society and by patients who are usually very grateful

- opportunities to enhance skills and achieve promotion and increased pay.

The European project included a variety of research questions and approaches, since each national team of researchers developed its own case study. The Danish study was concerned with one ICU. All 32 nurses were interviewed and observations were conducted on the ward. The Irish study looked at five hospitals and included interviews with 52 nurses who worked in intensive care, coronary care and neonatology. The Italian study compared the use of technology in an intensive care unit of a university hospital and in the Hyperbaric Treatment Centre of the Padua Divers Club, and included a discussion of the nature of 'Intensive Care Syndrome". In the British study researchers examined the attitudes of student nurses to their work and to new technology, and assessed their level of general health. The researchers also compared the attitudes of intensive care nurses who were about to be transferred to a new unit with the attitudes of a control group of coronary care nurses. In the Dutch study six units in two hospitals were involved: one intensive care unit and one cardiology unit were classified as 'high technology' units, whereas a surgical unit, a unit for paediatric surgery, a neurological unit and a medical unit were classified as "low technology". This study used a questionnaire that addressed issues of desired and actual work practices. The Federal Republic of Germany study looked at the implementation of a ward-based management information system.

The diversity in approaches in the European project sometimes makes it difficult to draw general conclusions. Regarding the issue of social support, the Darish study reports that there are good relations with colleagues and superiors in an open climate of co-operation, and that there are good opportunities for social support and help in difficult work situations. Thus, these aspects of the work situation are positive and can help to reduce the negative effects of the stressors. On the other hand, the Irish study reports a bureaucratic climate and lack of recognition for the nurses with poor and unsupportive teamwork. The Italian study points to the reduced need for communication between nurses as a result of the introduction of computer-based monitoring equipment. The Dutch study (de 
Vries et al., 1987), has attempted to look at the consequences of technical change at several levels and has assessed how murses see their work in terms of "caring" and "curing' aspects. One conclusion is that nurses on 'low technology" wards experience slightly more stress than nurses on 'high technology' wards. The researchers argue that funds and staff are re-allocated to 'high technology' wards, thus draining 'low technology' wards of resources and leaving the staff with higher workloads. On these 'low technology' wards the emphasis was on caring tasks, while on the "high technology' wards the curing aspects were more prominent. The researchers made a comparison of the ideal or desired function profile and the real or actual profile, to find out how nurses think they ought to spend their time and to contrast this with what they do in practice. The results were similar for all nurses in the sample, regardless of the work place; they all wanted to spend more time on psycho-social care and on organisational activities. These elements of the work are currently overshadowed by physical, technical and domestic tasks. The researchers conclude that all nurses seem to agree on the ideal job description in which caring and technical aspects are integrated.

Studies on the role of technology in the development of stress have found that new technology has contributed to an increase in the workload of nurses, but conclude that stress in ICUs is compensated for by positive job characteristics. In fact, one study found higher levels of stress outside the ICUs on wards that use less technology, and this finding is thought to be related to the generally higher funding and staffing levels on ICUs. We continue the review of psychological studies by considering the issue of gender differences with regard to career choices in nursing.

\section{How do men and women differ in their career choices in nursing?}

The issue of the position of men in nursing is particularly relevant in the study of intensive care, because this is one of the few areas in nursing in which a relatively large number of men works. We will address the gender identities of intensive care nurses later on, but it is important to note here that studies of personality characteristics of nurses do not even mention how many men and women were included in the sample (e.g. Levine et al., 1988, Boyle et al., 1991, Seymour and Buscherhof, 1991). We assume that the respondents were all women, since the studies were done in the USA where very few men enter nursing.

Estimates of the relative numbers of men in nursing vary considerably between countries. Galbraith (1991) notes that in the USA the number of male nurses has never exceeded 5\%, and Davis-Martin (1984) reports that in the 1970 s it was close to $1 \%$ and by 1984 had increased to $2 \%$. In the United Kingdom in 1991 women made up $95 \%$ of the nurses and midwives in the NHS, but they accounted for less than $4 \%$ of top managers. Men held over a third of nursing officer posts, but they only constituted $8 \%$ of nurses (BMJ, 1991). The Netherlands has a relatively high percentage of men in nursing: 18\% in 1985 (Dassen et al, 1990). In the Netherlands as well as in the UK the percentage of men is larger in the higher pay scales, and the percentage of women in higher functions has decreased in the last twenty years (Sibbes, 1989). A comparison of the percentage of women in managerial positions (head nurses and above) shows that $82 \%$ of these positions were filled by women in 1971, and that by 1985 this had decreased to $61 \%$. In the same period, the percentage of women in non-managerial positions dropped from $92 \%$ to $84 \%$ 
(NZI, 1988). Thus, men are increasing their presence in managerial positions by a greater percentage than they are increasing their presence at the bedside.

Moreover, men are concentrated in a few areas of nursing. Egeland and Brown (1989) asked American male Registered Nurses for which areas of nursing they had a preference. Some of the outcomes of this study are presented in Table 2.3 below. Of the 24 entries in the original table, six were selected. The respondents were first asked to indicate which area of nursing they had preferred when they were students of nursing. This question, the results of which are shown under the heading 'Preferred as student' in Table 2.3, revealed that $40 \%$ of the men had preferred the emergency room or the ICU/CCU. Psychiatry was a third favourite option, and the operating room came in fourth place. These four options accounted for almost $65 \%$ of the total number of replies. When the respondents were asked which area they preferred at the time of questioning, shown under the heading 'Prefer now', the previous top four options were still popular but only accounted for $47 \%$ of the total. When the respondents were asked which position they would prefer to be in in five years time, shown under the heading "Future job', the outcomes were quite different: $14.7 \%$ wanted a non-nursing job, $11.1 \%$ wanted to be in the ICU/CCU, and $10.6 \%$ wanted to be in administration.

\begin{tabular}{|c|c|c|c|c|c|}
\hline Fields of nursing & $\begin{array}{l}\text { Preferred } \\
\text { as student } \\
(\mathrm{N}=362)\end{array}$ & $\begin{array}{l}\text { First job } \\
(N=360)\end{array}$ & $\begin{array}{l}\text { Most } \\
\text { recent job } \\
(\mathrm{N}=365)\end{array}$ & $\begin{array}{l}\text { Prefer now } \\
(N=363)\end{array}$ & $\begin{array}{l}\text { Future job } \\
(\mathrm{N}=360)\end{array}$ \\
\hline Emergency room & 21.3 & 8.1 & 9.9 & 13.2 & 9.2 \\
\hline $\mathrm{ICU} / \mathrm{CCU}$ & 19.7 & 18.1 & 18.4 & 15.2 & 11.1 \\
\hline Psychiatry & 12.5 & 10.0 & 9.5 & 11.3 & 9.2 \\
\hline Operating room & 11.2 & 6.1 & 6.8 & 7.7 & 6.9 \\
\hline Administration & 1.1 & 0 & 5.4 & 6.3 & 10.6 \\
\hline Non-nursing job & - & - & 0.8 & 1.4 & 14.7 \\
\hline
\end{tabular}

Table 2.3 Fields of rursing in which male Registered Nurses have worked, are working or prefer to work, by percentages. A selection of the data as presented by Egeland and Brown (1989), p. 701

Several studies have concentrated on the personality characteristics and gender identity of men and women in intensive care nursing. Four gender identities are generally distinguished, based on the predominance of male (M) and female (F) traits. The masculine type is high on $M$ and low on $\mathbb{F}$, the feminine type is high on $F$ and low on $M$, the androgynous type is high on $M$ and high on $F$, and the undifferentiated type is low on $\mathrm{M}$ and low on $\mathrm{F}$. There is much support for the outcome of the study by Levine et al. (1988) that we already mentioned: the ideal intensive care nurse is androgynous. As we pointed out, the gender identity is established regardless of the biological sex of the respondent. A study of men in nursing was conducted by Galbraith (1991), using the Personal Attributes Questionnaire, the Bem Sex Role Inventory and the Important Components of a Career scale in order to find out what men would find attractive in a nursing career. Galbraith finds that "even though men in non-traditional roles focus on relationship-oriented components in their career, they retain traditional maleoriented components". In other words, they still valued the "non-relationship- 
oriented factors such as money, power and prestige in their career". Galbraith argues that there is little support for men who want to "cross the sex role boundary", and he hopes that prospective male nurses may benefit from knowing what qualities in their career are rewarding and important to men who are currently practicing professional nursing. Davis-Martin (1984) welcomes the prospect of more men in nursing, as she believes that men may assist nursing to achieve higher prestige and more power, and that they will bring increased commitment and new personality characteristics into nursing.

From a theoretical perspective, we could expect men to have a difficult time when they are in a minority position. The token theory as developed by Kanter (1977) would suggest that any small group or single person who has to operate amidst a majority of the other sex, will encounter problems because they are singled out and treated as a 'token'. This theory seems to apply better to women in minority positions than to men in minority positions. Ott (1983) studied female police officers and male nurses, and found that the police women were treated as 'Cinderellas', while the male nurses were treated as 'Crown Princes'. Williams (1992) examined experiences of men and women in four 'female' professions: nursing, social work, librarianship and elementary school teaching. On the basis of 99 in-depth interviews she finds that men encounter prejudice from individuals outside their profession, but within the profession they generally encounter structural advantages which tend to enhance their careers. She calls this phenomenon "the glass escalator", and notes that it works even to the extent that men who do not want to move upward are expected to do so. The statistics on the positions of men and women in nursing seem to support the suspicion that men are possibly advantaged, but alternative explanations cannot be ruled out, and so far this phenomenon has not been investigated in nursing.

In the study of Egeland and Brown (1989) of American male nurses, questions were asked regarding the ways in which men adapt to the role strain of being a man in a female-dominated occupation. The researchers found that the ICU/CCU, operating room and administration ranked high in terms of their congruence with the stereotypical male role, while general medicine and obstetric and paediatric nursing ranked low. The attitudes and positions of men and women in intensive care nursing in the Netherlands were investigated in a survey in 1987. Dassen, Nijhuis, Philipsen and Topman reported in several publications (1990, $1987)$ on this study. Based on a questionnaire survey that covered all registered intensive care nurses, they tested hypotheses about professionalisation, career orientation and preference for technical departments. They found that on ICUs/CCUs the percentage of male nurses is twice the percentage of the hospitall as a whole. Within ICUs/CCUs male nurses are over-represented in the managerial functions, while nearly $50 \%$ of the male nurses and $15 \%$ of the female nurses aspire to become head of a unit. In addition, male nurses see their work as very close to the medical profession and expect that intensive care nursing will become less of a nursing and more of a medical profession. However, these differences are not reflected in the work of intensive care nurses, according to de Vries et al. (1987), who concluded that a division of labour along gender lines was not found within intensive care nursing.

Thus, the number of men in nursing is relatively large in the Netherlands when compared with the United Kingdom and the USA. A similar pattern exists, however, across these countries with regard to the preferences and career choices 
of male nurses. Intensive care nursing is a specialisation that attracts a relatively large number of male nurses. The psychological studies reviewed in this section have indicated that personality factors as well as factors in the social environment are important to counteract the sources of stress and burnout. Technology as such has not been identified as a major influence on the stress that is experienced by intensive care nurses. In terms of personality characteristics, the androgynous type is found to be most successful in intensive care nursing. This is consistent with other results that portray intensive care nursing as compatible with the stereotypical male role within a female-dominated occupation.

\subsection{Sociological studies}

The sociological studies that are reviewed in this section address the dominant values and the role of the nurse in intensive care as well as nurses' perspectives on their work. The studies in this review originate from debates inside intensive care nursing and have mostly been written by nurses and published in professional journals of intensive care nursing. In the current debates a tension is apparent between social and technical aspects of the work. This tension has inspired discussions about the dominant values in intensive care nursing. The underlying theme is that technology may be receiving too much attention at the expense of human interaction with the patients. A related discussion addresses the role of the intensive care nurse in relation to the role of the medical practitioners. Reflections on the extended role of the nurse will be addressed in the second part of this section. This is followed by a review of sociological studies that adopt a symbolic interactionist perspective and focus on how nurses perceive their work in intensive care.

\section{What are the dominant values in intensive care nursing?}

A selection of articles discussing the nature of intensive care nursing and the role of technology in it includes the following titles: "Preserving the essence of nursing in a technological age" (Henderson, 1980), "High technology and humanity for intensive care" (Ashworth, 1990) and "Empathy and technology in the coronary care unit" (Hudson, 1993). Fairman (1992) argues in her historical overview that intensive care nursing in the 1970 s moved away from caring for the patient and towards handling technology. Yet, since the 1970s a debate has taken place in the professional nursing journals about the values in intensive care nursing. In general, what we find is discussion of conflicts between humane and technical aspects of intensive care nursing, and ways to remedy the situation. Henderson (1980) discusses nursing in general and contrasts the personal and human character of nursing with the present impersonal character of health service. According to Henderson, the essence of nursing is giving holistic care, but she realises that practice is sometimes far removed from this ideal. She illustrates this in a description of an ICU where she visited a friend. Henderson summarises the atmosphere in the intensive care unit as "anxiety-laden and machine-dominated". The friend she visited had been very cold but had not wanted to disturb the nurses because they were so busy. Henderson notes: 
"Vigorous young nurses wearing stethoscopes around their necks seemed normally" busy and, by contrast with the patients, outrageously cheerful - and more or less unconcerned."

Henderson (1980) p. 247

A similar observation is made by Jablonski (1994) in one of only a few studies of the experiences of patients who have been on a mechanical ventilator. These patients criticise the nurses for their "cold, callous, irresponsible and dangerous behavior". Not only did patients feel that they were being ignored and neglected, they also believed that the nurses were unable to assess and correct potentially dangerous problems, such as the malfunctioning of a ventilator. The conclusion of the author is that nurses should strive to "administer technically safe, but humanly sensitive, care" (Jablonski, 1994). The conflict between technical and social aspects in nursing as discussed by Henderson (1980) focuses on the question how nurses can be stimulated in this 'technological age' to develop an attitude that focuses on the patient as a person. Rather than try to reverse the increasing demand for technical skill in nursing, Henderson proposes measures in nursing administration, education, research and practice to encourage holistic nursing care. Elements of this approach are the assignment of patients to nurses rather than the assignment of tasks, increased professional responsibility and accountability, continuing education, emphasis on health problems and basic needs, and the opportunity for student nurses to observe clinically expert role models giving patient care (Henderson, 1980). The issue of technology in the intensive care setting is discussed by Ashworth (1990) in terms of the benefits and problems associated with the use of technology. According to Ashworth, machines in intensive care have the characteristics that are listed in Table 2.4.

\section{Benefits}

- substitute for human functions

- save time

- measure accurately

- measure physiological variables that are not directly perceptible by humans - avoid frequent patient disturbance

\section{Problems}

- are not infallible

- can depersonalise activities and people

- can cause iatrogenic harm

- quality of output is only as good as quality of input

- have no intuition

Table 2.4 Benefits and problems of technology on the ICU, after Ashworth (1990), p. 151-152

She concludes that the technology itself is neither good nor bad; it is only as good as those who use it. The list only indicates potential effects that may materialise depending on how people use the technology. Ashworth (1990) further argues that nurses have to possess theoretical and technical knowledge as well as experience in order to make the best use of the resources available. They have to be effective with machines, so that the technology becomes an extension of the nurses" hands, eyes, ears and other senses. At the same time, nurses have to be effective with people, helping the patient to feel safe and cared for in a situation where the presence of the equipment may be causing anxiety or fear. Hudson (1993) also sees empathy and technology as equally important aspects of nursing. She analyses the situation in the coronary care unit ( $\mathrm{CCU}$ ) and contrasts her observations with 
traditional images of nursing. Wichowski (1994) shows in an empirical study that nurses are ambivalent regarding the benefits of technology in patient care. The benefits and problems associated with the use of technology in Wichowski's research are consistent with those described by Ashworth. On the issue of timesaving, however, the nurses in Wichowski's study are ambivalent. While one nurse is quoted as saying: "I can spend more time with patients. Technology has freed me up", another nurse says: "All I do all day long is work with technology". This ambivalence is regarded by Wichowski as symptomatic of professional uncertainty, which stems from the discrepancy between the psycho-social emphasis in nursing education and the focus on technology in the hospital. This theme of coping with different expectations is present in many studies of nursing. Melia (1987) found that student nurses had problems with the division they noticed between nursing as it was presented to them in college and nursing as they observed and practiced it on the hospital wards. Wolf (1988) and Benner (1975) show how nurses who are new to the acute care environment can have serious problems trying to get accepted by the team. The problem is double-edged. First, the newcomer has to find out that there are tacit rules and implicit values that are part of the culture, but that may be very different from the rules and values that the nurse has adopted so far. Second, the new nurse has to adapt to this culture in order to become part of the group. Benner (1975) gives an example of a young nurse who experienced problems with a staff nurse in an emergency unit, because the young nurse considered it important to talk with the patients. Her attitude did not match the culture of intensive care which, according to Parfitt (1988), gives priority to physiological and technological concerns. Parfitt argues that it is time to "humanise" the ICUs and to change the current cultural values.

The dominant values in intensive care are at the centre of an ongoing debate which addresses conflicts in particular between technical and humane aspects of the work. This debate features more prominently in British and American journals upon which this review is based than in the Dutch professional literature. The suggested division between technology and humanity in the Dutch context will be discussed in the concluding chapter in the light of the outcomes of this study.

\section{What is the role of the nurse in intensive care?}

The role of the nurse in intensive care is discussed here in relation to the roles of other practitioners. The most significant other group of health workers in intensive care are the physicians. Several authors have criticised the traditional image in which the nurses' values are associated with caring and emotional support, while the doctors' values are associated with curing and technical interventions (Briggs, 1991, Zussman ${ }_{*}$ 1992, Shuldham, 1986). It has been argued that intensive care nursing contains elements of nursing practice as well as elements of medical practice. Shuldham (1986) speaks of an extended role for intensive care nurses, as opposed to a traditional role. She distinguishes three elements in this extended role of the nurse: clinical, managerial and teaching. The nurse as clinician has to combine the art and science of nursing, providing both technically and socially high-quality care to patients who are totally dependent on that care. The nurse as manager organises patient care and facilitates cooperation and support in the unit. Finally, the nurse as teacher is responsible for patient 
education as well as staff development. This extended role is not by any means fixed, but changes over time and can vary from hospital to hospital: The nursing role gets extended by the addition of new skills to the range of duties of the nurse (Shuldham, 1986). These new skills are often medical skills that are transferred to nursing. As a result, the boundaries between nursing and medicine become blurred. Briggs relates this process directly to developments in medical technology as she says:

"(...) what today are essentially medical tasks will change ower time as technology progresses; high-technology procedures such as recording blood pressures and giving intramuscular injections were once the prerogative of medical staff."

Briggs (1991) p. 226

She argues that technological change contributes to the extension of the role of the nurse. The traditional nursing role does not apply to intensive care, and this has implications for the doctor-nurse relationship. Junior medical staff in particular find it difficult to establish what their relationship with the specialist nurses should be (Briggs, 1991). In fact, there are practical skills, such as medication order writing, that medical students learn from nurses (Wolf, 1988, p.165). Intensive care nurses do not perform the traditional nursing role and do not have a traditional relationship with the medical staff, Briggs (1991) concludes.

A different perspective of the role of nurses in intensive care is presented by Zussman (1992). In his study of ethical problems he carried out observations on two ICUs. His conclusion is that nurses, like doctors, have become technicians. Zussman places the role of the technician opposite the role of the patient advocate, whom he also calls the 'angel of mercy'. He points to two specific situations where nurses could use their influence to advocate more humane treatment of the patient, but where they concentrated on technical aspects instead. One situation involves decisions about the continuation or withdrawal of treatment, and the other situation involves patients who have not been told the truth about their condition or treatment. Instead of speaking for the patient, negotiating for less aggressive treatment or supporting patient and relatives, the nurses do what the doctors decide. Zussman summarises:

${ }^{x}$ Nurses earn respect from physicians insofar as they are able to help complete the technical tasks that are the stock in trade of the physicians themselves. At the same time, it is in terms of technical skills - not patient advocacy or a distinctive commitment to care rather than cure - that nurses make their strongest claims against physicians and express, however faintly, their most principled criticisms of patient care."

Zussman (1992) Intensive care, p. 77

He concludes that this emphasis on technical skills is in large part a matter of choice of the nurses, both individually and collectively. This choice is complicated by the fact that in the hospital hierarchy as well as in the medical profession technical skills are recognised and rewarded, but not empathy or kindness (Zussman, 1992). Yet, this is not to say that nurses and doctors assess a patient situation in the same way. The fact that nurses are at the bedside 24 hours of every day, gives them a unique perspective on the situation of the patient (Henderson, 1980). Anspach (1993) distinguishes two kinds of cues for information: interactive 
cues and technological cues. Nurses have unique access to information that emanates from interaction with the patient and his or her relatives. However, in the medical decision-making about intensive care patients, the information based on interactive cues is not valued, and information based on technological cues is decisive. This does not mean that the decision-making process is straightforward. Topman (1987) adds to this discussion that medical care in ICUs is often fragmented as the patient is divided up into aspects that belong to one medical specialty or another. In this situation each physician can focus on his or her own specialty and disregard the general condition of the patient. Difficult decisions can thus be avoided on the basis that there is no conclusive scientific evidence to support one decision instead of another. Both Anspach (1993) and Topman (1987) note that this situation can be frustrating for the nurses who would prefer clear decisions that involve consideration of the whole situation and make use of interactive as well as technological cues. The nurses' frustration is strongly related to the fact that they have only limited influence in the decision-making process, while on the other hand they have the closest interaction with the patient and the anxious relatives (Harvey, 1985, Carnevale, 1991, Topman, 1987).

Thus, the role of the nurse in intensive care is not well-defined. Whereas the role of the nurses has extended in the sense that medical technical tasks have been delegated to them by doctors, the decision-making authority still rests exclusively with the doctors and the influence of nurses on the decision-making process is very limited.

An alternative to the analysis of the role of the nurse as discussed above, is the study of the practice of nursing through the perspective of symbolic interactionism (Chenitz and Swanson, 1986). This perspective focuses on the meaning of events to people, and explores how people define events or reality and how they act in relation to their beliefs. In order to give meaning to objects in the outside world, however, individuals need to develop a concept of self. This concept of self allows the individual to take a role in the interaction with others and to reflect on one's self. In the symbolic interactionist perspective, objects and events do not have an intrinsic and universal meaning, but individuals have to give a meaning to them through interaction with them. Thus, the symbolic interactionist studies are concerned with the following question.

\section{How do nurses perceive themselves and their work in intensive care?}

Adoption of the symbolic interactionist perspective for research requires that human behaviour is examined in natural settings where interaction can be observed, and that the researcher aims to understand behaviour as the participants understand it. The researcher has to become a participant, but, having understood the meanings in the particular practice under study, he or she is responsible for the translation of these findings into the language of his or her own scientific discipline. This translation often involves the researcher developing a theory regarding the practice that was studied. To this end, the interactionist perspective is often coupled with the grounded theory method, which offers a structure for the development of theories from empirical data. (For the methodological rationale of the grounded theory approach, see Chapter 3.) 
In these studies the researchers did not limit their analysis to the work of health professionals, but they directed their attention at everyone who was involved in the situations under study. Central to their analysis was that health care professionals work "on and with humans", and that they deal with the patient "as a human being: who responds, has a life/biography, a family, etc." (Wiener et al., 1979). Thus, the patient and his or her next of kin are also involved in the work that is required to deal with disease.

The researchers distinguish five kinds of work: machine work, safety work, comfort work, sentimental work and articulation work. This classification is fundamentally different from other ways to look at work arrangements, where emphasis is on the division of labour, assignment of tasks or career choices: The study of the division of labour is specifically aimed at the distribution of tasks among individuals in an organisation. The study of the division of work is more concerned with the tasks that are performed within an illness trajectory, and how decisions are made about which tasks are required.

Other studies of the practice of nursing have generally had narrower scopes. Benner (1984) studied expert nursing practice and the stages in skill acquisition that nurses go through in order to become experts. This work will be discussed at greater length in the next section on theories of learning and working. Marcus (1989) has investigated how nurses give meaning to their work and how they organise themselves and think about the work of the unit. She studied a surgical intensive care unit and found that nurses constructed 'workframes' in which patients were grouped according to anatomical part, major symptoms, surgical procedure or expected outcome. She also distinguishes three 'work realms' that each involve particular strategies. 'Work with patients' is a work realm in which the strategies are: monitoring, maintaining and documenting. 'Work with others' involves the strategies coaching, advocating and managing. Finally, 'work with self $f^{\prime}$ involves dealing with stress, risks to personal health, death and handling affronts to personal values. Marcus concludes that

"(...) nurses make decisions to act, or to refrain from action, according to professionally prescribed mandates for care tempered by their individual sense of the work. Their individual sense of the work is a product of professional education and experience, the need to respond to situational imperatives in their everyday world, and a culturallyderived pregiven self."

Marcus (1989) Surgical intensive care nursing work, p. 177

Neonatal intensive care units (NICUs) have been studied from an interactionist perspective by Swanson (1990) and Hutchinson (1984). Swanson (1990) defines four aspects of the process of care provision in the NICU: caring, attaching, managing and avoiding bad outcomes. These aspects affect the ways in which parents and professionals perceive the situation and how they act in the situation. Hutchinson (1984) uses the anthropological concept of culture to investigate how nurses deal with the overwhelming problems in neonatology. Her story is entitled "Creating meaning out of horror". She characterises the NICU as a place where horror is pervasive and she asks how nurses can survive in this environment. According to Hutchinson, the nurses create meaning by reconstructing the reality of the NICU so that they obtain new ways to see the situation. Hutchinson identifies three ways of creating meaning: emotionally by processes of attaching and separating, technically by monitoring and intervening, and rationally by justifying 
and accepting. The process of creating meaning allows the nurses to reduce their experience of horror in the NICU.

Thus, in this review of sociological studies of intensive care nursing we have seen that a conflict between technical values and humane values is perceived in the profession. Several authors have argued that intensive care nursing has gone too far in its enthusiasm for technology and that a reassessment of the values is necessary to bring more humanity into the work on ICUs. In addition, this review has shown that the role of the nurse in intensive care is not well-defined and overlaps to a certain extent with the role of the doctor. This involves nurses carrying out medical tasks, but it does not give them much influence on medical decisions. For nurses this is an unsatisfactory situation since their insights are not fully recognised and because they are expected to back the medical decisions in their contacts with the patient and the relatives. The studies that focus on questions of work and meaning take the patient and the course of the illness as their starting point. According to these studies, the nurse has to construct an image of self and an image of the situation in order to carry out the work that is required in the care for the patient. Giving or creating meaning is a strategy that enables nurses to cope with the extreme situations that are characteristic of the ICU.

\subsection{Man-machine interaction}

In this section we discuss the influence that the increasing use of computers and other "intelligent" machines may have on the practice of nursing. To introduce this issue we will start with some reflections on the nature of the relations between people and computers. Two related questions will be addressed in order to highlight how the boundaries can be drawn between what humans can do and what machines can do. These questions are: "How do humans learn?" and "Can machines replace humans?" We will begin with a summary of Dreyfus and Dreyfus" model of skill acquisition. This model describes how people learn, and it distinguishes between rule-based learning and experience-based learning. The authors argue that the human expert learns and performs chiefly on the basis of experience and therefore has one crucial quality that the computer cannot match: intuition. We then turn to the issue of the replacement of humans by machines. According to Collins, machine action is of necessity different from human action because machines can only mimic certain kinds of human acts, whereas humans can think and act. Thus, humans can theoretically be replaced by machines only for those kinds of acts that can be mimicked by machines. We continue this discussion with reference to the future of nursing and the prospect of 'the nurse as engineer".

\section{How do humans learn?}

In their analysis of skill and expertise, Dreyfus and Dreyfus (1986) distinguish between two forms of knowledge: 'knowing how' and 'knowing that'. Their conclusion about the limits of Artificial Intelligence and 'expert systems' is that computers will not be capable of expert behaviour because they lack the capacity for intuition. Machines are good at doing things that involve a set of clear rules. 
Knowing the rules and applying them is basically what is meant by 'knowing that'. For many everyday actions, however, there are no clear rules, and simple things like riding a bicycle cannot be captured in a set of rules. Knowing how to ride a bicycle is "knowing how" and is learned not from rules but through practice and experience. The approach of Dreyfus and Dreyfus is to analyse the development of human skilled behaviour in order to see "how far along this path the digital computer can reasonably be expected to progress" $(1986$, p.19). The direction of this development is from rule-guided "knowing that' to experience-based 'knowing how'. In this development, the authors identify five stages: novice, advanced beginner, competent, proficient and expert. The fact that Dreyfus and Dreyfus speak of stages does not imply that every learner will inevitably go through these stages and will become an expert. The authors have opted for 'stages' because they argue that there is a particular order in which the learner will proceed, namely from novice to advanced beginner and so on, and because the most talented individuals in a particular stage will perform more skilfully than the most talented individuals at an earlier stage. The characteristics of each stage of the novice-to-expert model are listed in Table 2.5. In Chapter 6 this model will be discussed further with regard to the learning process of nurses in intensive care.

\begin{tabular}{|c|c|c|c|c|}
\hline Skill level & Components & Perspective & Decision & Commitment \\
\hline Novice & context-free & no & analytical & detached \\
\hline $\begin{array}{l}\text { Advanced } \\
\text { beginner }\end{array}$ & $\begin{array}{l}\text { context-free } \\
\text { and situational }\end{array}$ & no & analytical & detached \\
\hline Competent & $\begin{array}{l}\text { context-free } \\
\text { and situational }\end{array}$ & chosen & analytical & $\begin{array}{l}\text { detached understanding } \\
\text { and deciding; } \\
\text { involved in outcome }\end{array}$ \\
\hline Proficient & $\begin{array}{l}\text { context-free } \\
\text { and situational }\end{array}$ & experienced & analy tical & $\begin{array}{l}\text { involved } \\
\text { understanding; } \\
\text { detached deciding }\end{array}$ \\
\hline Expert & $\begin{array}{l}\text { context-free } \\
\text { and situational }\end{array}$ & experienced & intuitive & involved \\
\hline
\end{tabular}

Table 2.5 Five stages of skill acquisition, as summarised in Dreyfus and Dreyfus (1986) Mind over machine, p. 50

\section{Can machines replace humans?}

Humans can think and act, and machines can mimic human acts. This is the thesis of Collins (1990), who introduces the concept of machine-like action to refer to those acts that can be automated because they only require that explicit rules are followed, or because the act can be mimicked without explicating the rules. It follows that the acts that cannot be fully automated rely less on following explicit rules and more on the use of skill and knowledge that is embodied or "embrained". Collins distinguishes between behaviour-specific action or machine-like action 
that can be mimicked by machines and regular action that cannot be performed by machines. He sees intelligent and other machines as mere tools, and concludes his book with a warning:

"(...) if we use them with too much uncritical charity, or if we start to think of ourselves as machines, or model our behavior on their behavior ${ }_{*}$ not only will we lose sight of what we are, the tools we make will not be good ones."

Collins (1990) Artificial experts, p. 224

Thus, the theory of human learning of Dreyfus and Dreyfus (1986) and the theory of human action of Collins (1990) both lead to the conclusion that computers cannot think and they cannot become experts the way humans can. Yet, computers do affect our lives and are the subject of debates regarding the future of work. In nursing, this debate focuses on the influence that computers can have on the walues and culture of nursing practice. Josefson (1990) argues that the language of science, and hence the new technologies, are in conflict with the values of nursing. A key value in nursing knowledge, that cannot be learned theoretically, is the capacity to 'see'. Josefson feels that this value will be marginalised if theoretical teaching and using technology become more important. This would lead to a situation in which the care-oriented nurse would be "hopelessly antiquated". This is already happening, according to Josefson, who writes: "I have noticed that many nurses who emphasize the human meetings in nursing often refer to themselves as being old-fashioned". A related issue is how the role of the nurse will be defined in relation to new technology, and how nurses will define their own role in the emerging situation. The introduction of computer systems for patient records has been criticised for adding to the nurses' workload and actually disorganising the work methods (Campbell, 1990). While the bedside process of care giving is interactive, interpretative, intuitive and collaborate, these characteristics do not apply to the systems for automated administration that have been introduced in some hospitals. One system that was studied by Campbell produced work plans for nurses, based on 'objective' measures of the needs of patients, expressed in units of work time. A consequence of working with this system, was that nurses began to see their own work in the terms of the system, to the extent that they altered their own ideas of what the patient needed to match the time allocation that the computer indicated. Nurses transformed the needs of the patient" into 'units of work time', in other words, they adjusted their thinking to match the requirements of the system. Further, Wagner (1991) notes that work practices are changing as activities are increasingly based on 'objectified' data and explicit rules and categories. According to her, the introduction of computers at the ward level triggers off a process of cultural transformation that extends to the core of nursing. Josefson (1988) sees a very limited role for the nurses if the current intuitive model of nursing is replaced by the scientific model: the nurse would be reduced to being a carrier of information. 'The nurse as engineer' is a prospect that Josefson thinks is possible, but not desirable. This opinion is also held by Blackburn, who writes:

"The acute care nurse of the future will have to deal with being a 'nurse-engineer'. Biological instrumentation will frustrate, perplex and challenge her. For nurses working in today's NICUs, however, it appears that tomorrow is already here."

Blackburn (1982) p. 1709 
Thus, students of nursing are less than optimistic about the future as they fear that nurses" work will be determined increasingly by machines. The emergence of the 'nurse-engineer' is seen as a threat to the unique and human character of the practice of nursing. In the opinions of Dreyfus, Dreyfus and Collins, however, machines will only be able to replace humans to the extent that humans will allow. Since machines cannot learn from experience or develop intuition, they cannot achieve the kind of expert performance that humans can. People, then, should be aware that they are in control of the machines.

\subsection{Conclusions}

The review of literature in this chapter has highlighted a number of aspects of the study of technology in health care. We have seen that this area has been investigated by scholars from various disciplines, applying a great variety of approaches and using many different methods. Yet, little evidence was found of attempts to integrate concepts and approaches, and therefore we characterise the current state of knowledge as fragmented. In this concluding section we summarise the findings of the review and outline how the present study of work and technology in ICUs is positioned with regard to its contribution to existing knowledge in this area.

Our review of literature on technological change in medicine has shown that medical technologies are developed and modified in a cooperative process between manufacturers and users. This mechanism has attracted recent attention in policy research as the traditional methods of technology assessment are under review and proposals are developed to make assessment part of a constructive process. The review also finds that the consequences of new technologies are greatly influenced by the context in which these technologies are developed and used. Although the influence of technological change on the practice of medicine cannot be established in general terms, it is suggested that the direction of the influence is towards a greater reliance of both doctors and patients on technology. Since it is difficult to develop a theory that explains the behaviour of medical technologies in general, arguments are put forward in favour of an approach that takes into account how circumstances influence the change process and how these circumstances at the same time are influenced by technological change.

The historical overview of nursing and technology in ICUs has shown that technology has become increasingly important in patient care. Nurses have gradually become involved in the medical aspects of intensive care, and it was suggested that nursing has become more technology-oriented and less patientoriented. The studies of ethical problems in this review illustrate that the growing range of technologies in intensive care can contribute to the complexity of the moral dilemmas that staff, relatives and patient have to cope with. The economic studies that are reviewed here indicate that significant differences exist between ICUs in terms of outcomes and organisation. It is suggested that efficiency in ICUs can benefit from clearer admission criteria and from the distinction of several levels of care.

The psychological studies concerning burnout, stress and gender differences have portrayed the ICU as a complex and demanding environment. It is argued in some studies that a particular combination of personality characteristics can reduce 
the chance that an individual nurse will develop psychological problems in this environment. In other studies, however, it is proposed that the ICU as a work place can be organised in ways that make it less likely for stress and burnout to be developed by staff. The findings regarding the role of technology in the development of stress in ICUs underscore the importance of the organisational arrangements within which the technologies are used. With regard to the career choices that nurses make, it is shown that among the nurses who are attracted to intensive care nursing, there is a relatively large number of men. The successful intensive care nurses have been characterised as androgynous, which means that they score high on feminine as well as masculine traits in the standard psychological tests.

In the sociological literature that we reviewed, a division is suggested between care and technology, expressed in a conflict between those values associated with humane patient care and those values associated with technical expertise. With regard to the role of nurses in intensive care, two issues are discussed. Firstly, the tasks and responsibilities of nurses in the ICU do not fit the traditional role as many medical tasks are included and therefore these nurses are said to perform an extended role. Secondly, because nurses are involved in the medical tasks, the professional relationship between nurses and doctors does not follow the traditional clear boundaries and is often less hierarchical and more cooperative. In the symbolic interactionist approach to intensive care nursing, the focus is on the process of giving or creating meaning in a dramatic situation. The human interaction between the patients and the nurses is analysed in these studies, and the results showed that giving or creating meaning is a process that enabled nurses to work in this situation.

The discussion of the influence of computers on the practice of nursing has addressed a fundamental difference between people and machines: people can develop intuition on the basis of experience, and machines cannot do this.

According to the Dreyfus model of skill acquisition, this experience is gathered during a process of learning in which five stages can be identified: novice, advanced beginner, competent, proficient and expert. Benner has shown that this model applies to nursing. The expert level of practice is qualitatively different from the previous stages as it is characterised by involvement and intuitive decision-making. With regard to the influence of technology on nursing practice, however, we noted that nurses themselves fear that in future their work will be determined increasingly by machines.

The present study seeks to explore the work of intensive care nurses with special reference to the role of technology and the organisational context in which the work takes place. Based on the study of day-to-day practice of intensive care and the views of the practitioners who shape it, this study investigates the phenomenon of intensive care nursing from within. The study differs from those that were reviewed above in two important ways. Firstly, the present study focuses on the process of intensive care nursing and attempts to identify and to integrate concepts that are relevant to the understanding of this process. Secondly, the study adopts a comparative approach as it investigates three types of ICUs and a total of eight sites. These characteristics are discussed below with reference to the existing literature. The choices that are discussed here have consequences for the methodological design of the study and are detailed further in Chapter 3 . 
By focusing on the work process of intensive care nurses, the present study avoids making an a priori selection of relevant concepts for the investigation. Whereas other studies have their origins in a specific discipline and adopt the concepts that are current within that discipline, the present study is guided by the research problem and is conducted in such a way as to discover the relevant concepts that pertain to this problem. This does not mean that the existing concepts are deemed irrelevant at the onset of the study. Rather, it was anticipated that integration of existing concepts would be highly problematic since the concepts that are put forward in the literature stem from a wide range of scientific disciplines. Since this study is not a theoretical exercise, but instead aims at the understanding of practice, this line of enquiry was not followed. The literature is, however, important as a source of insights. Historical, sociological and psychological insights are used to reflect on the findings of the study. The growing importance of technology, the extended role of the nurse, the suggested conflict between technology and care, as well as the nurses' perception of their work and their coping behaviour, are all issues that are addressed in this study. However, it should be noted that these issues are discussed only because they are relevant to our understanding of the work process in intensive care nursing. This relevance is determined during the research when the evidence gradually begins to form patterns and the story unfolds. The study explores these issues and others, such as gender differences and skill acquisition, by close examination of current practice.

A second feature sets this study apart from those that were reviewed, namely the comparative approach that is adopted here. Researchers so far have concentrated on one type of ICU only, and field work has generally been limited to one site in each study. While some studies are concerned with GICUs and others with NICUs, it is not possible to establish how these are different on the basis of the literature reviewed. By bringing NICUs, PICUs and GICUs together in one study and investigating more than one site for each type of ICU, the present study explores differences as well as similarities between these types of ICUs. However, this is only done in order to develop a more comprehensive insight into the process of intensive care nursing and not in order to compare the units as such. The eight ICUs that are studied should be seen as eight case studies that address the same phenomenon. The methodological arguments for this approach are presented in the following chapter. 



\section{Chapter 3}

\section{Research methodology}

The present study explores the relationships between technology, work and organisation in the specific setting of intensive care nursing. Its aim is to describe, analyse and explain the nursing process in ICUs, thus constructing a theory which integrates insights regarding three types of ICU and which is grounded in the practice of intensive care nursing. By studying the day-to-day practice of work in this setting where technology is highly visible we further contribute to the wider debate about technology at work, which is discussed in Chapter 7.

As we have seen in the literature review in Chapter 2, the empirical data base concerning the work of nurses in ICUs to date is in a fragmented and primitive state. Although a range of theoretical, practical and societal concerns relating to hospital ICUs have been studied from a number of mono-disciplinary perspectives, these studies have not been integrated into a thorough understanding of the process of intensive care nursing. In addition to the fragmentation that follows from the prevalence of mono-disciplinary studies, a second form of fragmentation characterises current research, namely that each study typically addresses one type of ICU only. The present study focuses on the work process and investigates this process in three types of ICU. This requires a research design that is suitable for study of contemporary practice, empirical data, process and comparison. This chapter discusses the research design in terms of the research strategy for the study and the research methods for data collection and data analysis. We will begin, however, with a discussion of the conceptual framework and the research questions that provide the basis for the further methodological decisions. Then we shall address the ongoing debate in the literature on qualitative methodology regarding inductive and deductive reasoning. This is followed by a discussion of the case study strategy, the methods that were employed in the collection of data and the method by which the theory was constructed from those data. An outline of the actual research process and some reflections on validity and reliability of qualitative research conclude this chapter. 


\subsection{Conceptual framework and research questions in qualitative research}

There is widespread agreement among methodologists that the design of a study should match the research question and the conceptual framework of that study (see, for example, den Hertog and van Sluijs, 1995; Miles and Huberman, 1984, 1994; Yin, 1989; Robson, 1993; Bryman, 1988). The conceptual framework is defined by Miles and Huberman (1994) as follows: "A conceptual framework explains, either graphically or in narrative form, the main things to be studied - the key factors, constructs or variables - and the presumed relationships among them" ( $\mathrm{p}$. 18). They add that frameworks can vary in their outlook and level of detail, ranging from rudimentary to elaborate. The essential functions of the conceptual framework are to focus and to bound the collection of data. The conceptual framework is operationalised in the research questions (Miles and Huberman, 1984, 1994; Robson, 1993). These questions represent the facets of an empirical domain that the researcher most wants to explore (Miles and Huberman, 1994, p. 23). Thus, the conceptual framework and the research questions together capture the essence of the research. It should be noted, however, that according to Miles and Huberman (1984) qualitative research is essentially an investigative process in which "one makes gradual sense of a social phenomenon" (p. 37). The research questions of qualitative research projects cannot be definitively specified at the start, according to Jorgensen (1989) and Marshall and Rossman (1989). Strauss and Corbin (1990) summarise the function of the original research question as follows:

"The original research question is a directive that leads the researcher immediately to examine a specific performance, the site where events are occurring, documents, people acting, or informants to interview. It gets the researcher started and helps him or her to stay focused throughout the research project. (...) through the analysis of the data, which begins with the first collection of data (the first interview or observation), the process of refining and specifying the question will begin."

Strauss and Corbin (1990) Basics of qualitative research, p. 39

Miles and Huberman (1994) argue in favour of flexibility of both the conceptual framework and the research questions which they say may be refined or reformulated in the course of the field work. Their main concern is that some kind of conceptual framework must be defined at the outset of the research, thus demanding that the researcher considers what will be studied, where, how and why. In the discussion of inductive and deductive reasoning we will address the reasons for formulating a conceptual framework in more depth, but first we will present the conceptual framework and the research questions that guide the present study. A rudimentary conceptual framework was devised after the initial search of the literature and a round of interviews with actors involved in various areas of health care. Three elements of intensive care nursing are central to the investigation: nurses, technology and care. Together, these elements and their relations are considered to constitute the work process. A diagrammatic presentation of the conceptual framework is shown in Figure 3.1. It should be stressed that this is only intended as a schematic overview of the possible structure of the phenomenon, and that at this stage no attempt is made to divide process and context. 


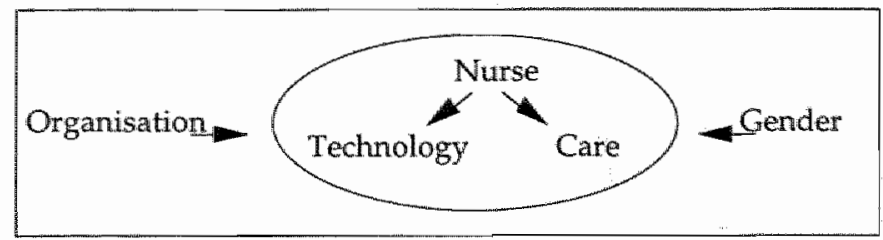

Fügure 3.1 Diagram of conceptual framework

On the basis of the findings of the literature review it is assumed in Figure 3.1 that nurses have to divide their attention between care and technology. For the same reason, it is further assumed that malle nurses would be more attracted to technology and female nurses more to care. With regard to the organisational. aspects of intensive care we assumed that these presented the conditions within which the work takes place. These assumptions are tentative and only serve to make explicit what we expected to find. Marshall and Rossman (1989) call these 'guiding hypotheses'. Since they are not intended for empirical testing, Robson (1993) describes these tentative hypotheses as "interim guesses about what lies behind the "how" in the question" (p. 29). Regarding each element of the framework, further investigation is required to establish how these abstract concepts appear in practice. Thus, questions need to be asked with respect to which factors characterise an intensive care nurse, what can be considered technology and what is care in the context of the intensive care, how gender can be operationalised as an explanatory factor, and what are the organisational aspects of intensive care. In addition, the assumed relations between these elements require analysis. Thus, in the framework the work process is the core concept that is assumed to be influenced by gender and organisation. At the same time, however, the aspects that constitute the work process, namely nurses, technology and care, and their relations, are not clearly defined. These concerns were summarised in the following three initial research questions:

How do intensive care nurses use and perceive technology in their work?

How do male and female nurses differ in their use and perception of technology?

How do organisational arrangements influence the work process?

This study, then, addresses the primary process of the ICU, namely the nursing process, and attempts to establish how this process is structured and how, if at all, it is influenced by organisational and gender aspects. It was decided to focus on the work process as the central theme. Therefore, the study was designed in such a way that the work process would be the centre of the data collection with the dual purpose of investigating the characteristics of the work process as well as the possible influences on it. For this reason it was considered appropriate to study the everyday work of intensive care nurses as and where it took place: on the ward. Furthermore, participant observation and interviews were chosen as the methods for data collection since they could be employed in an open and flexible design. These methods are detailed in Section 3.3 below. We will now turn to a discussion 
of inductive and deductive ways of reasoning in qualitative research in order to clarify the logic that underlies the formulation of a conceptual framework in an exploratory study.

\section{Induction and deduction}

Induction and deduction are two opposite models of scientific reasoning (Kidder and Judd, 1986). Deduction starts with general theoretical principles that follow on from existing theory. At the start of the study there is a clear conceptual scheme to work from and there are specific hypotheses to be tested. The empirical research then consists of gathering data in order to test the hypotheses that are dictated by the theory. It is obligatory that variables have been identified and relations between them have been stated before the data are collected. At the other extreme is induction, which does not start with given variables and relationships. Instead, the process of identifying variables is part of the inductive process. Variables, concepts, hypotheses and theories are the result and not the starting point. The research is aimed at constructing theory from empirical material. In the empirical cycle of scientific research, induction and deduction both have a place (Swanborn, 1984; Marshall and Rossman, 1989) as they both contribute to the development of knowledge; induction by developing theories and deduction by testing theories. In practice, however, purely inductive or purely deductive research is hardly ever conducted (Kidder and Judd, 1986).

The grounded theory method is aimed at developing theories and is therefore essentially inductive. The classic books on grounded theory (Glaser and Strauss, 1967 and Glaser, 1978) advocated a purely inductive approach and recommended that the researcher should try to enter the field with as little theoretical insight as possible. Consultation of literature prior to conducting the field work was discouraged, because the literature may mislead or distract the researcher. Rather than investigating the phenomenon as it presented itself, the researcher would be at risk of unconsciously starting to accept what was written. Glaser and Strauss (1978) do, however, recommend the use of literature in the later stages of the research, when the researcher is in a position to assess the existing literature in the light of the emerging theory. At present, the use of literature is encouraged in all stages of the grounded theory research process (Field and Morse, 1985; Strauss and Corbin, 1990). It should be noted, however, that the literature is perceived as data, to be analysed and evaluated like any other source of data (Chenitz, 1986). This means that one does not search the literature in order to find a theory that can be tested, but instead uses the literature to develop insights and gather knowledge that will help the investigation of the phenomenon under study. In this way the literature is used to enhance and stimulate 'theoretical sensitivity', which is the ability to recognise what is important in data and to give data meaning (Strauss and Corbin, 1990).

From a different position Miles and Huberman $(1984,1994)$ make a similar point. They argue that purely inductive research is an illusion, because "any researcher comes to field work with some orienting ideas, foci and tools" (1984, p.27). They emphasise that since the researcher is the instrument in qualitative research, it is important that the researcher brings experience and a multidisciplinary perspective to the study. This makes the researcher less vulnerable to data-overload and naive interpretation (Miles and Huberman, 1984). Equally important is that the researcher makes clear from the start what the ideas are that 
guide the research. Miles and Huberman $(1984,1994)$ argue that a conceptual framework and research questions can be formulated, and indeed must be formulated, even for qualitative and exploratory studies. These can be formulated in broad and general terms depending on the aims of the study. This point of view is also reflected in the methodological handbooks of Robson (1993) on real world research, Marshall and Rossman (1989) on qualitative research, Field and Morse (1985) on qualitative nursing research, Moustakas (1990) on heuristic research and Fetterman (1989). The latter argues with regard to ethnography that theory is a guide to practice and that in fact everyone "tackles a problem with a theory or set of theories in mind about how things work" (Fetterman, 1989, p. 15).

Thus, research that is essentially inductive nevertheless starts with questions and ideas that guide the researcher. It is the responsibility of the researcher to give meaning to data, and in this process the researcher needs 'theoretical sensitivity' as well as an explicit conceptual framework. In the present study the literature was searched initially to idlentify the scope, range, intent and type of research that had been done so far. During the study an ongoing assessment of the literature took place, and this led to the identification of concepts that could be introduced into the emerging theory after it was established that they fitted the data. Thus, a combination of induction and deduction was used; constructing from practice a theory that incorporates elements of other theories in a process that involved both analysis of material and testing of theoretical constructs against empirical data. This combined and alternating approach is further detailed in Section 3.4 on grounded theory as a method of analysis.

\subsection{The case study strategy in exploratory research}

In principle, there are three research strategies to investigate social phenomena: the experiment, the survey and the case study (Robson, 1993; Yin, 1989). Each strategy has a different approach to the situation under study. An experiment involves measuring the effects of manipulating one variable on another variable. This requires that the variables are known and well-defined at the outset of the study and that the researcher creates a situation in which he or she has control over the presence and manipulation of these variables. A survey consists of the collection of information in standardised form from groups of people. Unlike the experiment, the survey does not require the researcher to have control over the situation. Instead, it demands that the people who are studied are representative of the larger group that the survey is investigating. Thus, the total population must be known and a representative sample of this population must be defined. For example, many economic studies utilise survey-based data that underlies most time series, while others use census data (where the sample is the entire population of people or transactions). The case study is "a strategy for doing research which involves an empirical investigation of a particular contemporary phenomenon within its real-life context using multiple sources of evidence" (Robson, 1993, after Yin, 1989). This strategy is employed for the development of detailed, intensive knowledge about a single 'case' or about a small number of related 'cases'. A 'case' can be many different things, for example an individual, a group of people, an organisation, a policy programme or a product. The case exists in a context from which it cannot analytically be separated at the outset of the 
research, and the case study strategy requires that this context is included in the research (Yin, 1993). Thus, in a case study the researcher has no control over the situation under study, again unlike the experiment. On the other hand, the case is not selected on the basis of its representativeness of a larger group, but it is a way to study a particular phenomenon, as is also done in the experiment $(Y$ in, 1989). Thus, following the same logic that applies to experiments, the case study is not generalisable to populations, but instead is generalisable to theoretical propositions (Miles and Huberman, 1994, 1984; Robson, 1993; Yin, 1989). Another similarity between the experiment and the case study concerns the types of research question that can be addressed by either method. These questions are referred to as 'how" and "why" questions, thus referring to the ways in which a phenomenori occurs and the reasons for its occurrence. This is in contrast to the survey, which is more suitable for questions of who, what, where, and how many (Robson, 1993; Yin, 1989).

The case study was chosen as the strategy for the present study, since it is suitable for the study of a phenomenon in its context when the variables pertaining to this phenomenon are not known at the outset of the research and questions of 'how' and 'why' are asked. This characterisation also explains why the experiment and the survey were rejected as possible strategies for the study of the work of intensive care nurses. Notwithstanding the above comment, a small-scale survey was conducted during the project with the specific aim of studying the career paths of male and female intensive care nurses. The results of this survey are reported in Chapter 5. Next, we will address the decisions that were made regarding the selection of the cases and the selection of sources within the cases. This process is called sampling and is done on the basis of the conceptual framework and the research questions.

\section{Sampling sites and sampling within-site}

Sampling decisions are made tentatively at the outset of the study and are reviewed during the research process (Miles and Huberman, 1994). These decisions reflect the choices that are made regarding the people to be observed and interviewed, the settings in which this will be done and the processes and events that will be covered. The conceptual framework and research questions determine the foci and boundaries within which samples are selected (Miles and Huberman, 1994, 1984; Robson, 1993; Hammersley and Atkinson, 1983). Sampling in qualitative studies tends to be purposive and theory-driven (Miles and Huberman, 1994). This means that the sites as well as the people, settings, processes and events are selected because they are expected to contribute to the understanding of the phenomenon under study. This so-called 'theoretical sampling' is quite different from statistical sampling, which demands an operational enumeration of the entire pool of potential respondents and then uses a statistical procedure to select a specific subset of respondents to be surveyed (Yin, 1989). Theoretical sampling is an essentiall element of the grounded theory approach (Strauss and Corbin, 1990; Glaser and Strauss, 1967) and is applied by Yin $(1989,1993)$ for the selection of cases in a multiple-case study. It should be noted that Yin $(1989,1993)$ refutes the term 'sampling' in favour of 'replication'. In the remainder of this study we will use 'replication' in the discussion of the selection of multiple cases, following Yin for this purpose. However in the discussion of the selection of elements within a case, we will follow the terminology of Miles and Huberman (1984, 1994), using 
'sampling'. The choices that were made with regard to the sampling parameters in this study are listed in Table 3.1 below.

$\begin{array}{ll}\text { Sampling parameters } & \text { Choices } \\ \text { Setting } & \text { Ward, coffee room } \\ \text { Actors } & \text { Mainly: nurses, trainees, leadership, doctors } \\ & \text { Occasionally: visitors, auxiliary and paramedical personnel } \\ \text { Events } & \text { Bedside nursing } \\ \text { Processes } & \text { Looking after patient and equipment, preparing and } \\ \text { delivering } & \text { drugs, administration, interaction between professionals }\end{array}$

Table 3.1 Sampling parameters

In other words, the within-site sample reflects the choices that were made in the conceptual framework by concentrating on the work place and the work process of intensive care nurses. The first site to be included in the study was a NICU, as will be detailed in Section 3.5 below. This NICU was located in a teaching hospital, and was initially considered relevant to the study because it employed mainly female nurses in a highly technological environment. The research was, however, concerned with the phenomenon of intensive care in more general terms and therefore it was decided to include several ICUs in the study. Table 3.2 shows how these ICUs were distributed according to the type of ICU and the type of hospital that they were part of.

\section{Type of ICU}

NICU PICU GICU

$\begin{array}{lllll} & \text { Teaching hospital } & 2^{*} & \text {-** }^{* *} & 2 \\ \text { Type of hospital } & \text { Regional hospital } & - & - & 1 \\ & \text { Paediatric hospital } & 1 & 2 & -\end{array}$

* One NICU was formally part of a paediatric hospital but located in a teaching hospital.

* One PICU was in the process of being established in a teaching hospital. At the time of the research this meant that two beds on a GICU were available for paediatric intensive care.

Table 3.2 Research sites

It should be noted that some cells represent a situation that does not occur and these cells are therefore empty. NICUs and PICUs are normally not located in regional hospitals because they require the support of other sophisticated clinical functions that are only available in teaching hospitals or paediatric hospitals. The absence of GICUs in paediatric hospitals is self-evident. A brief description of these types of ICU was given in Chapter 1.

A further consideration that is implied in the research questions refers to the differences between male and female intensive care nurses. During the research it was found that a general pattern prevails in which the female nurses are over- 
represented on PICUs and NICUs, whereas the male nurses are over-represented on GICUs. This seemed to be related to the kind of patients that a particular type of ICU specialises in, namely children in PICUs and NICUs, and adults in GICUs. In Chapter 5 this apparent division is discussed in further detail. The observation that some ICUs attract predominantly male or female nurses was a guiding principle in the selection of the cases.

The cases were selected during the research process on the basis of their relevance to the research question as well as the insights that the research had generated so far. For this purpose, the replication logic was followed, which is aimed at analytical generalisation (Yin, 1989; Robson, 1993). Two types of replication are distinguished: literal replication and theoretical replication. Both were used in this study. In a literal replication, an additional case is selected for study on the basis that expected outcomes are similar to the previous case. In this study, literal replication meant that 3 NICUs, 3 GICUs and 2 PICUs were included. The outcomes within each type of ICU were expected to be similar. This expectation was tested by selecting at least two cases of each type, in different hospitals. Theoretical replication refers to the selection of cases that are expected to generate different outcomes. The inclusion of three types of ICU in the study is a form of theoretical replication, as these types are known to differ with regard to the kind of patient they treat and also with regard to the gender of the nurses who work there. Theoretical replication was used in order to establish if and how NICUs, PICUs and GICUs differ from each other in terms of the work process. The comparison of these cases follows a replication strategy: after one case is studied in depth, the next case is analysed and examined to see if the pattern matches that already found in the first case (Yin, 1989; Miles and Huberman, 1994). In this way a number of cases can be compared, either because a similar pattern is expected or because on a theoretical basis a different pattern is expected. This latter situation is also known as negative case analysis (Kidder and Judd, 1986) and is used to revise the emerging theory (Strauss and Corbin, 1990).

\subsection{Methods of investigation}

\section{Participant observation}

Participant observation is a way to learn in a direct way about "the world of everyday life", in other words the "ordinary, usual, typical, routine or natural environment of human existence ${ }^{\prime \prime}$ (Jorgensen, 1989). It is a way of doing social research in which the researcher is the principal tool (Robson, 1993) or instrument (Miles and Huberman, 1984, 1994; Sanday, 1983), i.e., the researcher is the means through which the data are collected. The method requires 'immersing oneself' (Shaffir and Stebbins, 1991) in a specific area of human existence and can be applied to all kinds of situations. Participant observation is also referred to as ethnography (Hammersley and Atkinson, 1983), field work (Shaffir and Stebbins, 1991) or gestalt research or clinical field research (Blanck and Turner, 1987). Notwithstanding these different labels, the common characteristic of these methods is that the researcher "participates, overtly or covertly, in people's daily lives for an extended period of time, watching what happens, listening to what is said, asking questions; in fact collecting whatever data are available to throw light on the issues with which he or she is concerned" (Hammersley and Atkinson, 
1983, p. 2). Thus, participant observation relies on common-sense methods and common-sense knowledge that are also used in everyday life. Hammersley and Atkinson (1983) note that social research always is, and should be, reflexive. They continue: "All social research is founded on the human capacity for participant observation. We act in the social world and yet are able to reflect upon ourselves and our actions as objects in that world" (p. 25). Since the aim of participant observation is to uncover, make accessible and reveal the meanings people use to make sense of their daily lives (Jorgensen, 1989), the method cannot be classified as objective or subjective (Agar, 1986). Instead, participant observation is interpretive as it is used to study a group and to communicate the findings regarding that group to an audience. The researcher is in this process a mediator or interpreter who can relate to the group as well as to the audience (Agar, 1986, Sanday, 1983).

There are several ways to conduct participant observations in real-life situations. They differ with regard to the extent to which the researcher becomes involved in the situation under study (Jorgensen, 1989). A common classification of observational styles distinguishes four such roles (Robson, 1993; Hammersley and Atkinson, 1983; Field and Morse, 1985). Two of these roles require involvement: the "complete participant", who seeks to become a full member of the group and usually does not reveal that he or she is also an observer, and the 'participant as observer', who presents him- or herself as a researcher and tries to establish close relationships with the members of the group. Two non-participant roles are the "observer as participant", who operates overtly, and the "marginal participant" (Robson, 1993) or 'complete observer' (Hammersley and Atkinson. 1983; Field and Morse, 1985), who works covertly.

One of the concerns in doing participant observation is that the researcher wants to study the group as it normally behaves in its natural environment, but it is difficult to be sure that this is achieved. This is the problem of ecological validity (Hammersley and Atkinson, 1983). On the one hand it is difficult for the researcher to keep the roles of the observer and the participant separate. The researcher may become too much of a participant and thus lose sight of the scientific reasons for doing the research. This is referred to as 'going native" (Hammersley and Atkinson, 1983; Field and Morse, 1985) or "becoming the phenomenon" (Jorgensen, 1989). The strategy that Hammersley and Atkinson (1983) recommend in order to avoid 'going native' is to aim to "maintain a more or less marginal position" and to avoid feeling 'at home' in the setting. On the other hand, the group under study may have difficulties acting as if the researcher were not there. Robson (1993) notes that a non-interactive style may make the researcher stand out as someone who does not belong to the group. He argues that it may be more natural and less disturbing to take up an explicit role in the situation. The measures that were taken to improve ecological validity will be discussed in greater depth in Section 3.5 below. In the present study, an overt participant observation style was employed, which meant that I introduced myself as a researcher to the nurses before the observations started and made a point of introducing myself to others during the observations. How the role of the observer evolved during the research is detailed in Section 3.4 below. For now, we will just note that the observations are most effective when a two-way process can be established in which the researcher tries to fit in and the participants are willing to share their experiences with the researcher. During the observations, evidence 
was sought in order to establish how the researcher's emerging understanding of the situation differed from or agreed with the views of the participants.

Another distinction in participant observation pertains to the ways in which the researcher seeks out and records the events that are observed. At one extreme is the unstructured approach that allows the researcher to follow up events as they unfold, with the researcher taking notes in a free format. At the other extreme is the structured approach that requires the researcher to make an observational schedule that is filled in during the observations. This latter method is appropriate when the stidy is aimed at coding behaviour for quantitative analysis. Barley (1990) used structured observations in a study of the roles of technicians and consultants in radiology departments. In the present study the unstructured approach is adopted in keeping with the exploratory character of the research. As Bryman (1988) argues "unstructured ethnographic research (...) is particularly capable of undergoing a change of direction and also permits a more opportunistic approach to making contacts and following up new leads" (p.10). The qualitative data that are collected through the observations are analysed, as is described is Section 3.3 , in a qualitative manner following the grounded theory approach. As will be argued, in order to develop a theory that is grounded in empirical evidence it is necessary to combine the processes of data collection and data analysis. In the present study an alternating approach was implemented, with data being collected during the observation period and analysed shortly afterwards. The preliminary analysis was then presented to the participants in a group meeting, and their comments were considered for the next version of the analysis. The data collection was then continued on another ward and the process repeated. This was an effective way to establish to what extent the emerging theory captured the processes on the wards and reflected the work of the nurses.

\section{Interviews}

During participant observations the researcher asks questions to obtain clarification and explanation regarding the situation. The conversations that thus take place are referred to as informal interviews (Chenitz, 1986; Fetterman, 1989). Usually this is done by asking participants what they are doing while they are doing it, or shortly afterwards. The details and meanings of the situation can be captured much better than if the researcher were only looking. In the present study the informal interviews were conducted at the bedside, elsewhere on the ward and in the coffee room. The informal interviews were also used to obtain validation of the previous findings. To this end the researcher approached several nurses with similar questions for explanation and clarification. Thus, the answers of the participants could be compared and the researcher acquired insight into the different citcumstances that could influence the actions of the nurses. It was found that actions that looked the same might be done for different reasons, depending on the nurses' perception of the situation. In Section 3.4 we discuss the practical considerations regarding the informal interviews. It should be noted here that the purpose of the study, namely to gain insight into the work of intensive care nuises, can only be achieved if the researcher gives the participants the opportunity to express how they see their work as well as the specific actions they do in the course of their work. Thus, as much as possible the researcher maintained the attitude of the interested and curious visitor, also known as the professional stranger. This required that the researcher did not display or take for 
granted what knowledge had been acquired before. Therefore questions were presented in a way that invited the participant to talk about his or her personal perception of the situation. The informal interviews were sometimes extended to a comparison of the participant's answer with answers that had been given by other participants. This proved an effective way to highlight the complexities and contingencies of the work, something that the researcher could not have accomplished independently on the basis of the information available. Thus, the informal interview was used for data collection as well as interpretation. The method as described was used on each ICU in the study, so that insights that were acquired earlier in the study were scrutinised in later stages, involving other settings and other people.

A second kind of interview that was also used in the present study is the formal interview (Swanson, 1986; Fetterman, 1989), in which the researcher asked the respondent, usually in a one-to-one setting, to reflect on his or her work and career, and to give his or her personal opinion about developments concerning the work. These interviews were semi-structured as they were guided by a topic list. The topics in this list that were covered in each interview included age, education, experience and motivation with regard to the choices made in the nursing career and particularly concerning intensive care nursing. This information was used in the small-scale survey that was done concurrently with the observations to provide background information regarding the career paths of male and female intensive care nurses. Most of the interviews included the personal opinions of the respondent on issues that related to the practice of the work, for example shift work, the relationship with the medical staff or the introduction of a new technology. Since these interviews were conducted to record the views of the respondent, the transcript was returned to the respondent for comments. These comments were incorporated in the final version that was used for further analysis.

\subsection{Grounded theory as method of analysis}

"A grounded theory is one that is inductively derived from the study of the phenomenon it represents. That is, it is discovered, developed, and provisionally verified through systematic data collection and analysis of data pertaining to that phenomenon. Therefore, data collection, analysis, and theory stand in reciprocal relationship with each other."

Strauss and Corbin (1990) Basics of qualitative research, p. 23

The aim of the grounded theory method is to generate a theory that "is faithful to and illuminates the area under study" (Strauss and Corbin, 1990, p.24); it should. explain as well as describe (Corbin and Strauss, 1990). The phenomena under study are perceived as dynamic and changing in response to evolving conditions, while the actors are viewed as being capable of influencing the situation. Thus, grounded theory seeks not only to uncover relevant conditions, but also to determine how the actors respond to changing conditions and the consequences of their actions (Corbin and Strauss, 1990). Since the theory is grounded in empirical material, it is initially inductive, but still requires the formulation of an initial research question. As we discussed in Section 3.1, it is important in this kind of research to 
recognise the fine line between utilising previous knowledge in a constructive way and letting previous knowledge block the theory development. The 'theoretically sensitive' researcher thus utilises knowledge and experience in order to give meaning to the data and to identify further questions to be asked (Strauss and Corbin, 1990). The grounded theory method uses both inductive and deductive ways of reasoning. From the specifics of the research situation the analyst works towards general ideas about the topic by a process that moves "from inductive to deductive and back again, as the researcher moves through the research process" (Corbin, 1986). Thus, the researcher can turn to deductive thinking and hypothesise possible situations that are different, then go back to the data and look for evidence to support, refute or modify that hypothesis (Strauss and Corbin, 1990). In other words, a reciprocal relationship exists between gathering data and constructing a theory. The analysis is a continuous process that does not start after the data have been collected, but takes place during the data collection. Questions that emerge in the analysis can be incorporated in the further collection of data. This formed the basis of the present study, as it is aimed at the development of a theory and therefore adopts the grounded theory approach.

The grounded theory method uses a systematic set of procedures to develop a theory about a phenomenon. These procedures are referred to as coding (Strauss and Corbin, 1990; Corbin and Strauss, 1990) and constitute the constant comparative method of analysis" (Glaser and Strauss, 1967). Open coding is the first step in this process and involves breaking down, examining, comparing, conceptualising and categorising data. Thus, initial categories are developed that are specified in terms of their properties and dimensions. This is followed by a procedure called axial coding, during which the data are put back together in new ways, making connections between the categories and their subcategories. Thus, a category is specified in terms of the conditions that give rise to it, the context in which it is embedded, the strategies by which it is handled and the consequences of these strategies. Although the procedures of open coding and axial coding are analytically distinct, according to Strauss and Corbin (1990) the researcher alternates between the two. Thus, the categories can be redefined as the study progresses, and this may influence insights regarding the relations between the categories and the subcategories. Finally, however, selective coding takes place, and this means that the categories are integrated so that they form a theory. In this process the core category is selected and is systematically related to other categories. The core category is the central phenomenon that has emerged from the analysis, and is captured in the story line. Several inspiring examples exist of the application of grounded theory in organisation science (Turner, 1983, 1988; Roberts, 1993) as well as in nursing science (Chenitz and Swanson, 1986; Strauss, Fagerhaugh, Suczek and Wiener, 1985; Wilde, 1992).

\subsection{Chronology of the research process}

With hindsight, the research process of the present study can be divided into five stages. In this section we will describe these stages first and then review the learning process that evolved concurrently with the research process. Table 3.3 summarises the characteristics of the five stages in the research. 


$\begin{array}{llll}\text { Stage } & \text { Activity } & \text { Topic } & \text { Methods } \\ \text { Stage 1: } & \text { Literature review } & \text { Work and technical } & \text { Semi-structured } \\ \text { Preparation } & \begin{array}{l}\text { and consultation of } \\ \text { actors involved }\end{array} & \text { change } & \begin{array}{l}\text { interwiews with educators } \\ \end{array}\end{array}$

Formulation of conceptual framework and research questions

\begin{tabular}{|c|c|c|c|}
\hline $\begin{array}{l}\text { Stage 2: } \\
\text { Pilot study }\end{array}$ & Pilot study & Neonatology & $\begin{array}{l}\text { Observations } \\
\text { Interviews } \\
\text { Report }\end{array}$ \\
\hline
\end{tabular}

$\begin{array}{llll}\begin{array}{l}\text { Stage 3: } \\ \text { Reflection }\end{array} & \begin{array}{l}\text { Consultation of } \\ \text { actors involved, } \\ \text { continuation of } \\ \text { literature review }\end{array} & \begin{array}{l}\text { Views on intensive } \\ \text { care }\end{array} & \begin{array}{l}\text { Interviews with educators, } \\ \text { administrators, } \\ \text { professional association } \\ \text { and university researcher }\end{array} \\ \begin{array}{l}\text { Stage 4: } \\ \text { Second case } \\ \text { study }\end{array} & \begin{array}{l}\text { Theoretical } \\ \text { replication }\end{array} & \begin{array}{l}\text { General intensive } \\ \text { care }\end{array} & \begin{array}{l}\text { Observations } \\ \text { Interviews } \\ \text { Report and feedback } \\ \text { Basic pattern for model }\end{array} \\ \begin{array}{l}\text { Stage 5: } \\ \text { More cases }\end{array} & \text { Further replication } & \begin{array}{l}\text { General, neonatal } \\ \text { and paediatric } \\ \text { intensive care units }\end{array} & \begin{array}{l}\text { Observations } \\ \text { Interviews } \\ \text { Reports and feedback } \\ \text { Further development of } \\ \text { model }\end{array}\end{array}$

Table 3.3 Five stages in the research process

Stage one, the first consultation round, followed on from the preliminary work we did in order to write the research proposal. I carried out semi-structured interviews, and as part of the interviews I asked respondents to name a next informant. One of the interviews took place in a clinical chemistry laboratory and included some explanation of the work processes there. Another interview ended with a tour of the neonatology unit and an introduction to the head nurse with whom I was to make further arrangements for an extended visit. At the end of the consultation round no formal theory had been identified and 1 began to consider the grounded theory approach as a method to develop a theory. It was decided that the data in which the theory would be grounded, would be collected by means of participant observations. In order to find out if this approach would work, a pilot case study was carried out.

In the second stage of the research I undertook field work on a NICU. The purpose of this field trip was to establish at the methodological level how to collect the data and what could be done with this kind of data. The other purpose was to develop a sense of the characteristics of work on a nursing unit and ideas about the focus of the remainder of the project. This stage was decisive for the direction of the research. 
The pilot study was followed by a period of reflection. In the third stage I spoke to a wide range of people who are professionally related to the questions specified in this project. Among the topics discussed were the research method, specific questions and hunches to explore, related studies, and how to get access to other sites. The most important decision that was taken at the end of this stage was to do a multiple case study, involving two kinds of intensive care units: neonatal and general.

Stages four and stage five of the research process consisted of the seven remaining case studies. The fourth stage was the second case study. This particular case study marked a turning point in the project, because at the end of this case the preliminary model was presented. It was also the first possibility to compare work processes in intensive care, and this experience was valuable in order to develop an attitude for the other cases.

The emerging theory required further development, and this was done in the fifth stage of the project. By means of six more case studies further data were collected and analysed, ideas were discussed, and changed and discussed and verified again. This stage was by no means more straightforward than the preceding stages. Until the last day in the field I was looking for events, comments, discussions that would confirm or refute the emerging theory. This is a characteristic of sociological research which is called the constant comparative method. During the fifth stage, a third type of intensive care was introduced in the design: the paediatric intensive care.

\section{Learning and doing}

In effect, the first three stages of the research were concerned with the further development of the research question. Kirk and Miller (1986) call this phase in the project the 'invention phase', or the problem of 'finding the field'. In the first stage of the research I interviewed the chief engineer of a teaching hospital, who characterised neonatology as an area at the forefront of medical technology where change was very rapid indeed. To me, that was a new perspective since I had characterised neonatology as an intensive care environment with a relatively high percentage of women nurses. I subsequently interviewed the professor of neonatology, and we organised a visit to the ward to do observations. With the dual purpose of trying out participant observations and collecting data about neonatology, I started the pilot study there.

I introduced myself to the nurses one day after the changeover and feared that it might be difficult to gain the nurses" trust. As it turned out, the main reassurance the nurses wanted from me was that I would not take up much of their time. The ward participated in many trials and projects, and for the nurses this meant that they had to do extra tasks, especially administration and taking samples. I assured them that I would only ask questions and that they could always tell me when I should not disturb them, in which case I could always go and interview someone else.

Once inside, I had to consider precisely how I was going to 'observe'. How does a 'professional stranger' behave? What does 'impression management' mean in practice? "This was not easy: I had to learn what to do and what to say. I decided to display my ignorance of life on the ward and to ask the questions I wanted to answer in my study. Yet, I noticed that nurses were not comfortable with some of the questions I asked. This was not related to the sensitivity of the issues, but 
reflected that the nurses did not know how to answer. For example, I soon found out that there was little point in asking the nurses directly how they saw the role of technology in their work or how the roles of men and women differed in intensive care. These questions were out of place in the NICU and they indicated to the nurses that I was a researcher, an outsider. I discovered that the nurses felt much more comfortable answering questions about what they were doing or how things worked on the ward. It proved very informative to ask questions like: "Can you tell me what you are doing now?", "What do you see?", "To which aspects do you pay attention?". These questions indicate that the researcher is interested in the things that nurses do and how they perceive what happens on the ward. Thus, the nurses are invited to explain what their work involves, much like they would explain this to a trainee nurse. The researcher could thus fit into the setting of the ward in the role of some kind of trainee. Nurses expressed that they liked to explain what they were doing, because they thought it was good to reflect on their work, and they found that teaching and instruction were part of their job. For the researcher this approach offered a good position to investigate the day-to-day work of the nurses.

The formal interviews, on the other hand, gave me an opportunity to probe some of the more abstract questions. "Have you considered working on a general intensive care unit?" was one such question that I asked the neonatology nurses. This revealed a perception that was shared by all respondents, namely that they saw themselves primarily as paediatric nurses. Working with adults did not appeal to them. Thus, it was not so much intensive care in general that they were attracted to, but specifically intensive care for children. I had not expected such a strong division between areas of intensive care, and I decided to add this question to my plans for further research.

What to do with all the notes I had taken? I typed them out and started sorting them to see which questions I could try to answer. This proved very difficult, and therefore I decided to prepare a descriptive report for the feedback session with the nurses that focused on the handling of a baby on a respirator. I concluded that it was often hard to draw a line between 'technology' and 'patient', since the two are intimately connected in intensive care. The nurses made positive comments on my description and expressed as their view that the patient and the technology should be seen together. More precisely, they agreed that the essence of neonatal nursing is the care for the patient and that the technology is integrated in this.

Thus, at the end. of the pilot study a start was made on the exploration of the question how intensive care nurses use and perceive technology in their work. The questions of gender and organisation had hardly been addressed. Although I had observed much of the work that the nurses do and had heard many explanations, I could not see a pattern in the data.

I continued the observations on a general ICU. This experience highlighted a problem of doing multiple case studies: when and how does the researcher compare? This was complicated by the fact that I had been told anecdotes by the neonatology nurses, who had painted a picture of 'what goes on in adult intensive care' from their perspective. I decided to try to postpone the comparison until after the observations on this unit. Occasionally, nurses asked me to make a comparison with neonatology, but $\mathbb{I}$ learned to turn these questions around to their own work. I applied the role of the trainee from the beginning and concentrated the more reflective questions in the formal interviews. 
It was particularly interesting that this unit for general intensive care had two beds for children, and most nurses had been given special training for paediatric intensive care. There were nurses with paediatric qualifications working with adults, and general intensive care nurses working with children. None of the respondents, however, was interested in working at neonatology. With regard to the nursing process, it appeared that many things that I had seen at neonatology were also happening on this ward. The basics of intensive care nursing that $I$ had picked up at neonatology were also at work here, and I could investigate them now because $I$ recognised them. I could thus give more consideration to the circumstances in which the activities took place. I felt quite comfortable just observing and monitoring the flow of activities. Again, the nurses were very willing to explain, to share their thoughts with me or to point out where to see 'something interesting for your research'. Nurses were keen to explain how they deal with the changing circumstances and demands; why every situation is different, how quickly a situation can change, how they assess the situation and how they assess which information is important.

Using a concept from grounded theory, we could say that the experiences in the pilot study were used as 'sensitizing concepts' in the second case study. The search was directed at the essential characteristics of work in intensive care, and this was done in two kinds of ICU. The relationship between the two cases was therefore characterised by accumulation of insights, rather than comparison of the specific environments. In this manner I looked for patterns in the material I had gathered. The most striking characteristic of intensive care that I noticed and that nurses mentioned, is that life on the ward swings from hectic to near standstill, from action-packed hours to uneventful shifts, and that these swings are essentially unpredictable. I had noticed two things about hectic times on the wards. First, there would be more staff at the bedside. Second, it nevertheless looked calm, since staff showed no explicit signs of distress, such as running, shouting, or brisk movements. When I mentioned this to some nurses, one of them said: "That"s right, we don"t show it, but we all feel it. The panic is on the inside". There seemed to be a way for the nurses to know that things were not going well, and they needed few words or signs to communicate this.

At the end of the second case study I presented my preliminary analysis to the nurses. I described the busy and quiet situations on the ward in terms of the activities that nurses would be involved in. In addition to these two extremes I proposed a third kind of situation, which I considered characteristic of intensive care. This was a situation in which uncertainty dominated and staff were busy trying to find out what was happening. I had arranged the activities of the nurses into seven categories and used examples from my observations to illustrate the model. The nurses responded positively to the preliminary analysis. They considered that it captured what they were doing, and made suggestions for refinement. Thus, I could finish the second case study with a preliminary model that was recognised by the nurses.

The next case study was a neonatology unit in another teaching hospital, and I followed the same strategy for the observations. This was the second neonatology ward, and it was quite different from the one I had visited in the pilot study. These differences mainly applied to the medical decision-making and to a number of organisational aspects. After I had collected my material and gone through it, I compared the results with the preliminary model. The new data appeared to 
support the analysis, and I presented my ideas to the nurses. Again, interesting questions were asked, and opinions were offered, of which I took notice.

A similar procedure was followed at the next case study: a unit for adult intensive care in a non-teaching hospital. Practical and organisational differences were noted in comparison with the previous unit for adults and the neonatology units. At the end I presented the model and received positive reactions and valuable remarks.

After four case studies the model had been revised on the basis of comments from the nurses and seemed more or less complete. There was however one kind of intensive care that I had not included: paediatric intensive care. In order to test the modell, refine the analysis and broaden the empirical basis of the research, 1 decided to take my work to one more teaching hospital where I would study one NICU, one GICU, and two PICUs. The time spent on each of these wards was shorter than in the previous cases, but the procedure remained the same. Until the last day of my field work I noticed interesting features of the work on intensive cares. Some events were interesting because I could predict them, and others because I had not seen them before. Yet, it was time to stop. During the field work I had tried to understand the way in which nurses worked and perceived their work. I had developed ways of looking at work on intensive cares, and tested my understanding by asking more questions. My ideas were adjusted on the basis of feedback from the participants on a continuous basis.

The learning process for the participant observer has thus two main aspects: how the researcher presents him or herself and how the researcher perceives the situation. Skills in impression management were developed during this project. Kirk and Miller (1986) capture the role of the observer in the phrase to look a fool for the sake of science', and this underscores that in addition to curiosity the researcher must display modesty when doing observations. We have also seen that the observer's perception of the phenomenon changes as more knowledge is acquired. By carefully constructing several layers of understanding it is possible to untangle very complex and changeable situations. This requires, however, that the researcher combines data collection and analysis. Such an approach has the additional benefit that the observer is constantly aware that he or she is primarily a researcher. The danger of identifying with the participants, known as 'going native', can thus be reduced.

\subsection{Reflections}

"Sometimes I wondered whether just hanging on the street corner was an active enough process to be dignified by the term 'research'. Perhaps I should be asking these men questions. However, one has to learn when to question and when not to question as well as what questions to ask."

Whyte (1955) Street Corner Society, p. 303

The main body of scientific literature consists of textbooks on how to do research and accounts in which the results of studies are presented. Textbooks and other publications on theoretical issues of methodology include Robson (1993) as a general resource book, Yin $(1981,1989,1993)$ and Bruns (1989) on the case study, Blanck and Turner (1987), Rosen (1991), Kirk \& Miller (1986), Van Sluijs (1991, 
1995), Fetterman (1989), Hammersley \& Atkinson (1983), Agar (1986), Jorgensen (1989) on ethnography, and Glaser \& Strauss (1967), Strauss \& Corbin (1990), Becker (1993) on grounded theory. These texts are of a prescriptive nature, but do occasionally touch on the practical issues involved in conducting research. On the other hand, a large body of literature exists in which outcomes of research are reported and these publications typically do not address the practical aspects of the research process. Particularly with regard to exploratory and qualitative studies such information is highly desirable, however. Kanter $(1977,1984)$ includes a methodological appendix in her books, in which the research process is summarised and she gives insight into her methods. In other books that are clearly based on observational research, however, such an appendix is missing, and one is left to guess how The soul of a new machine (Kidder, 1981) and Excel's progress (Mumford and MacDonald, 1989) came about. In addition to textbooks that deal with the theoretical issues and research reports that deal with the outcomes, there are volumes and articles in which researchers describe the research process in their projects, the experiences, decisions, fears and joys that were involved in actually 'doing the research'. Some inspiring examples of such inside accounts are provided by Barley (1990), Leonard-Barton (1990) and the edited volumes by Shaffir and Stebbins (1991), Bryman (1988) and Van Maanen (1983). These so-called 'inside accounts' have become a tradition in ethnography, inspired by the work of Whyte, who added an appendix to the second edition of his famous book Street corner society in 1955 in which he gives "an account of the way the research was done" $e^{\prime \prime}(1955$, p. 280). His main aim in writing the appendix was to contribute to an understanding of the actual research process and to provide a picture of field research that went "beyond the logical intellectual picture" (p. 280). Whyte is contrasting the way in which scientists present their research with the way they do the research. This distinction was made in more general terms by Kaplan (1964) when he introduced the terms 'reconstructed logic' and 'logic-in-

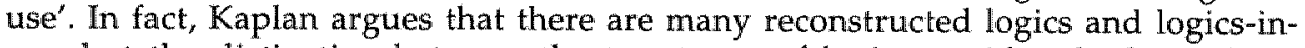
use, but the distinction between the two types of logic provides the basis for a distinction between the outside and the inside of scientific work. According to Kaplan, the reconstructed logic that is presented in a report should be qualified by a description of the logic-in-use that was applied during the research. This view is echoed in many texts on field work and can be summarised as the need to make explicit what happened during the research process, which procedures were used, which choices were made, and how ideas were developed. As Van Maanen remarks: "(...) the key analytical decisions of qualitative study are most often accomplished by the investigator in the research setting itself, and (...) the selection of substantive topics to pursue in a given study cannot be disembodied from the actual research process itself ${ }^{\prime \prime}(1983, \mathrm{p} .14-15)$. Indeed, the inside account has a double purpose, since it can be used by other investigators to "check and develop similar procedures" (Blanck and Turner, 1987) and thus provides an important tool in the discussion of validity and reliability of an ethnographic study (van Sluijs, 1995). It can also inspire and instruct other researchers (Bryman, 1988).

Two publications that dealt explicitly with the choices involved in doing multiple case studies are discussed here at greater length. "Images of imaging" is the title of an article by Barley (1990a) in which he discusses the problems and processes involved in conducting longitudinal ethnographic research in two hospitals. He remarks that "regardless of calculated attempts at discipline, field 
work inevitably intensifies the tensions, the relationships, and the serendipitous events that influence all research" (p. 220). Barley studied the introduction of a CT scanner in two radiology departments, each in a different hospital. He did participant observations for one year, alternating his one-day visits between the two hospitals on four days of the week. This simultaneous study of two departments allowed him to follow the process of the introduction of the new technology in real time at both sites. He has reported on his findings in several articles (e.g. Barley, 1986, 1990b). Also concerned with technological change is Leonard-Barton, who describes the methodological considerations of her study in "A dual methodology for case studies" (Leonard-Barton, 1990). The phenomenon of implementation of new technology was studied by means of a three-year realtime case study and nine retrospective case studies. These studies were conducted simultaneously, and this approach allowed analysis of the patterns of the dynamic processes as well as insight into how these patterns evolve over time. Furthermore, the validity of the results was improved by this approach as theoretical and literal replications indicated to which situations the emerging pattern applied, while the in-depth real-time case study uncovered detailed information that helped to explain how the pattern was shaped over time. It was decided that since the present study does not investigate the process of change as such, there was no immediate reason to collect the data for several cases simultaneously. It was, however, considered appropriate that the period for data collection in the later cases was shorter than in the earlier cases.

\section{Practitioner-researcher}

We discussed some issues regarding the role of the researcher in Section 3.2. Here, we want to reflect on the situation in which the researcher is also a practitioner in the field under study, the so-called "practitioner-researcher" (Robson, 1993). Studies conducted by practitioner-researchers are common in nursing studies, and in fact most of the sociological studies we reviewed in Chapter 2 were conducted by nurse-researchers. The special problems that can occur when nurses are studying their own profession are illustrated by Wilde (1.992), Reid (1991) and Benner (1975), who point to a potential and real conflict of roles. Wilde (1992) explores the relationship between the researcher and the participant and the use of counselling strategies and self-disclosure in interviews. Reid (1991) uses the expression 'nonparticipant observation' to describe her activities in the field since she did not participate in the nurses" work. She describes her approach as 'collaborative', which means that the participants are regarded as partners and the researcher tries to do something that is useful for the participants. Reid presents this as an alternative to the kind of research that asks respondents to contribute to a project that has no relevance for their own work. In the collection of field reports that Davis et al. (1975) edited, the role conflict that nurses perceive when they do observations in a nursing setting is nicely illustrated. Benner's contribution to this volume (Benner, 1975) contains references to her own position and to the way she thinks other people must perceive her. She thought it would be useful to wear a nurses' uniform during the observations because it would make her blend in with the group of nurses, but she realised that when there was no other nurse on the ward the patients were looking to her for help. Also, being an intensive care nurse herself, she felt slightly offended when the nurses on the ward explained the basics of intensive care nursing to her. Thus, dilemmas can arise for the nurse- 
researcher from knowing how hard the work can be and feeling more comfortable helping out than watching how the others resolve the situation and realising that she herself would not have appreciated someone standing around and watching. Several authors agree that the role of the researcher and the role of the nurse cannot become completely separated (Chenitz and Swanson, 1989; Wilde, 1992; Reid, 1991). In the present study the researcher is not a practitioner, but similar practical problems as what to wear and how to behave were encountered. It was decided to adopt some characteristics of the role of a trainee, and this occasionally involved offering help when a pair of extra hands was asked for. My role as a researcher involved me showing interest in the work, but not trying to become or pretending to be a nurse.

\section{Validity and reliability}

Establishing the trustworthiness of a study requires validity and reliability to be demonstrated (Robson, 1993; Yin, 1989). Validity is broken down into three types:

- construct validity: Are the measures relevant to the concepts under study?

- external validity: In which domain can the findings be generalised?

- internal validity: Can the causal relationships be explained by other factors?

All three types of validity can be applied to case studies and qualitative social research, but internal validity is only relevant if the research is explanatory and thus concerned with establishing causal relationships. Construct validity and external validity, however, apply to studies regardless of whether they are descriptive, exploratory or explanatory. Especially for ethnographic research, an additional type of validity is relevant, which has been referred to as "ecological validity". Hammersley \& Atkinson (1983) describe this as "the effects of researchers and the procedures they use on the responses of the people studied" (p. 11). A last test for scientific research is the test of reliability, which demands that if the research was repeated by another investigator, he or she would arrive at the same conclusions. We will now discuss how these criteria apply to the present study.

In order to achieve construct validity, we have used multiple sources of evidence and asked for feedback at several points during the research. One problem with construct validity in ethnographic and exploratory studies is that the concepts are not defined at the onset of the project, but evolve during the process (Hammersley and Atkinson, 1983). In the present study, efforts have been made to ensure that relevant data were not overlooked. However, in the grounded theory approach it is considered "just as important to find evidence of differences and variation, as it is to find evidence that supports our original questions and statements." (Strauss and Corbin, 1990, p. 109). This is part and parcel of the reciprocal relationship between theory and data, and the integration of data collection and analysis. Thus, while making an effort to remain within the original research topic of work and technology, a variety of ideas and directions were tried. The primary sources were the people who worked on the wards, including head murses, nurses and trainee nurses, doctors and junior doctors, cleaners. We watched them at work and asked questions in the form of informal and formal interviews. They were asked to comment on emerging ideas and interpretations of their work. Thus we made sure that what we did was recognisable and made sense to the participants. Of course, it is always the 
responsibility of the researcher to ensure that relevant questions are pursued and that obsolete ones are discarded.

As for the test of external validity, the same phenomenon was studied in different settings. Using a multiple case study design, we began in one intensive care environment with particular characteristics: the patients were newborn babies and the nurses were predominantly women. Then we moved to an intensive care where the patients were adults and the nursing staff had a far greater proportion of men than the hospital average. We knew from informants and reports that this particular pattern was a national phenomenon. Having looked at two wards in the same teaching hospital, we wanted to know how much our material was coloured by local characteristics, and we took the project to another neonatology ward and another adult ward, both in different hospitals. With the general model established, we repeated the field work on four more wards in a single teaching hospital. The staffing pattern was similar for a specific kind of ward in each hospital. On other aspects we also identified similar patterns, and we noted that these patterns in the Dutch setting did not match the descriptions in the available British and American literature. Thus, we suggest that the results can be generalised within the Dutch system to other hospital units for intensive care. For other wards and other countries no conclusions can be drawn.

A discussion of internal validity is not relevant here, since the research does not seek to establish causal relationships. The study has considered those factors that have so far been entered in the literature, but has not established factors or mechanisms that have explanatory power. The research has identified patterns in the complex process of intensive care nursing that may serve as a basis for further investigations.

In order to establish the ecological validity of the research, I will consider to what extent responses may have been influenced in this project. My experience suggests that it would be very difficult for a researcher to alter the course of events on an ICU. Two aspects of nursing work are crucial to this observation. First, there is work to be done, and second, giving explanations is part of the job. The overriding concern of the nurse is the condition of the patients on the ward. Often there are several tasks competing for attention, and the only way to deal with this situation is to set priorities. The top priority is done first, no matter what else is happening, at least until something else gets top priority. "This way of working makes it possible to deal with many demands and yet maintain an overview. One of the demands that is often made of the nurses is the request for instruction or explanation. Trainee nurses and rellatives of the patients are frequently asking questions. In this sense an observer doing informal interviews is not introducing a strange element into the setting. The setting itself is characterised by openness, in the sense that nurses perform their work in a space where it is witnessed by all kinds of people who may or may not be involved in patient care themselves. Patients and their relatives, doctors, paramedical staff, laboratory and imaging technicians, students, ambulance staff and a host of other people come and go. The large number of people who have to learn something from their visit to the intensive care unit have to be told about the rules, where to find things and how to make themselves useful by doing odd jobs. Nurses are used to dealing with people and answering queries. Sometimes they complain about this, because it is distracting. In my experience, however, they are very happy to talk to somebody who takes an interest in their work. They were not reluctant to talk to me when 
they had time, but they were also not reluctant to tell me when there was no time. II deliberately presented myself as a visitor who was interested, but who could not be allowed to disturb the ordinary life on the ward. It was also clear that I was an independent investigator, who had no links with the hospital administration. Nurses came forward with their opinions and they talked frankly about things they did not agree with. I had made it clear that I was not judging their work. In short, I would argue that the ecological validity of this study is not threatened, partly because of characteristics of the setting and partly because of the field relations the researcher developed.

The reliability of this study is difficult to establish. The study provides an example of the use of grounded theory techniques on ethnographic material applied to the problems of work organisation in a technology-intensive human service environment. Case study protocols were used, feedback from the participants was obtained and a database was created in which the field notes and the final versions of the interviews are stored. Finally, the research process is documented in this chapter, indicating how the research questions were developed, in which context the research was conducted, which methods were used and how these were integrated in the design, and how the research was done.

\subsection{Conclusions}

To conclude, the present study adopts a case study strategy and uses participant observation and interviews as methods for data collection. The grounded theory method is employed for the analysis of these data. Thus, qualitative data are analysed in a qualitative manner within a multiple case study design. This combination of methods was chosen in order to conduct an exploratory study of the phenomenon of technology in intensive care nursing. The research questions address the use and perception of technology by intensive care nurses, the differences between male and female nurses regarding this issue, and the influence of organisational arrangements on the work process. A preliminary conceptual framework was constructed on the basis of the findings of a review of current literature on intensive care nursing. According to this framework, the work process is divided into a 'technology' part and a 'care' part; accordingly, nurses have to divide their attention between the two parts.

The research employed inductive as well as deductive ways of reasoning, using a variety of sources. An ongoing assessment of the literature was combined with periods of field work and periods of reflection. The field work consisted of overt participant observations and interviews. To conclude each case study, a feedback session was organised in which the preliminary outcomes were discussed. Each interviewee was given the opportunity for personal feedback as each interview was transcribed and sent back to the interviewee for comments. These procedures enhanced the construct validity of the study, while the use of a multiple case study design enhanced the external validity. With regard to ecological validity it was argued that the characteristics of the setting and the field relations between the researcher and the respondents both contributed to a situation where the threats to ecological validity are reduced to a minimum. Careful consideration of the above and documentation of the research process contribute to the reliability of the study. 


\section{Chapter 4}

\section{Careers in nursing}

During the periods of observation, a small-scale survey was carried out, which consisted of semi-structured interviews with 83 nurses. The survey was conducted in order to study the career paths of male and female intensive care nurses. The interviews explored the career choices that nurses had made and the motivation for these choices. This chapter details the findings of the survey and begins with a description of the methods that were used and the composition of the sample. Then a model is introduced that outlines the main choices that are made by general intensive care (GIC) nurses on the one hand and paediatric and neonatal intensive care (PIC/NIC) nurses on the other. This model is used to structure the presentation of the results as it distinguishes three main choices: going into nursing, specialising within nursing and deciding on a work place. The presentation of the quantitative analysis is concluded with a refined version of the model of nursing careers. Further findings will be presented in a narrative form as they pertain to the motivation of the respondents for choosing intensive care and the perceptions that nurses have of the three types of intensive care.

\subsection{Method and sample}

The method of data collection in this survey was the semi-structured interview. On average an interview lasted forty-five minutes, during which the respondent was asked about his or her career in nursing, the choices inwolved, the motivation for these choices and the perception of work and training in intensive care. A list of topics was used to guide each interview. Notes taken during the interviews were processed into reports, and these were given to the respondents for comments. All received comments were incorporated in the final text that was used for analysis. Qualitative analysis was then done with the assistance of the HyperResearch computer package. For the quantitative analysis, tables were devised that allowed counting and clustering of data. Thus, typical career paths and other patterns could be established ${ }_{r}$ and these were related to the three types of intensive care.

The sample consisted of 83 nurses, all of whom were working on the ICUs that took part in the study. An average of 10 respondents were selected per ICU, including qualified nurses as well as trainees. All respondents were included in 
the sample on the basis of their availability and willingness to be interviewed. Table 4.1 gives an overview of the characteristics of the populations on the ICUs as well as the samples that were drawn from these populations.

The sampling method that was used for the survey is known as 'purposive' or 'theoretical" sampling (Robson, 1993; Miles and Huberman, 1984, 1994; Glaser and Strauss, 1967; Strauss and Corbin, 1990). This means that the sample is constructed so that it meets the specific needs of the project. Thus, the sample used here is a non-probability sample (Robson, 1993) and is not suitable for statistical generalisation. Rather, in keeping with the replication logic as discussed for multiple case studies, the sample is built up with the aim of theoretical generalisation. In fact, there are elements of disproportionate sampling (Robson, 1993) in this sample with respect to gender. Table 4.1 gives the percentages of men and women for each ICU in column 5 . These percentages vary from $99 \%$ female and $1 \%$ male nurses on one NICU to $44 \%$ female and $56 \%$ male nurses on one GICU. In the same column it can be seen that some ICUs employ as few as 1 or 3 men. The extent to which disproportionate sampling took place becomes clear when column 5 is compared with column 7 , where the numbers of men and women in the interview sample are given. Men were over-represented in most samples as they counted for $30 \%$ of the respondents in the sample but only for $17 \%$ of the population as a whole. In this way, more data were gathered on male intensive care nurses so that their accounts became less incidental and the analysis could address the existence of differences between men and women in a more systematic manner. Another sampling decision that should be mentioned here applies to the ward management. On each ICU an attempt was made to interview the head nurse and at least one team leader.

A breakdown of the qualifications that nurses had obtained at the time of the interview is shown in Figure 4.1 below. A total of 42 nurses were qualified in PIC/NIC nursing, and 38 were qualified in GIC nursing. However, a group of 7 nurses ( $9 \%$ of the sample) had qualified in both areas. One of the 11 trainees had already qualified in GIC, the other trainees (12\% of the sample) were specialising in GIC, PIC, NIC or paediatrics.

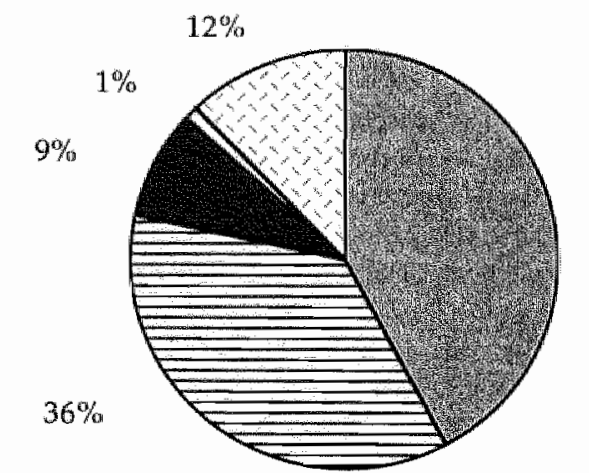

$42 \%$

Figure 4.1 Distribution of qualifications in the sample 


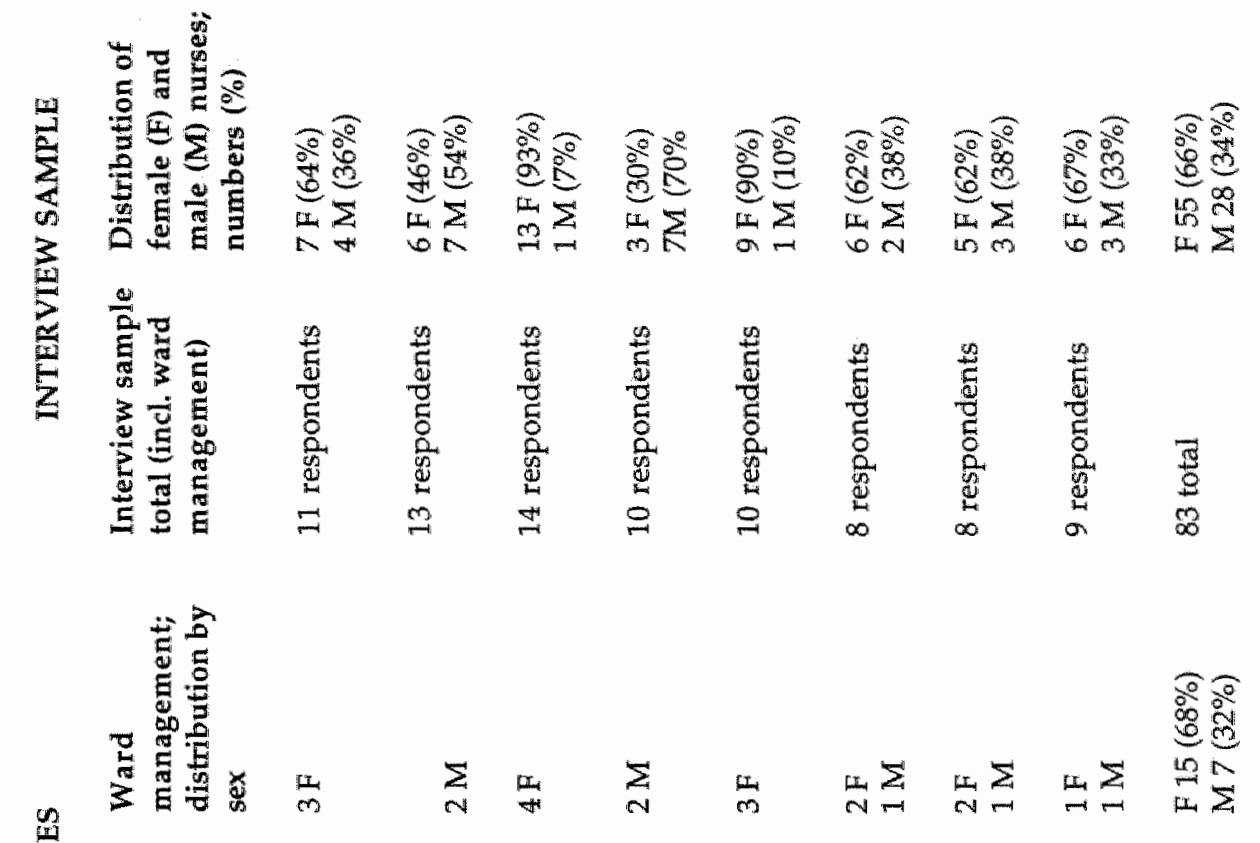

$n$
0
0
5
$Z$
5
0
$Z$
0
5
5
5
5

范若

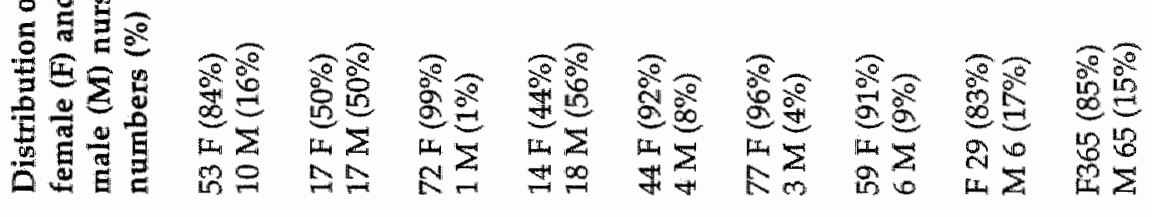
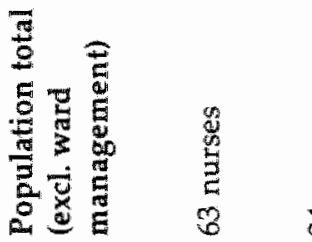

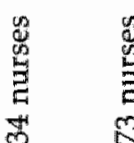

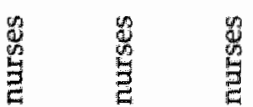

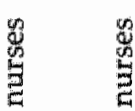

$\frac{9}{5}$

查

焉

焉

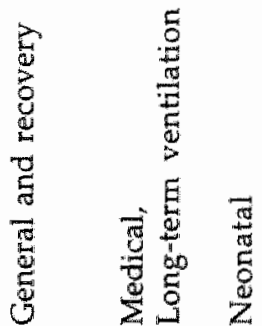

$\sum_{0.9}^{0}$

$\frac{\sqrt[y]{4}}{8}$

$\frac{8}{3}$
$\frac{5}{3}$
है

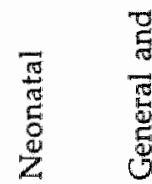

踣

胥

를

를

8

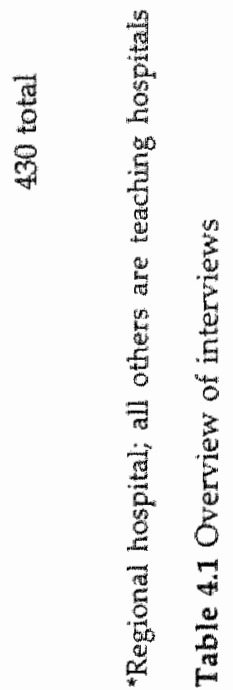


The age distribution of the respondents is shown in Figure 4.2 below. In the sample of 83 there were 11 trainees. Of the 72 qualified intensive care nurses, 51 $(70 \%)$ were between the ages of 29 and 39 . The remaining 30\% was divided evenly between the groups under 29 and over 39 . The trainees varied in age from 24 to 33 years.

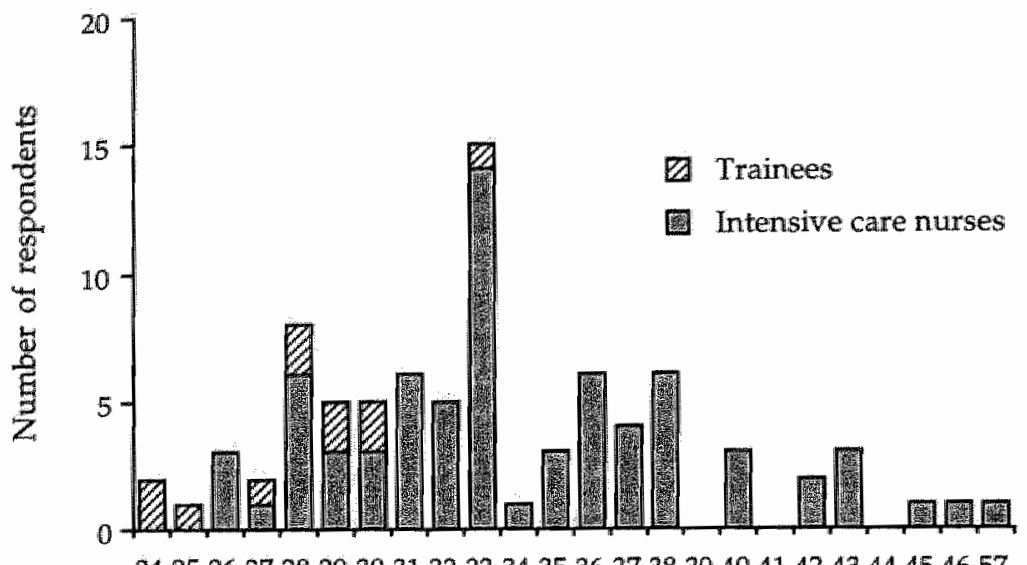

Age

Figure 4.2 Age distribution in the sample

To introduce the further findings we will now outline the career paths that the nurses followed into the different types of intensive care. Figure 4.3 indicates the three main choices that are involved: going into nursing, specialising within nursing and deciding on a work place. After the initial choice to pursue nursing as a career, the next choice is to choose an area of specialisation. After qualification in general nursing there are a number of options, of which the most relevant ones are included in the model: general intensive care or paediatrics. Following on from paediatrics it is possible to specialise further in paediatric or neonatal intensive care. Since the specialised training qualifies one to work in a particular area, the choice of a work place is likely to be determined by the specialisation. This simple model describes the careers of more than $80 \%$ of the respondents: 32 working in a GICU and 40 working in a PICU/NICU. However, by further analysis of the main choices and motivations we will refine this model so that all the careers can be fitted in.

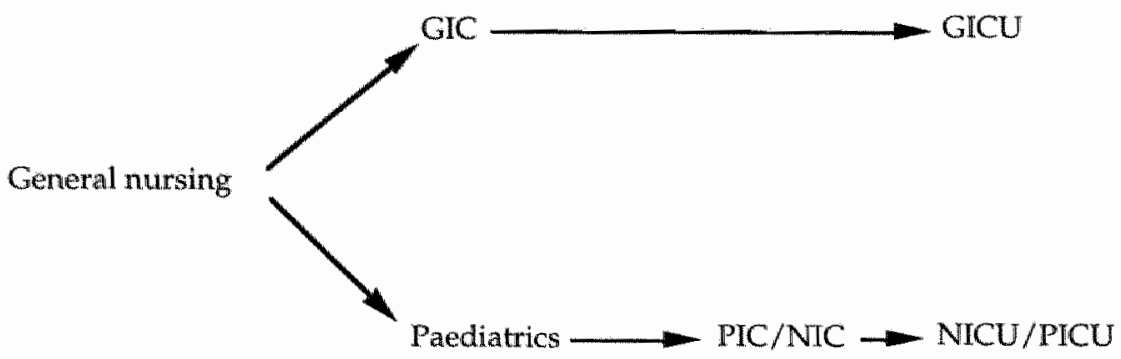

Figure 4.3 A simple model of career choices 


\subsection{Going into nursing}

The decision to take up nursing as a career is influenced by considerations regarding the content of the work, the training system, and the labour market for nurses. When I asked nurses about their motivation for going into nursing, I received answers along the lines of "I wanted to work with people" or "I wanted to work in the health care sector". Some respondents ascribed their choice to the inspiring influence of nurses they met, for example while working for a temporary job agency. Some male nurses became acquainted with the work of nurses while doing their military service. A small group of respondents said they "had always wanted to be a nurse", and had not considered other options. Another small group wanted to do something else, for example become a physiotherapist, physician or school teacher, but when that fell through they opted for nursing for practical reasons. Some nurses had pursued careers such as supermarket manager or office clerk. Others had started and some had finished education in other areas such as hotel management, farming, biochemistry and primary school teaching.

All of the 83 respondents except four followed the in-service nursing education. Three of the four nurses who took the school-based education did so because they were too young to start the in-service training and had attained a high enough level of education. The minimum age for the in-service system is 17 years and 7 months. Those respondents who finished school at sixteen usually opted for an extra year of school or started working in a health care facility as unqualified aids doing odd jobs. As can be seen in Figure 4.4, the majority of the respondents (62) started their nursing education before the age of 20 , usually directly following on from secondary school. Most of the nurses who started later allready had work experience or had attended other training programmes.

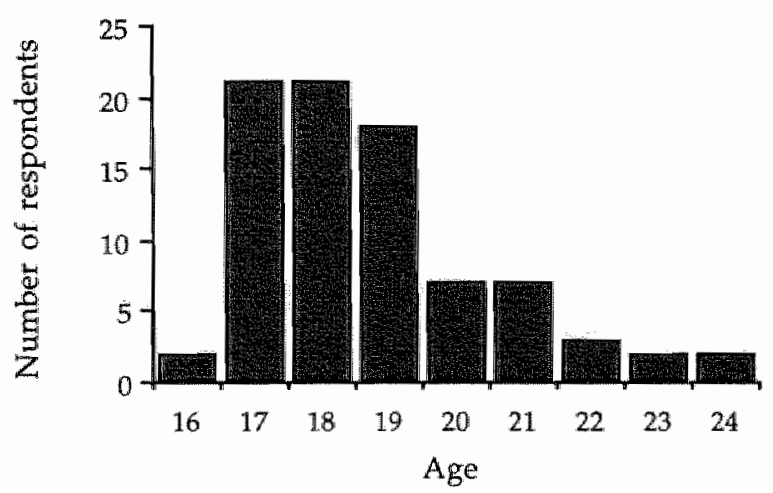

Figure 4.4 Distribution of ages at which respondents started general nursing training

In all the interviews, nursing was presented as a practical and accessible option. The way in which the in-service system is organised was a factor the respondents had considered when they made their choice. One aspect that appealed to them was the prospect of earning money while at the same time receiving training. This meant that they could live independently from their parents. For the respondents who had already worked or lived away from home, nursing was often seen as a 
way to maintain this situation and work towards a professional qualification. Another attractive feature of nursing education was its practical nature. Respondents appreciated that they could apply in practice what they were learning in class, and they expressed a preference for a learning process that combines the development of skills and theoretical insight. A few respondents remarked that they did not agree with the extent to which they were expected to take responsibilities as a trainee, but on the other hand they felt that today's trainees are protected too much. Part of the learning process should be to make your own discoveries, they argue, but the current trainees are restricted to following small incremental steps.

Yet another attractive feature of nursing was considered to be the labour market for nurses. Nursing does go through phases of mass redundancies; however, these are often followed by a shortage of qualified nurses. In the Dutch system trainees make up a large proportion of the nursing workforce, and there is therefore almost always a demand for trainees. Since the labour market cycles are quite short, redundancy is not considered a serious career problem, and there is a strong belief that a qualified nurse will always find work. Several of the respondents had been laid off after they had qualified as nurses. Some of them started working for a temporary job agency and waited for demand to increase again. Others responded to the threat of unemployment by signing up for a training programme in a specialised area of nursing and could thus remain employed. These nurses felt that the prospect of redundancy after qualification had sped up their decision to specialise, although not all of them remained within this initial specialisation.

\subsection{Specialising in intensive care}

As we have seen, an important decision is made after obtaining the qualification of general nurse. We will concentrate here on the choice between a specialisation in general intensive care and a specialisation in paediatrics. As Figure 4.5 shows, for the intensive care specialisation two groups stand out. A group of 15 (35\%) nurses started within one year, and a group of $8(18 \%)$ nurses started two years after qualifying in general nursing. The nurses who started after more than two years worked on general wards or took other courses after the general nursing education, for example psychiatry, cardiac care or paediatrics. One nurse had specialised in paediatric intensive care before taking the course in general intensive care. However, she returned to paediatric intensive care after completion of the course. 


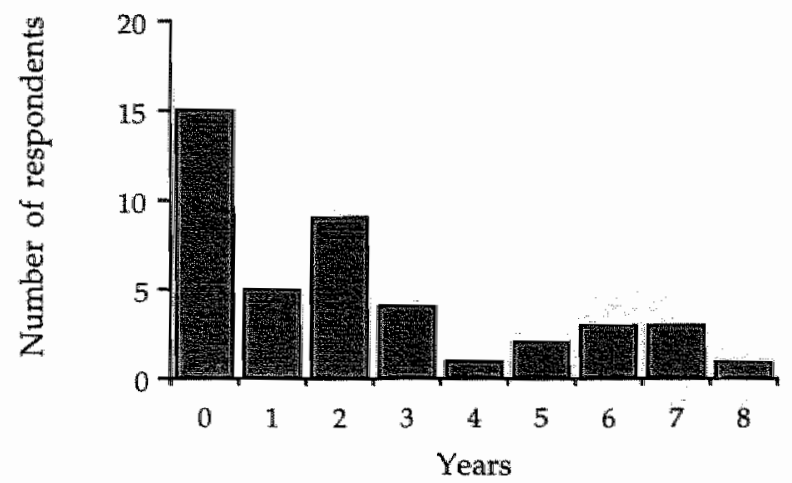

Figure 4.5 Number of years between qualification as general nurse and start of GIC training

Nurses who specialised in paediatrics after general nursing generally started within one year after they qualified. Figure 4.6 shows that $80 \%$ of the 43 paediatric nurses had started their specialisation within two years after qualifying in general nursing. The nurses who started more than two years after the general qualification had worked on general wards, and one of them completed the general intensive care course before starting the paediatrics specialisation. Of the 43 paediatric nurses in the sample, 10 are men.

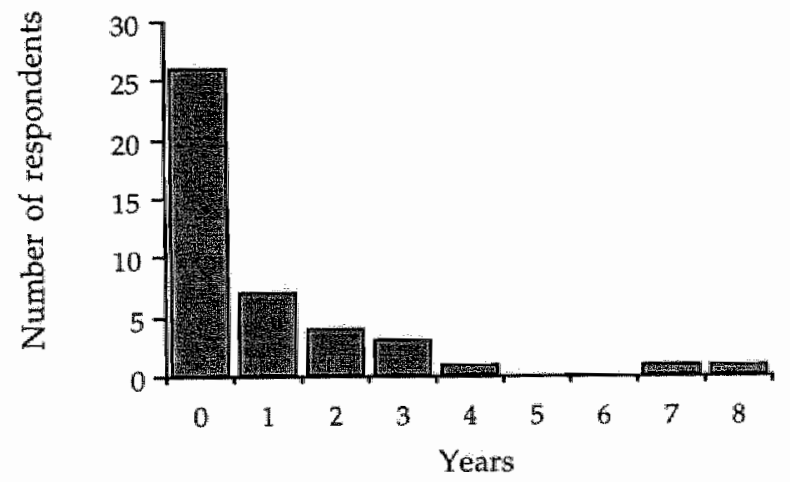

Figure 4.6 Number of years between qualification as general nurse and start of paediatrics specialisation

Forty-eight nurses specialised in paediatric or neonatal intensive care. In Figure 4.7 this group is broken down by background. It shows that $42(87 \%)$ of the trainees and qualified PIC/NIC nurses have a background in paediatrics, and two out of this group had qualified in paediatrics as well as in general intensive care before they moved into PIC/NIC. Six nurses did not have paediatric training before they started the neonatal or paediatric intensive care course. Of these, four had a background in general intensive care and one in cardiac care. They had spent 
between one and six years working in these areas, and they all went into neonatology. One nurse went into neonatology immediately after her general nursing training, since paediatric specialisation was not required at the time.

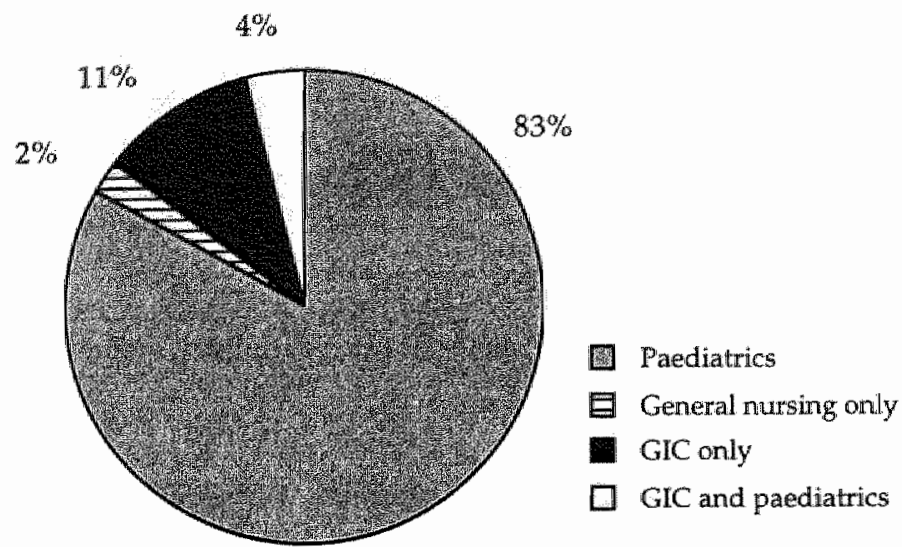

Figure 4.7 Background of qualified nurses and trainees in paediatric and neonatal intensive care

Thus, we have seen that most respondents followed the typical career paths, either from general nursing to intensive care, or from general nursing to paediatrics to neonatal or paediatric intensive care. A few nurses took a different route however, either from paediatrics to GIC, from GIC or general nursing to NIC, or from PIC to GIC and back again. The refined model of career paths therefore looks quite complicated, as is shown in Figure 4.8 below. The thick lines indicate the path as described in the simple model. The thin dotted line from general nursing to PIC/NIC represents the one nurse in the sample who started PIC/NIC training without previous specialisation. The thin dotted triangle between paediatrics, GIC and pointing at PIC/NIC represents two nurses who did paediatrics as well as GIC before they started PIC/NIC training. One nurse specialised in paediatrics after general nursing and later moved into GIC. This path is shown by the thin continuous line from paediatrics to GIC. The thick dotted line from GICU to PIC/NIC represents 6 GIC nurses who initially worked in a GICU and later retrained as PIC/NIC nurses and are currently working in a PICU/NICU. The thick dotted line from GICU to PICU/NICU represents the 3 GIC nurses who initially also worked in a GICU and later went to work as head nurses in NICUs/PICUs without retraining in PIC/NIC. The thin line from PIC/NIC to GIC and on to PICU/NICU shows the path of one nurse who followed this unusual route of retraining in GIC immediately after specialising in PIC/NIC and then returning to work in a PICU/NICU. 


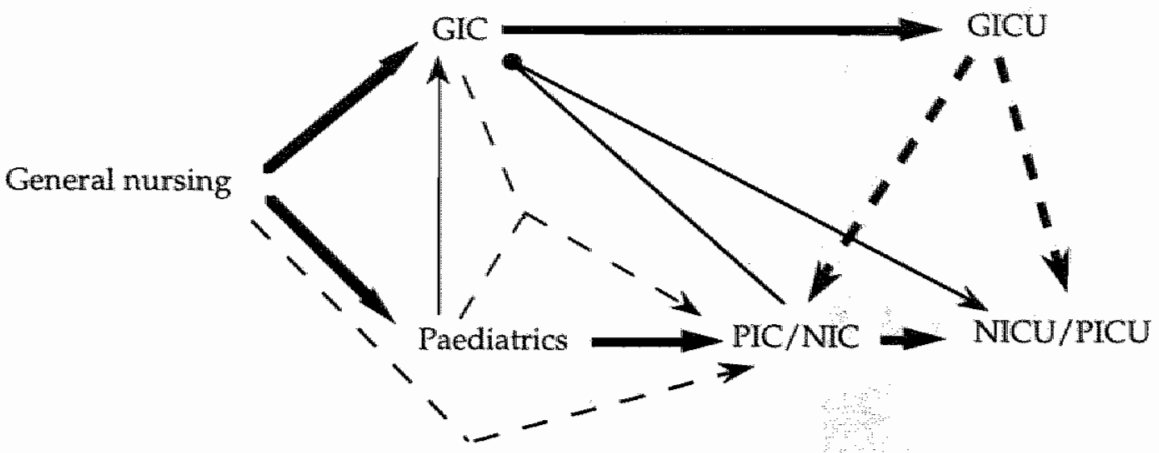

Figure 4.8 A refined model of career choices

Thus, while the simple model describes the paths of $80 \%$ of the respondents, the refined model shows that other paths are possible. The most important contribution of the refined model is that it shows movements from GIC to PIC/NIC and to PICU/NICU for $8(10 \%)$ of the nurses, while no such movement is found in the opposite direction. This is illustrated in Figures 4.9 and 4.10 below. Figure 4.9 shows the distribution of the 38 respondents who had obtained a certificate in general intensive care at the time of the interview. Twenty-seven $(73 \%)$ of these nurses worked in GIC: 21 of them as nurses and 6 in a position of ward management. The remaining $11(27 \%)$ worked in PIC/NIC at the time of the interview: 5 as nurses and 6 in ward management positions.

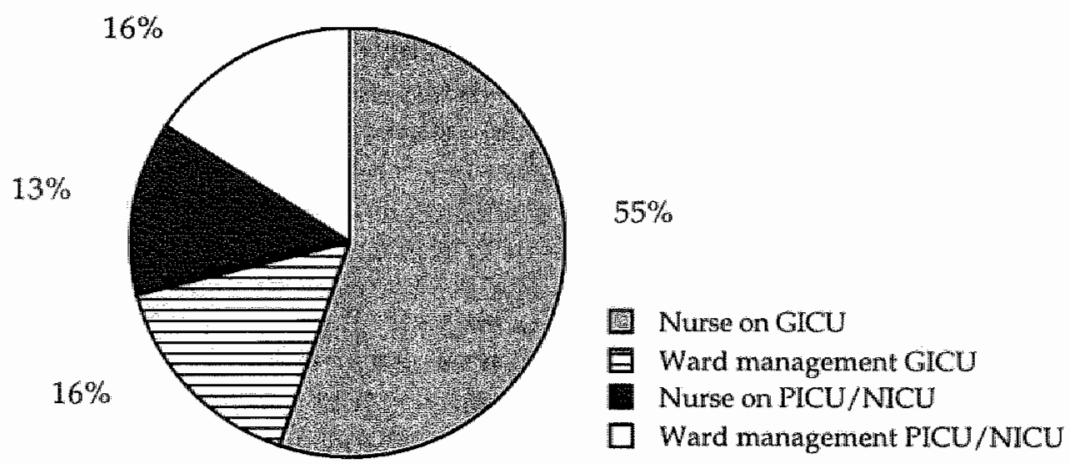

Figure 4.9 Distribution of qualified GIC nurses

As is shown in Figure 4.10, the picture looks quite different for PIC/NIC nurses. All of the 42 PIC/NIC nurses in the sample work in PICUs or NICUs. It should be noted that the nurses who obtained both a GIC and a PIC/NIC certificate are included in this presentation. Thus, 3 nurses in ward management $(7 \%)$ and 4 nurses in nursing positions $(9 \%)$ have dual qualifications. 


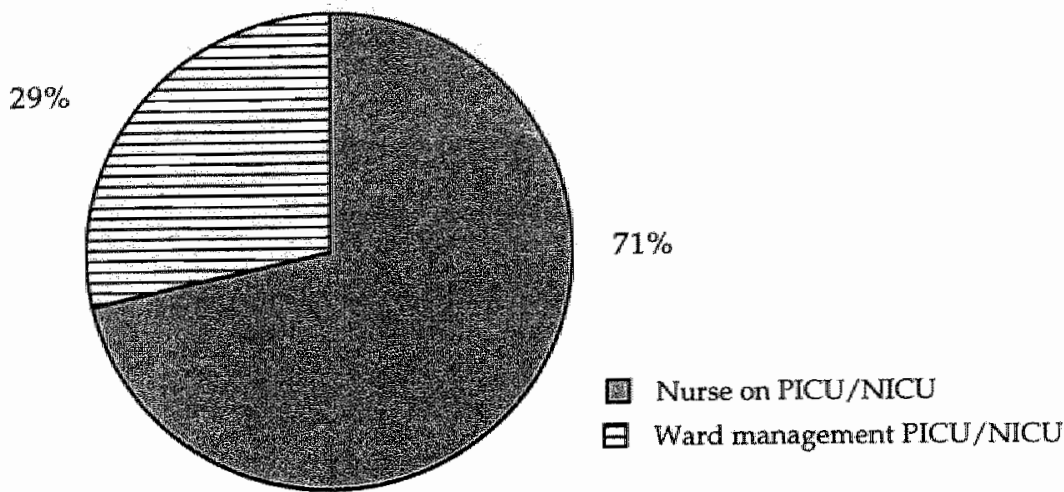

Figure 4.10 Distribution of qualified PIC/NIC nurses

\subsection{Working in intensive care}

With regard to the reasons for working in intensive care, a high degree of similarity was found between nurses from the three types of ICU. The motivation of nurses for specialising in intensive care and the way in which they perceive the technology in their work are further explored here.

\section{Motivation}

The persistence of the separate paths of specialisation is reflected in the individual interviews, as very few nurses would consider working in another speciality than their own. A comparative analysis of the interview data shows, however, that nurses across the specialities have very similar opinions on the attractions of working in intensive care. It appears from the interviews that the reasons for going into intensive care are difficult to separate from the characteristics that nurses find attractive about their work in intensive care. For most nurses, specialization in intensive care was an opportunity to extend their knowledge, to learn more. Some nurses expressed dissatisfaction with the superficial nature of their previous training as general or paediatric nurses. They wanted to know more about the way the body works and the interventions that are possible. Nurses in general intensive care indicated how impressed they were as general nurses when they saw intensive care nurses 'in action'. Mostly this referred to instances when intensive care nurses came to a general ward as part of the resuscitation team, and the general nurses noticed how they "seemed to know what to do" as well as the independent and knowledgeable way in which the nurses went about the resuscitation. In the case of paediatric and neonatal intensive care, such inspiring events are not mentioned, mainly because these wards operate in relative isolation and do not have a resuscitation team that provides a service for the whole hospital. Nurses in neonatal and paediatric intensive care do mention that when they were working as paediatric nurses, they sometimes had to prepare a patient for transferral to an intensive care unit. Such incidents made them realise 
that "more could be done for these children" than they could offer on their general paediatric ward.

The provision of complex care is a characteristic of intensive care that many nurses refer to as essential to their work. As the term suggests, complex care has many aspects. Nurses stress that it is the combination of all these aspects that makes intensive care attractive. Central to complex care is the patient who is in a life-threatening situation. Nurses note an interdependence between the condition of the patient, the complexity of care, and the use of a range of technologies. The critically ill patient demands a higher complexity of care and the use of more technology. This relationship is referred to by nurses regardless of the type of intensive care they work in. They see it as central to their work. Critically ill patients, complex care and technology are seen as a trinity, no aspect of which may be removed. This attitude has two important implications. Although intensive care nurses agree that their work has an important technical aspect, they would not consider working in a field where technology is used outside patient care. Alternatively, the work with patients but without the requirements of complex care or technology does not appeal to them either. This was frequently expressed in the interviews with reference to the work on general nursing wards. Indeed, of the nurses interviewed in this study, none intend to go back to general nursing.

The work on intensive care units differs in many ways from general nursing, including the kinds of patients, the responsibilities that nurses have, the relations with the medical staff and the financial rewards that nurses receive. The general impression that nurses give of work on a general ward is practically the mirrorimage of work on an intensive care. The patients on a general ward are in a very different situation from those in intensive care. Often they are mobile and able to speak or to communicate in other ways; the average hospital patient can partly look after himself or herself as well as express sensations, opinions, and feelings. The intensive care patient is unable to do any of these things and is generally in a life-threatening condition. The patient is dependent on others to assess the situation and take the necessary action. This increases the responsibility of the staff, and in particular the nurses, to monitor the patient closely and continuously. The system of patient assignment, as described in Chapter 1, has been implemented on many ICUs to deal with the need to be informed about all details and changes in details at every point in time. Having one nurse responsible for a patient during the whole shift means that the nurse is in a position to have the overview of the patient situation. Nurses have the responsibility to inform the doctors of their observations, and often give their own opinion as well. Doctors often appreciate the nurses' comments and, in general, relations between doctors and nurses are based on the understanding that the nurses have valuable information to contribute. In contrast, nurses' opinions about working on a general ward are negative, especially regarding the subordinate role of the nurses as well as the system of task assignment. In addition, the salaries in general nursing are considerably lower than in intensive care.

Work in intensive care is seen as a challenge as it demands continuous alertness combined with the ability to interpret information from different sources. The nurse is the key figure in the process of monitoring and investigation. The doctors see the patient for a short time each day; the nurses are on the ward at all times and can concentrate on a small number of patients. Nurses enjoy this central role in the care for the patient, and they often mention it 
when talking about the attractions of their work. They can use their own insights and knowledge in their work, and they are keen to pick up any clues that could indicate a change in the condition of the patient. Both the details and the overview are monitored by the nurses, and possible consequences are dealt with. A major challenge for the nurses is to prevent a crisis situation from developing, to recognize the early signs, and to act adequately. With patients already in a critical condition, the medical and nursing care given can make the difference between life and death, as well as the difference between a good or poor quality of life afterwards.

\section{Role of technology}

Nurses use a wide variety of sources to assess the situation. One of these is the medical equipment, but the best source of information is the patient. Technology is seen as an aid in the process of care that can assist the direct observations, but not replace them. This statement characterises the views of intensive care nurses on technology. They acknowledge that the technology reduces the time needed for certain activities, such as taking the patient's blood pressure or temperature. Also, they see great advantages in the possibilities of continuous electronic monitoring of vital signs, such as breathing, heart rate and thythm, blood pressure and oxygen saturation of the blood. Older nurses recollect that continuous monitoring of vital signs was done by a nurse sitting at the bedside watching the patient. This observation had a different nature from the continuous monitoring that machines do. The machine keeps track of a number of parameters and sounds an alarm when one of these parameters exceeds the set margins. Monitoring done by the nurses involves a number of quantitative aspects, such as pulse and breathing counts, but combined with qualitative assessments such as the strength of the pulse, the manner of breathing, the colour of the skin and the way it feels. These qualitative observations are still considered essential by the nurses, and the dominant relationship with the technology is one in which machine readings are never accepted as absolutely true. The information from the machine has to match the information the nurse gets directly from the patient. Thus, the technological aids are not valued per se but are judged on their contribution to the delivery of care. Nurses claim that technology does not distract attention away from the patient, since it is part of the complex care that the patient needs. They feel that as little time as possible should be spent handling the technology. Thus, they advocate that nurses should be proficient in operating the machines, in order to do more for the patient.

\subsection{Perspectives on differences between types of ICU}

Although the general picture of working in intensive care is painted by nurses across the types of intensive care, the analysis of the interviews also showed differences between GIC, PIC and NIC. In the interviews with PIC/NIC nurses the patient is viewed as consisting of a child and parents: a trinity. In this perception the parents need almost as much support as the child, and the nurses see it as their task to provide this support. The child and the parents, and possibly other siblings, are encouraged to develop family relationships in the alien environment of the intensive care unit. The child itself is regarded as a patient who does not fret and 
worry, but who lets you know when it is happy or sad, and it allows you to comfort it. The paediatric nurses on the whole enjoy looking after small children and cuddling them occasionally. They also like to work with the parents. They feel that they can make a difference by helping a family in this difficult situation.

There are, however, differences perceived by the paediatric nurses between PIC and NIC. Some neonatology nurses would not want to work with older children, because they have young children of their own. They prefer the very young and often premature babies and characterize their work as "giving them a chance". Indeed, these babies would not survive outside the NICU. Nurses feel that if one of the patients dies, it is something they can accept, although it is never easy. As a special characteristic of their work that distinguishes it from other kinds of intensive care, the neonatology nurses mention that they are dealing with the beginning of life. In that sense they find the NICU a "happy" environment, whereas they consider general intensive care to be more about the end of life and a less positive environment. They also expect that in general intensive care they would have less contact with the family of the patient, and this is something they enjoy in their work. Some neonatology nurses would like to work on a paediatric intensive care unit for a short time, because they feel that neonatology has a limited patient group, which displays a narrow range of disorders. Nevertheless, nurses enjoy working in neonatal intensive care partly because it provides them with a challenge in a turbulent environment where work is unpredictable.

Nurses in PIC also enjoy working with children and parents. They enjoy the contact they have with the children and they feel that this kind of interaction would be lacking on a GICU or NICU. In GIC they expect less involvement of the family and a less attractive patient population. PIC nurses perceive NIC on the other hand as a rather limited specialty, and one where ethical problems are more prominent. To counteract the stress that builds up in the PICU and the NICU, the nurses regularly spend a period of time on the High Care unit. This system of rotation is appreciated by the nurses, for it provides them with periods of relatively less stressful work and makes them more aware of basic care considerations.

General intensive care nurses work only on their own unit and are not keen to work anywhere else. The cardiac care unit and the recovery room were mentioned as the least popular alternatives, because they are perceived to be less challenging and the work is perceived as heavily structured by protocols. A few nurses mentioned emergency medicine, working on an ambulance or in an operating theatre as possible options, while others said they were not attracted to the kind of short and one-way contact with patients in these areas. Most GIC nurses do not consider working with children attractive for various reasons, and a few mentioned that they felt uncomfortable with the atmosphere on paediatric wards. they had worked on during their general nursing training.

\subsection{Conclusions}

In this chapter the results of interviews with intensive care nurses were discussed. It was argued that a simple model of career paths serves well to describe the careers of the majority of the respondents. Thus, the paths into GIC on the one hand and PIC/NIC on the other are to a large extent separate. However, the refined model 
showed that a considerable movement of nurses takes place out of GIC into PIC/NIC, whereas there is no movement in the opposite direction. The opinions of the respondents regarding the characteristics of intensive care nursing and its attractive features showed much congruence across the types of intensive care. It was found that the combination of critically ill patients, complex care and technology is perceived by the respondents as the main attraction of intensive care nursing. The role of the technology in intensive care is seen as limited in the sense that the technology can contribute to the work process but cannot replace it. The respondents have different perceptions of each type of intensive care, and most of the respondents do not consider moving out of the type of intensive care that they work in. 


\section{Chapter 5}

\section{A model of the work process}

"An intensive care unit is a place, not a technology; much of what goes on there is nursing care, not technology; and much of the technology is monitoring, not therapy." Jennett (1984) High techology medicine, p. 58

In this chapter the complexities of the work process of intensive care nursing are analysed. Two introductory sections discuss the functions of technology and the dynamics of life on the ward respectively. There follows a description of each of the seven activities that were found to be the basic categories of the model of the work process in intensive care nursing. These activities are: work on patient, work on equipment, administration, provision of supplies, instruction and support, relaxing and teamwork. On the basis of these activities, four phases in the work process were identified: 'hands-on routine', 'hands-on emergency', 'hands-off" and 'vigilance'. Each phase is characterised by a particular pattern of activities. The model of the work process is presented in Section 5.4. This is followed by descriptions and illustrations of the patterns of activities in each phase in Sections 5.5 through 5.8. In the concluding section two themes are identified concerning the role of technology and the importance of teamwork. These themes are explored in detail in Chapter 6.

\subsection{Complex care and the functions of technology}

Intensive care patients need complex care which involves continuous monitoring and the use of medical technologies at the bedside. We have already seen that the use of bedside equipment is perceived by the nurses as part and parcel of complex care. The equipment can be divided into two groups: monitoring equipment and treatment or support equipment. The various types of monitoring equipment are used to measure and display a number of parameters read from the patient. In intensive care some parameters are routinely monitored for every patient, for example heart rate, respiration, blood pressure, body temperature, and oxygenation of the blood (saturation). All these measurements, and many others, can be done either as one-off readings or as a continuous process. The devices with which these measurements are done vary from simple analogue instruments like a mercury thermometer or a blood pressure gauge to complicated digital systems 
for continuous parallel monitoring of several parameters. The most advanced electronic monitors are comprehensive and flexible, as they can handle many parameters and are easily modified for a particular patient. Each parameter is handled by a separate module that can be inserted into the machine. In this way the monitor can be set up with the relevant parameters for each patient. The choice of continuous or regular one-off measurements is related to the situation of the patient, so that on the ward a wide variety of devices is in use.

Treatment or support equipment is used for the interventions that are done in intensive care to help patients recover. The functions that these machines perform range from completely taking over a function of the body to supporting the activity of the patient. A ventilator, for example, can be used in such a way that the machine performs the breathing activity for the patient or it can be set up to facilitate spontaneous breathing. Ventilator support is withdrawn gradually in a process that is referred to as "weaning the patient from the ventilator", during which great care is taken to ensure that the patient suffers no adverse effects. A cardiac pace-maker can also be used for various degrees of support. Another form of medical intervention is the use of drugs. There are many types of medication that either substitute for a bodily product (e.g. insulin, pancreatine) or that support the physical system, for example by regulating the blood pressure or by influencing the electrical conductivity of the nerves that control the heart. In order to deliver the drugs at a particular rate, either continuous or at intervals, a range of intravenous (IV) pumps are used in intensive care. There are also technologies that are used to take over a function of the body. Two examples are continuous arterial-venous haemodialysis (CAVHD), which is much like renal dialysis, and extra corporal membrane oxygenation (ECMO), which takes over the functions of heart and lungs. All these invasive interventions affect vital functions of the body and therefore require close monitoring of those functions. The increasing possibilities in interventions have also increased the need for continuous monitoring.

These technologies share a number of characteristics that have implications for their use on units for intensive care. Not only do these machines perform their monitoring or support functions, they also monitor their own performance. For example, a ventilator checks if it achieves the output or frequency that is required, and a monitor checks if it is receiving useful signals. Yet, if these machines detect something wrong, they can usually do no more than sound an alarm signal. Some machines distinguish between possible sources for the alarm, and give indications of where the problem could lie. There are for example ventilators that ask "Tube obstructed?" or monitors that beep quietly with the message "No signal. Electrode disconnected?". For patient-related problems most monitors have two alarm signals, both faster and higher than the technical alarm. These alarms are accompanied by messages like "shallow breathing" or "Apnea $>15 \mathrm{sec}^{\text {". }}$. One type of ventilator has a feedback facility which allows it to switch to a different mode of ventilation without intervention from a person. This happens when the patient does not achieve a set number of spontaneous and effective breaths; the machine then switches to a suitable number of breaths per minute for that patient.

All in all, the machines require that experts in patient care are always present and available to make decisions and to intervene. The machines can only do their work under certain circumstances, and these circumstances can only be influenced by the staff and the patients. This implies that a number of the alarm signals from 
the machines will not point to a problem with the patient, but rather to a problem inside the machine or in the interface between the patient and the machine. Examples of such situations are when the machine has been assembled incorrectly, or when a connection or a sensor is loose. Thus, staff on an ICU must spend time setting up the equipment, adjusting it, cleaning it, calibrating it, and dealing with its alarms. Equally important, staff have to handle the information from the equipment with caution, because it is not always reliable, and even if it was reliable it would still be partial in the sense that it has to be judged in combination with other information about the patient. These factors are taken into account in the description of the work processes on the ward.

\subsection{Life on the ward}

Most of the intensive care units in this study had fewer than ten beds. Not all beds were filled at all times, and it was found that the number of patients on the ward alone does not make a ward more or less busy. The pace of work processes on the ICU is set by the patients. These patients are in a critical condition and they are dependent on intensive and complex care for survival. Yet, when we look at the ward as a whole, it can at times be surprisingly quiet. There are few overt signs of struggle and stress, and often the main noise is provided by the regular sighs of the ventilators. But this calm atmosphere often is the silence before the storm. We never know how long it will last, and we do not know what kind of storm will follow, but we can be certain that the calm will be disturbed. Although each patient is in a life-threatening condition, there are degrees of urgency. The staff refers to these degrees by means of the terms 'stability' and 'instability'. A patient can, for example, be in a critical but stable condition that does not require urgent intervention, and can be looked after in a relatively routine fashion with regular checks. This means that the patient is disturbed as little as possible and is seen by the nurse at regular intervals of one or two hours. A patient in a critical and unstable condition needs more frequent intervention and attention. When there are one or two unstable patients on a ward, the staff are very busy looking after them. In a crisis, a larger number of people than usual gathers around the bed. There is more talking and more movement to prepare drugs, fetch supplies, use the phone. Though this is a crisis situation, to an observer there appears to be no sense of panic. After a crisis has been dealt with, life on the ward resumes its normal pace.

These swings between the extremes of quiet and hectic periods are characteristic of life on the intensive care unit. The work is unpredictable and challenging. As we have seen, the technologies available on the ward are used to get information about the patient and to provide treatment for the patient. The use of technology in patient care means that nurses have to pay attention to the signals from the patient and to those from the machines. These are the basic mechanisms of life on an intensive care unit to which we will now turn.

\section{Working together}

The work of nurses on ICUs has individual aspects as well as group aspects. In theory, the system of patient assignment could lead to isolation and soloist work styles. Every nurse is expected to operate at the same level of competence and 
should be capable of providing total care for the patient. In addition, each nurse has the freedom to organise the time available, taking into account the scheduled procedures that need to be carried out at specific times. As has been argued before, nurses express a strong preference for this independent way of working. Yet, to them, working independently does not mean working in solitude. On the contrary, working on an intensive care requires good teamwork. There are many situations in which nurses find it useful to have an extra pair of hands or eyes, or in which they want to discuss a problem. The work creates many instances of interdependence, and the nurses are aware that they need each other. Teamwork works in two directions as each nurse is both a receiver and a supplier of teamwork. There is not a separate person who organises the teamwork, but the nurses themselves regularly assess from whom they can get assistance and to whom they can offer assistance. In practice this means that each nurse will make an assessment of the situation on the ward to estimate what kinds of patients there are, who the nurses are, who the doctors are, in short what can be expected during the shift and how the tearn will deal with it. This desire to anticipate events in a basically unpredictable environment is typical of intensive care nursing. The nurses regularly re-assess the situation in an effort to maintain the overview and set their priorities. As this mechanism is a core characteristic of intensive care nursing, it is explored in more detail in the remainder of this chapter.

\section{Images and overview}

Maintaining the overview is achieved at two levels: at the level of the individual patient and at the level of the ward. At both levels nurses create an image with which they work, against which they judge new developments, and which they adjust when the situation changes. In handling these images, the nurses show a great capacity to switch between foreground and background, in accordance with their set of priorities. To complicate matters, the set of priorities also changes, depending on the situation. In the process of assessing a situation and constructing an image, different types of information are used that come from a variety of sources. In Table 5.1 an overview is given of these types and sources of information. A further discussion of the ways in which nurses handle information and how they learn to do this can be found in Chapter 6 . 
Type of information

Vital signs

Course of illness

Events in previous shift

Scheduled events

Patient behaviour

What to expect

\section{IMAGE OF PATIENT}

\section{Sources}

Direct: obserwation of patient and equipment

Indirect: changeover, report, chart

Direct: experience and observation

Indirect: changeover, report

Indirect: changeover, report, chart

Indirect: changeover, report

Direct: experience and observation

Indirect: changeover

Direct: experience and observation

Indirect: changeover

\section{IMAGE OF WARD}

Type of information

Number of patients and situation

Sources

Direct: look around

Indirect: changeover

Roster and changeover

Number of staff nurses and situation

regarding experience, night shift,

absence

Situation of doctors regarding

experience and who is back-up

Scheduled events, 'announced'

transferrals, candidates for discharge

\section{Medical roster}

Changeover, operating schedule

Table 5.1 Images and sources of information

The changeover meeting between two shifts is clearly a very important source of information, but the process of information gathering starts even before that when the nurses enter the ward at the beginning of their shift. Nurses starting their shift usually walk around the ward to see what the patient population looks like and what changes have taken place. During the changeover meeting nurses from the previous shift report on their patients and nurses from the new shift ask questions and read the reports. These changeover meetings provide the new shift with much information that is relevant to the construction of the initial images of the patients and the ward. They find out who worked in the previous shift and on which patient, they meet the team from this shift, they hear the stories about the patients, and about the atmosphere on the ward, the events that took place and events to come. The changeover meeting is an important occasion where nurses discuss patients, debate impressions, and sometimes give warnings. The following sketch of a changeover meeting illustrates this last point.

Nurse $E$ reports during the changeover: "Mr A in bed six. Anybody who does not know Mr A? Charles, you have been off for a while, have you seen Mr A before? Well, not a lot has changed in that week. You remember Mr A joined us with a pancreatitis (inflammation of the pancreas), well he still has that and is increasingly dependent on the ventilator. He'll be with us for a while I guess."

A summary follows of major medical interventions in the history of this patient, and then the details of the last shift are listed: a string of numbers referring to blood pressure, heart rate, test results and ventilator settings. Nurse $E$ adds: "You have to 
watch him, he nearly pulled out his tube, and this morning we had to give him another feeding tube because he had removed it lhimself."

\section{Sketch 5.1 Changeover situation on GICU}

When all patients have been discussed, the new shift divides the patients. Usually both shifts drink coffee together. On most $1 \mathrm{CU}$, the nurses who have finished their shift give a short talk about the patient at the bedside after the changeover meeting. This talk is attended only by the nurse who will take care of the patient in the shift that has just started. On most wards this system is used, but on one neonatology ward the principle of patient assignment has been extended to the changeover, so each nurse is only told about the patient he or she will look after. This is done at the bedside.

Having read the report and heard the details from the nurse on the previous shift, the nurse then uses his or her own observations and experience to complete the image of the patient. Those patients who are on the ward for a long time will be looked after by the same nurse during several shifts. Some wards work from the idea that it is better for the patient if the same nurse works with the patient as much as possible. On other wards it is considered better for the quality of care if nurses do not work with the same patient on a long-term basis. In either case, the nurse builds up an image of the patient and takes into account previous experiences with this patient as well as general information about the condition of the patient. An important rule in the construction of an image, and in intensive care nursing in general, is that the nurse compares all information with his or her own observations. An example of a situation where a nurse is questioning what she has been told about the patient is given in the next Sketch 5.2. The scene follows on from the changeover meeting that was described in Sketch 5.1.

In this shift I follow nurse $\mathrm{H}$ who looks after $\mathrm{Mr} \mathrm{A}$. While she is taking notes of the IV settings, Mr A brings his hand up to his nose a few times and nurse $H$ puts it back down again. Does he want to pull out his feeding tube again? She talks to him: "You shouldn't remove that tube. You need it, and we would have to put another one in. You wouldn't like that, would you?" Nurse $H$ is standing next to him, ready to intervene if he does anything dangerous. This time she lets $\mathrm{Mr}$ A bring his hand all the way to his nose. He scratches it. Then he puts his hand down. Nurse H looks at me and says: "You see that it is easy to misinterpret an innocent move if you don"t take the time. It must be so awful if your nose itches and you are not allowed to scratch. I think Mr A is not as naughty as some people think."

\section{Sketch 5.2 Adjusting patient image on GICU}

In the changeover meeting, the impression had been given that $\mathrm{Mr}$ A was uncooperative and that he irritated the nurses as he often tried to pull out his gastric tube. Nurse $\mathrm{H}$ takes a different approach and makes up her own mind about the behaviour of the patient. During the shift, the image of the patient will be adjusted if new information becomes available that does not fit the initial image. Most of the time, however, the nurses have a firm idea about the situation. of the patient. Based on this image, the nurses have a frame of reference that they use to establish which events can be expected and which changes are acceptable in 
this condition. When the image is adjusted according to some new information, these expectations and margins of acceptability will change with it.

Experienced intensive care nurses construct a comprehensive image of the circumstances at the beginning of the shift. They make a quantitative and a qualitative assessment about the patients and about the staff. They find out how many patients there are and what degree of stability they can expect for each patient. Similarly, they know the number of doctors and nurses on this shift, and they have an idea of how these people work. The qualitative aspect is essential to their assessment, and it includes information about the formal position and work experience of a staff member (e.g. trainee), as well as impressions from having worked with this person before. If there are trainees on the ward, the roster should compensate for the level of experience of the trainee. A new and inexperienced trainee is coupled with an experienced qualified intensive care nurse, and this couple is counted as one full nurse in the roster. The more experienced trainees are not counted as extras, nor are they counted as full nurses. The balance of the roster is a crucial issue in intensive care, both in quantitative and in qualitative terms.

Though much of what will happen during the shift is unpredictable, there are scheduled events, such as trips to the MRI or to the operating theatre, or the patient's discharge from the ICU. Of course, the circumstances may change so that the scheduled events cannot take place. Yet, other events may have to be organised at very short notice. Although some procedures are in principle done only at particular times, there is always a way to organise these procedures at other times. Examples are the CT scan and the EEG, procedures that are normally done during office hours, but for which technicians are on call at all times. In addition, a procedure may take more time than expected, or the results may be inconclusive and the procedure has to be repeated. Especially the investigations that are not done on the ward can pose a problem, because most hospitals have the rule that transport of an ICU patient should be accompanied by at least one intensive care nurse and another nurse, intensive care nurse or doctor. Thus, the number of nurses available on the ward can vary during the shift. By the same token, the number of patients can vary. New admissions can be announced at any time, and sometimes several at the same time. If the ward has empty beds, these patients can usually be admitted without any problem. More surprisingly, even a fuli ward can sometimes admit new patients. This often involves transferral of the 'best' patient to another ward if the condition allows this. Admission and discharge of patients is surrounded by a number of household and administrative chores for the nurses, and thus puts extra pressure on the nurses during the shift. The emergency nature of most of the admissions results in concentrated and unpredictable activities in which usually several nurses and doctors are involved. In Sketch 3 an impression is given of a situation where two patients in a critical condition are admitted to the GICU almost simultaneously.

I arrive on the ward for the evening shift, just after changeover. The doors swing open, and with great speed a bed is pushed onto the ward and into room 5. Several nurses are busy connecting a new patient to the various machines. The patient is a grey-haired woman and she is fighting the ventilator. She tries to remove the tube from her throat. Her hands are busy, she is upset. She has been transferred from a medical ward where she was resuscitated. The phone rings and the arrival of another patient is announced. He is in the emergency department now, where he is being prepared for transport after 
resuscitation. When this patient arrives he is in a very bad condition, and his room fills up with doctors and nurses. The earlier arrival is still restless and has someone gtanding next to the bed to prevent her from removing the tube.

\section{Sketch 5.3 Multiple admissions on GICU}

This particular shift started in a hectic way, but within a half-hour the doctors had left, and the nurses sat down to read up on the newly admitted patients. Each patient had been assigned to a nurse, and the ward was calm until the next busy speil. The unpredictability of the work and the rapid changes between busy and quiet periods as illustrated in Sketch 5.3 are a characteristic of intensive care nursing.

In this study, a model has been developed to describe and analyse the work processes on ICUs, taking account of the changing circumstances. The aims of the analysis are to uncover the mechanisms that shape the work processes, and to present the conditions in which these mechanisms work. In the following sections, the model will be outlined and illustrated. Seven activities were identified, and these are outlined in Section 5.3 below. Six of these activities refer to work that is done for the patient for whom the nurse has primary responsibility; the 'own' patient. The seventh activity is teamwork and this is typically done for 'other' patients. These activities are the basic elements in the model that consists of four phases in the work process. This model is presented in Section 5.4. Each phase is described in detail in Sections 5.5 through 5.8 below.

\subsection{Activities}

The observational data on the work process were organised into categories during the coding process (see Chapter 3 ). The categories that were identified in the data during the second case study have been subjected to further investigation and testing in subsequent case studies. The model was discussed with the nurses on several ICUs, and evidence was sought that could confirm or refute the emerging theory. The final version of this theory is presented here and starts with a description of its basic categories. The work process is divided into six activities that together cover the activities a nurse would be involved in during a shift. These activities are listed in Table 5.2 and are discussed separately below.

\section{Activities}

Work on patient

Work on equipment

Administration

Provision of supplies

Instruction and support

Relaxing

\section{Observable actions}

Washing, feeding, dispensing medication, resuscitation, comforting

Assembly, calibration, testing, connecting, setting up

Medication, patient data, laboratory results

Bed linen, disposables, equipment

Bedside teaching of trainees, support and information for patient and relatives Coffee, meals, chatting, television, reading

Table 5.2 Six activities for 'own' patient in intensive care nursing 
The list of activities reflects what goes on during a shift and takes the observable actions of the nurses as the starting point. The activities are theoretical categories and are thus interpretations of the observations. Moreover, there is no direct link between the categories that are presented here and the official job descriptions or other formal arrangements regarding the contents of the work. The list of activities was developed and tested during the research process, but it was not used to make quantitative assessments about the amount of time spent on each activity, nor was it used as recording tool during the observations.

\section{Work on patient}

The physical care for the patient has many aspects. It includes basic care like washing, feeding, cleaning the bed, oiling the skin or giving a bed pan. In the continuous search for information, nurses use their senses to pick up clues about the condition of the patient, by looking at the colour, touching the skin, and they even get information from the smell of dirty nappies. In addition, there are the interventions that require manual manipulation of the body. This happens for example when a baby forgets to breathe and as a result gets a slower heart rate. In this situation, which is called bradycardia, the nurse will pat or shake the baby as if to wake it up. Another example of manual intervention occurs when a patient has a cardiac arrest. In that case, when the patient's heart is not working at all and the blood pressure is plunging, nurses and/or doctors apply cardiac resuscitation or cardiac massage. The massage in particular requires a considerable physical effort. Particular types of work on the patient are limited to neonatal and paediatric units, where the patients are sometimes cuddled and comforted by gentle stroking of the head. Particularly restless children are sometimes taken out of their beds and held by a nurse if the parents are not available.

\section{Work on equipment}

The bedside equipment is operated mainly by the nurses. Both the monitoring equipment and the support equipment require setting-up, regular checks, and cleaning. This means that some machines, most notably ventilators, are taken apart, the various elements cleaned and put back together again. Before the patient arrives the nurses set up the equipment and test if it works reliably. This involves testing the alarm settings and calibrating the machine to make sure that once the machine is switched on it will perform its function properly. For a complicated machine like ECMO, a detailed priming and testing procedure exists, which involves a "dry' run with salty water, before the system is filled with blood. Ventilators must be connected to gas supplies, and electronic monitors must be fitted with the relevant sensor modules. Many of these things are done before the patient arrives, but with a clear idea of what the patient will need. Incubators are switched on early to achieve a particular temperature and humidity depending on the age and condition of the prospective patient. A situation of over-pressure is created in an isolation room for a patient with leukemia, the parameters of the ventilator are set according to the anticipated need of the patient. All these preparatory actions are done by the nurses, and as we have seen they continue to monitor the equipment as long as it is used on the patient. Every two hours or more frequently the values that the machines display are copied onto the day sheet, so that a permanent record of the patient's condition can be kept. The machines also have to be supplied regularly with inputs, such as water for 
ventilators and incubators, to humidify the air, and syringes or bags with medication and fluids for IV pumps.

\section{Administration.}

A wide variety of forms and documents are used on the ICU. The largest number are request forms for laboratory tests or consultations: Officially, these forms are for the medical staff to fill in, but on a number of wards this task was delegated to the nurses. Each request form has to have a unique patient identification on it. On most wards the task of copying the patient details onto the forms was done by nurses and on a few wards by a secretary or junior doctor. One of the important administrative tasks carried out by the nurses is related to the supply of medications to the patient. The doctor is responsible for prescribing drugs and usually writes the orders in the patient file. The nurses are responsible for ensuring that the right drugs are given at the right times to the right patients and that a reliable administrative record is kept. There are several ways to organize this, but in each approach the nurse has to write the labels for the syringes, indicate in the patient sheet when the drugs have been given, and in the case of drugs from the 'poison cabinet' fill in a separate logbook. The nurses have one more major administrative responsibility which is to write down details of what happened with a particular patient during the shift. The nursing files on the patient are usually extensive and involve a system of report sheets for different topics. Most nursing files contain sections on changeover reports, the care plan, psycho-social aspects and the doctor's instructions.

\section{Provision of supplies}

In this category are the remaining tasks that a nurse performs for a patient, and that are often not done at the bedside or involve moving supplies from one place to another. For example, preparing medication and food for the patient are done in separate areas. Taking samples to the laboratory or picking up medication from the pharmacy involves leaving the ward for a while. A wide range of disposables is used at the bedside, including sterile and non-sterile gloves, plastic gowns, suction catheters, gauzes, adhesive tape. They are usually kept in small quantities near the bed and have to be restocked regularly. Usually this is done once per shift. Other supplies are fetched when needed, such as syringes, needles and test tubes for taking samples, tubes and intubation implements, resuscitation equipment. Bed linen, towels and other supplies for a bed bath also have to be transferred from the storage to the bedside.

\section{Instruction and support}

Explaining, demonstrating, educating, comforting and evaluating are also tasks that nurses do. They address several audiences in their work, including patients, relatives of patients, trainee nurses, visiting nurses and assistants. In each case, the nurse shares some of his or her experience with others. The patient and his or her relatives are in an anxious situation, and nurses help them deal with this by showing concern and explaining what is happening. Often, nurses explicitly tell the patient and the family that they should not worry about the equipment and the alarms because "that's our job." When working with the patient, instruction often takes the form of telling the patient how to get more comfortable or how best to cooperate. Trainee nurses and visiting nurses often have their own set of goals, 
and these are dealt with when time is available. Techniques such as ventilation and monitoring can be demonstrated at most times. Instruction takes a different form during emergency situations. Under these circumstances the experienced nurse provides a running commentary on the events that are taking place. The nurses in this study attach great value to experience and to seeing different situations. They combine the basics of intensive care training with the exceptions of intensive care practice. Some nurses remarked that they enjoyed having trainees on the ward, because they ask questions and thus help to keep the experienced nurses sharp, stimulating them to review their own theoretical knowledge. In addition, the medical assistants and junior doctors are often taught practical skills, such as calculating an IV drip schedule and the standard dosage for particular drugs, by the nurses, although they ought to be trained by other doctors.

\section{Relaxing}

There is often no time for relaxation, but at other times there is little else to do. In any case, nurses need time during the shift to sit down and be away from the bedside. Especially in NICUs where it is very hot and humid, staff must take regular breaks. Relaxation may take different forms, depending on the facilities on the ward. Most ICUs have a television set in the coffee room. Talking, drinking coffee or soup, eating, reading the paper and watching television or playing computer games are common ways to relax. Celebrations also provide an opportunity for relaxation as they usually involve cakes and coffee for the staff. Among the events that are celebrated are the birthdays of staff members and other achievements of the staff, for example when a premature baby grows to be over 1000 grams, when a junior assistant places his or her first Swan-Ganz catheter, or when a research project is concluded. In each case the member of staff concerned has to bake or buy a cake for the unit.

\section{The seventh category: teamwork}

It follows from the discussion in Section 5.2 that teamwork has an important place in the work process on ICUs. Teamwork is therefore included as an activity in the model, but it is by its nature very different from the activities described above. So far, we have looked at the activities that a nurse performs for the patient to whom he or she is assigned. The basic characteristic of teamwork, however, is that it is performed for other patients or for the ward in general. Thus, although the observable actions in teamwork and the other categories may look the same, they are analytically separated according to the context in which they are done, namely the context of the 'own patient' or the context of an 'other patient'. Another way to perceive teamwork, then, is to emphasise that it involves doing tasks for another nurse. This implies that some observable actions are not suitable for teamwork, most notably relaxing and to an extent also instruction and support. Table 5.3 below gives an overview of the observable actions that are found in the category of teamwork. 
Types of teamwork

Teamwork on patient

Teamwork on equipment

Administration for team

Provision of supplies for other patient

or team

\section{Observable actions}

Assisting with bed bath

Assisting with setting up

Writing medication labels

Distributing linen sets

Table 5.3 Observable actions in teamwork

Teamwork in routine situations may take the form of one nurse taking samples to the laboratory, or dispensing medication for patients other than their own. On units for neonatology, where feeding times are frequent, one nurse may warm the milk for all the babies that are fed at that time. Very often, one nurse will collect the waste from each patient, provide clean bags and put the full bags out. Similarly, checks on the general supplies for linen, disposables and medication are done by one nurse per shift. The 'crash car' with the resuscitation equipment and other emergency supplies are also checked regularly, to make sure they are ready for use. However, in emergencies and other situations where the patient cannot be left alone, teamwork fulfils the role of providing an extra pair of hands in the care for another patient. This kind of teamwork is essential to the smooth functioning of an intensive care, and usually it is provided promptly. Every nurse can get into a situation where he or she needs help, and this interdependence is the basis for the natural occurrence of teamwork. Thus, in the event of an emergency, several nurses will offer assistance, even without being asked. There are procedures that one nurse cannot do alone, for example preparing sterile syringes for IV pumps. Two nurses are necessary for this action, and neither of them can do anything else until they are finished. In these situations teamwork is expected from the rest of the team to cover the direct patient care.

\subsection{Overview of the model}

The model of intensive care nursing incorporates the seven activities that we have just described and relates them to the dynamics of the work process in which four phases are distinguished: 'hands-on routine', 'hands-on emergency', "handsoff' and 'vigilance'. These phases apply to the activities of each individual nurse, and it should therefore be borne in mind that the different nurses in the team may be involved in a different phase at any one time. As we have already seen, IC nursing is characterised by unpredictability. Nurses deal with this by setting priorities on the basis of images they construct, both of the individual patient and of the ward as a whole. We have also seen that the activities that nurses engage in during their shift can vary. In Table 5.4 the activities are displayed in relation to four phases in the work of intensive care nurses. The phases hands-on and handsoff can be seen as two states in which it is clear to the staff what the situation is and what can be expected. The hands-on routine phase involves the provision of the more or less standardised care that takes place at regular intervals, whereas the hands-on emergency phase usually involves the need to intervene in the 
condition of the patient at short notice. Hands-off indicates that activities are not directly aimed at the patient, but may take place elsewhere on the ICU. The phase of vigilance is different from the three phases we just described, as it is characterised by uncertainty and heightened alertness. The occurrence of these phases does not follow a particular order, as the emergence of a phase is dependent on the situation of the patients on the ward. In this model the dynamics of intensive care nursing are reflected in the pattern of activities in each phase and the corresponding changes in activities when a different phase applies.

\section{PHASES OF THE WORK PROCESS}

\begin{tabular}{|c|c|c|c|c|}
\hline & $\begin{array}{l}\text { Hands-on } \\
\text { routine }\end{array}$ & $\begin{array}{l}\text { Hands-on } \\
\text { emergency }\end{array}$ & Hands - off & Vigilance \\
\hline \multicolumn{5}{|l|}{ ACTIVITIES } \\
\hline Work on patient & Yes & Yes & Maybe & Dominant \\
\hline Work on equipment & Background & Dominant & From a distance & Yes but doubt \\
\hline Administration & Routine & Necessity & Update & Routine \\
\hline Provision of supplies & Necessity & Necessity & Optional & Necessity \\
\hline $\begin{array}{l}\text { Instruction and } \\
\text { support }\end{array}$ & Routine & Special & Possible & Special \\
\hline Relaxing & No & No & Possible & No \\
\hline Teamwork & Receive & Receive & Supply & Receive \\
\hline
\end{tabular}

Table 5.4 Activities related to phases

Here we see that for each phase a qualification is given to each activity. We will now discuss each activity in turn with respect to the different phases. For the activity work on patient the qualification 'yes' means that physical contact with the patient takes place. This is the case in the hands-on situations. In the hands-off phase there is no need for contact with the patient, so that the nurse can leave the bedside. In the vigilance phase, however, work on patient is qualified as 'dominant', and this means that it is the most important activity in that phase. Work on equipment is an activity' that takes place in the 'background' of the hands-on routine phase. Thus, the nurse keeps an eye on the equipment, but this is not a priority because in a routine situation the machines provide an effective and reliable service to the patient. On the other hand, the activity work on equipment is 'dominant' in the emergency hands-on phase. This means that technical interventions are required and take priority over other activities. In the hands-off phase this does not apply, and the qualification 'from a distance' indicates that the nurse does not have to be in the immediate vicinity of the equipment or the patient and can rely on audio signals from the equipment to attract attention in the case of a change in the patient situation. Work on equipment in the vigilance phase involves 'doubt'. Thus, while the equipment is relied on and used in most phases, it is distrusted in the vigilance phase. With regard to the activity administration we distinguish 'routine', 'necessity' and 'update'. 'Routine' administration takes place in hands-on routine and vigilance phases. It means that those data are collected and filled in that are required in the 
standard records. 'Necessity' administration is found in the hands-on emergency phase, when records are kept of the specifics of the situation. In the hands-off phase there is time to do 'update' administration, which means that missing records are filled in and other non-routine notes are taken. In three phases out of four the activity provision of supplies is qualified as 'necessity". This means that only those supplies are fetched that are required at the bedside. The hands-off phase provides an opportunity to deal with 'optional' provisions that have a more general character. With regard to instruction and support we distinguish 'routine', 'special' and 'possible'. The 'routine' instruction and support is related to the hands-on routine phase. Thus, the activity is concerned with the events that take place during the provision of standard care and can to an extent be planned in advance. Hands-on emergency and vigilance require non-standard care, and therefore the instruction that takes place in these phases is 'special' in character. Whereas 'routine' instruction often concentrates on one skill or aspect of the work, the 'special' instruction addresses relationships between the aspects and the interpretation of complex situations. Instruction and support are "possible" in the hands-off phase, and this phase is most convenient for contacts with the patient's relatives. For the activity relaxing only the hands-off phase is relevant. At all other times the nurses are occupied with patient care and are thus involved in other activities. Teamwork is an activity that is 'received' in three phases out of four and can be 'supplied' only in the hands-off phase. This means that in hands-on and vigilance situations nurses may need the assistance of others to provide care for the patient. The nurses who can provide this assistance are those who are experiencing a hands-off phase in the care for their own patient.

\subsection{Hands-on routine}

\section{PHASES OF THE WORK PROCESS}

\begin{tabular}{|c|c|c|c|c|}
\hline ACTIVITIES & $\begin{array}{l}\text { Hands-on } \\
\text { routime }\end{array}$ & $\begin{array}{l}\text { Hands-on } \\
\text { emergency }\end{array}$ & Hands - off & Vigilance \\
\hline Work on patient & Yes & Yes & Maybe & Dominant \\
\hline Work on equipment & Background & Dominant & From a distance & Yes, but doubt \\
\hline Administration & Routine & Necessity & Update & Routine \\
\hline Provision of supplies & Necessitty & Necessity & Optional & Necessity \\
\hline $\begin{array}{l}\text { Instruction and } \\
\text { support }\end{array}$ & Routine & Special & Possible & Special \\
\hline Relaxing & No & No & Possible & No \\
\hline "leamwork & Receive & Receive & Supply & Recelve \\
\hline
\end{tabular}

Table 5.5 Activities in hands-on routine phase

As Table 5.5 above shows, the hands-on routine phase involves work on the patient, with work on the equipment in the background. The situation is stable and the care follows the plans that are laid down in the plan of treatment for this patient. The scheduled actions are performed at the indicated times. This involves 
routine administration as well as providing the necessary supplies. An example of this situation is the so-called "care round" or 'observation round' that is usually' done at two-hourly intervals. This involves checks on the patient and recording standard patient measurements such as heart rate, breathing and saturation, as well as checks on the equipment and recording machine parameters such as frequency, air pressure and volume. These observations are noted down in the day report. A variety of other tasks can be done as part of the round, such as changing IV bags, delivering medication, suction, feeding and washing the patient. Some of these tasks are done as a rule by two nurses, for example giving an adult patient a bed bath. Each task has to be prepared, and this can either be done by each individual nurse per patient or it can be organised in a collective way. In the former situation there is little need for teamwork, whereas the latter situation requires more teamwork. We already mentioned that on some wards each nurse prepares the medication for the patient to whom he or she is assigned, while on other wards the medication is prepared by one nurse for all patients. Teamwork may thus be received by the nurse in the hands-on phase, but the need for this can vary depending on the organisational arrangements on the ward. In Sketch 5.4 a hands-on routine situation is described that was observed on a paediatric intensive care unit.

At $10.00 \mathrm{AM}$ it is time for Nurse $\mathrm{A}$ to give Daniel his porridge and do an observation round before the daily meeting. Daniel is 8 months old, and has been in intensive care all his life. He started in a NICU and was later moved to this PICU, where he is still using a mechanical ventilator. He is not quite awake when we arrive at his bed, but when he opens his eyes he smiles. He starts to cough and his face turns red. He calms down quickly and watches nurse $\mathrm{A}$ as she writes down his ventilator settings and checks when he is to get his next medication. She tells him that it's time for the porridge, which she is just going to warm up for him in the micro-wave. Nurse A leaves Daniel in his bed while she fetches the food, and when she comes back she prepares a place for the two of them to sit. Daniel is then put in his favourite chair, the Maxi Cosi, so that he sits up straight, and nurse $A$ sits on a chair opposite. Nurse $A$ explains to me that Daniel has problems eating, mainly as a result of the mechanical verntilation that he has needed since birth. His mouth and throat are very sensitive and easily irritated since he had a tube in for a long time. Moreover, because he has never had to eat or drink he does not know how to do it. Daniel finds swallowing very difficult, and he often just keeps the food in his mouth. By using a special spoon and placing it in his mouth in a particular way, staff hope to stimulate Daniel to start to learn to eat, and eventually to enjoy it. It takes Daniel and nurse A twenty minutes to get through half the bowl of porridge. The rest is thrown out, and Daniel gets some thinner food through his gastric tube.

\section{Sketch 5.4: Feeding Daniel, PICU}

In this example nurse $A$ is dealing with the patient, taking notes about the equipment, and fetching the supplies she needs for feeding Daniel. In this organisational arrangement nurse $A$ 's dependency on teamwork is low. During her work she observes Daniel's behaviour and goes patiently about her work. While encouraging Daniel to do his best, nurse $A$ explains to the researcher what she is doing. Eating is for Daniel an exercise, and not one that he particularly enjoys. Nurse $\mathrm{A}$ takes this into account when she decides that half a bowl is enough for the moment, and gives him additional food through his tube. In this 
situation nurse $A$ could have been educating the parents or demonstrating to a trainee which skills and considerations go into the feeding of a "difficult eater". The care plan indicates at what times this ritual is to be repeated every day, and the plan is adjusted on the basis of the condition of the patient, so that when Daniel became seriously short of breath during an infection, the eating training was temporarily cancelled. Thus, we have seen that work on an ICU can take on a routine character and that the patient care plans provide the structure for the delivery of care. It should be noticed that in this situation a good match exists between the expectations of the nurse, the signals from the patient and the information of the equipment, so that the image with which the nurses sets to work is an unproblematic one.

\subsection{Hands-on emergency}

PHASES OF THE WORK PROCESS

\begin{tabular}{|c|c|c|c|c|}
\hline ACTIVITIES & $\begin{array}{l}\text { Hands-on } \\
\text { routine }\end{array}$ & $\begin{array}{l}\text { Hands-on } \\
\text { emergency }\end{array}$ & Hands -off & Vigilance \\
\hline Work on patient & Yes & Yes & Maybe & Dominant \\
\hline Work on equipment & Background & Dominant & From a distance & Yes, but doubt \\
\hline Administration & Routine & Necessity & Update & Routine \\
\hline Provision of supplies & Necessity & Necessity & Optional & Necessity \\
\hline $\begin{array}{l}\text { Instruction and } \\
\text { support }\end{array}$ & Routine & Special & Possible & Special \\
\hline Relaxing & No & No & Possible & No \\
\hline Teamwork & Receive & Receive & Supply & Receive \\
\hline
\end{tabular}

Table 5.6 Activities in phase hands-on emergency

Although emergencies are not predictable, they can be planned for. The nature of an emergency in intensive care often requires the application of more or different pieces of equipment and this is usually available at the bedside or elsewhere on the ward. The technical interventions that are required to deal with the crisis then take priority over other tasks. Therefore, the most important activity in the handson emergency phase is work on equipment, as is shown in Table 5.6 above. Examples of such technical interventions are the use of a cardioverter or a defibrillator, the administration of drugs and manual ventilation with the use of a balloon. In addition, the effect of these interventions is monitored to a large extent by other equipment, since the physical parameters that have changed, such as the heart rhythm or the blood pressure, cannot be monitored directly. Work on the patient is another important activity in an emergency, but in most situations it can only be effective in connection with work on equipment. As we mentioned in Section 5.3, there are emergencies that require major physical interventions such as heart massage. The results of such interventions are however monitored by equipment. Other activities during an emergency are administration of the necessary information and provision of the necessary supplies. The assistance of 
other nurses, and often also doctors, is indispensable in a hands-on emergency. The kind of teamwork that it is required in a crisis must be available at a very short notice so that extra hands can be put to work immediately. This is particularly important since the nurse who looks after the patient in an emergency cannot leave the bedside and is thus dependent on teamwork for the provision of emergency supplies and the notification of doctors who may not be on the ward. In Sketch 5.5 these points are illustrated in an observation on a NICU.

Walt's mother is sitting in a comfortable chair, and nurse $S$ is transferring Walt from his incubator to his mother's arms. Nurse $S$ checks that Walt's tubes and lines are long enough so that his oxygen supply and his drips are secure. She covers him carefully, leaving his face free. Then she turns to another baby. Suddenly nurse $S$ calls out "Whose tube is that?" and quickly makes her way towards Walt. She had noticed the sound of air leaking and the cry of a baby that is not familiar to her. Normally Walt cannot use his voice because of the ET-tube. His mother looks surprised and says: "I don't know how it happened, but his tube has fallen out." By this time the alarms from the ventilator and the monitor have started, and are silenced by nurse S. Meanwhile nurse $\mathrm{S}$ has taken the oxygen mask from its hook next to the incubator, opens the oxygen supply, and holds the mask in front of Walt"s face. Nurse $M$ has come to see what she can do, and nurse $S$ asks her to get a doctor. Nurse $S$ is watching the monitor as well as Walt's behaviour and puts him back in bed with the help of nurse W. At the same time she speaks comforting words to Walt's mother, who is disappointed that she could not hold the baby longer. "What a pity this happened, I thought the two of you were looking so comfortable. You know that this can happen, it is not your fault. The doctor will place another tube." When nurse $\mathrm{M}$ and the doctor arrive, nurse $\mathrm{S}$ asks nurse $M$ to fetch the intubation material. Nurse $S$ is standing next to Walt, holding the oxygen mask in place, watching his condition and explaining to the doctor what happened.

\section{Sketch 5.5 Accidental extubation, NICU}

In an emergency situation fast thinking and fast acting are required. In this case the sound of leaking air is noticed quickly by nurse $S$, and combined this with the sound of a baby's voice that she did not recognise. These signals indicated to her that a possible emergency situation was at hand, even before the electronic alarms sounded. In other words, she noticed that some signals did not fit her image of the ward. Although she was attending to another baby at the time, she was monitoring the overall situation in the background. This background instantly became the foreground when she noticed the sounds that did not fit. She changed her set of priorities, quickly stopped the less urgent work, and started dealing with the emergency. Since baby Walt did not cope well at all with the interruption of the ventilation, nurse $S$ had to stay with him to stabilise his condition. Therefore, nurse $S$ enrolled the help of other nurses to get a doctor and to help her put the baby back in bed. Thus, in a hands-on emergency phase the need for teamwork arises from the patient situation and is less influenced by the organisational arrangements. Here again, it should be noted that the nurse used the equipment without hesitation. She applied the oxygen mask immediately and she acted in accordance with the information from the monitor, the ventilator and the patient. These sources were giving information that was consistent and therefore unproblematic: the nurse's image of the situation was clear. 


\subsection{Hands-off}

\section{PHASES OF THE WORK PROCESS}

\begin{tabular}{|c|c|c|c|c|}
\hline ACTIVITIES & $\begin{array}{l}\text { Hands-on } \\
\text { routine }\end{array}$ & $\begin{array}{l}\text { Hands-on } \\
\text { emergency }\end{array}$ & Hands -off & Vigillance \\
\hline Work on patient & Yes & Yes & Maybe & Dominant \\
\hline Work on equipment & Background & Dominant & From a distance & Yes, but doubt \\
\hline Administration & Routine & Necessity & Update & Routine \\
\hline Provision of supplies & Necessity & Necessity & Optional & Necessity \\
\hline $\begin{array}{l}\text { Instruction and } \\
\text { support }\end{array}$ & Routine & Special & Possible & Special \\
\hline Relaxing & No & No & Possible & No \\
\hline Teamwork & Receive & Receive & Supply & Receive \\
\hline
\end{tabular}

Table 5.7 Activities in hands-off phase

In the hands-off phase the technology is largely left to do its job for the patient without the physical presence of the nurse. There is time for other activities like administration, provision of supplies, teamwork, relaxing, and instruction and support. This phase is deceptively calm, and it would seem that the nurse trusts the technology entirely to monitor the patient. If they are not involved in any of the other activities, one or more nurses are usually sitting at the central monitor, glancing occasionally at the screen. From this position they assess the alarm. signals that are heard at times. Sketch 5.6 illustrates this situation.

Silence on the ward after the 22.00 o'clock observation round. The nurses gather around the central desk and flick through the patient files. Some nurses find another place to sit and write their shift report. Occasionally an alarm sounds on the central monitor. A nurse looks at it and says: "That's nothing".

\section{Sketch 5.6 Quiet, GICU}

For the observer who is less than an expert in intensive care nursing, it is virtually impossible to predict how a nurse will react when an alarm sounds. It is considered good practice to go over to the patient and deal with the alarm there. On some wards this is formalised in the set-up of the monitoring system, so that an alarm can only be silenced on the bedside monitor, and not on the central monitor. Often, though, an alarm does not need to be silenced because it stops automatically after a short while. Nurses seldom jump up and rush towards the patient. When this happens, it is often because the nurse is surprised by the information on the screen. Thus, when the information does not fit the image that the nurse had constructed, the alarm is more likely to provoke action. Thus, we can say that the hands-off phase is characterised by a clear image of what can be expected, combined with the impression that these expected events are going to be within the limits of what is acceptable. When an unacceptable event occurs, this 
image is distorted, and the nurse will start looking for information to clarify the situation. Sketch 5.7 however illustrates how an electronic alarm that was expected provokes immediate action.

A few days into the fourth case study I sit with the nurses of a GICU at the desk. We hear a bleep and nurse F says: "I knew this would happen", gets up quickly and rushes to $\mathrm{Mr}$ A The others are watching the central monitor and call up more extensive data on $\operatorname{Mr} \mathrm{A}$.

Nurse F comes back after a short while and I ask him what he did, why he expected the alarm and why he ran. I am puzzled, because on an ICU nurses do not usually run. An alarm does not frequently provoke this kind of rapid action. Nurse F explains that the alarm was produced by the intravenous pump. The syringe was nearly empty and had to be replaced. He recognized the sound of the alarm and knew which pump it was, so he got up to change the syringe.

The medication in the syringe was helping $\mathrm{Mr} \mathrm{A}$ to maintain his blood pressure. $\mathrm{Mr} \mathrm{A}$ was dependent on this medication to the extent that the time it took to change the syringe was long enough to make his blood pressure drop. Knowing this, nurse $\mathrm{F}$ was concerned to make the time for the changeover as short as possible. He had been listening out for the alarm, so that he could be at the bedside as quickly as possible.

On the central monitor his colleagues had been watching the blood pressure of $\mathrm{Mr} \mathrm{A}$ It had dipped briefly and stabilised again.

\section{Sketch 5.7 Expected event, GICU}

In the hands-off phase the nurse is not providing care to the patient in a direct way, but rather in an indirect manner. The image of the patient enables the nurse to compare new information with an expected and acceptable situation. Thus, the nurse is aware of the patient while doing other things, and acts upon unexpected or unacceptable changes. This is the only phase in which the nurse can supply teamwork and therefore it is crucial that hands-off periods occur.

\subsection{Vigilance}

\section{PHASES OF THE WORK PROCESS}

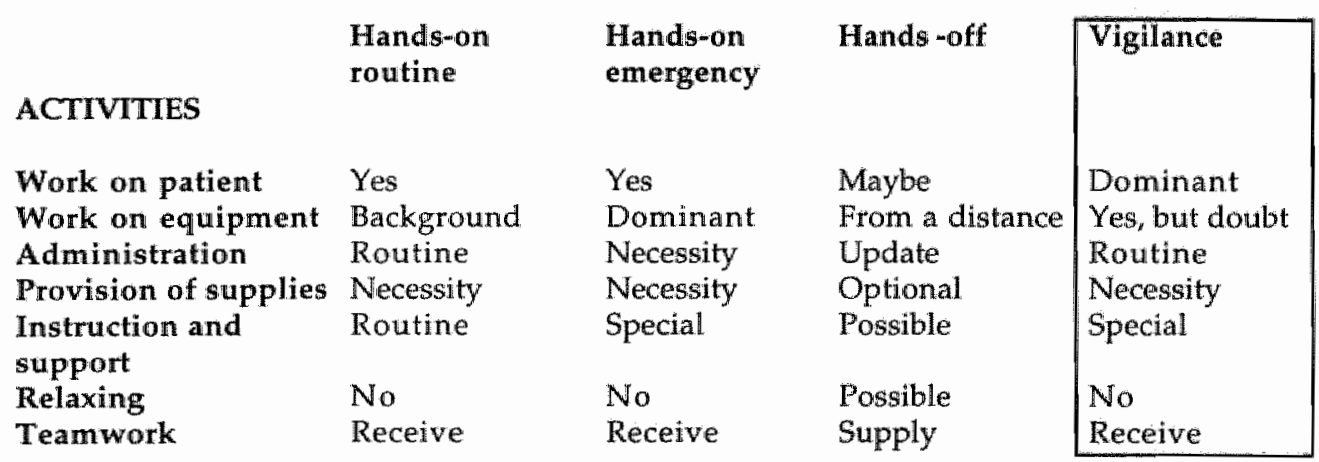

Table 5.8 Activities in vigilance phase 
Vigilance denotes an attitude of watchfulness, which is a basic characteristic of intensive care nursing. The phases in the work process that we have discussed so far have involved low levels of uncertainty. The hands-on routine phase is essentially standardised and pre-structured and although the hands-on emergency phase is unpredictable, it is planned for and relatively unproblematic. The handsoff phase reflects the nurses' confidence that they have a clear image of the patient and that this image is confirmed by the signals they receive. The vigilance phase is fundamentally different from the other three phases as it is is characterised by uncertainty and alertness. In this phase, the nurse is preoccupied with the reduction of uncertainty as the nurse has difficulties in the construction of an image of the patient. A fuzzy image has emerged because the information from several sources points in different directions. An important difference between the vigilance phase and the other phases is that doubt prevails regarding the reliability of the equipment. Thus, while the equipment is used without hesitation for intervention and monitoring in the other phases, the technology is treated with caution in the vigilance phase. Instead, the patient is perceived to be the main source of relliable information. In this situation the nurse usually does not leave the bedside, and often asks others to give their opinion. These aspects of the vigilance phase are illustrated in Sketch 5.8 below.

Nurse A looks after baby Mark. She is busy doing the morning care and observation round. Last night baby Mark had an operation on his windpipe, and he is still very quiet. Nurse A notices his feet are cold, and then she feels his hands. She turns to me and says: "Do you think his hands are cold?". I touch the hands of the baby and find them colder than mine. Nurse A looks puzzled. The central temperature is measured continuously and is fine. She looks in the bedside cabinet for a thermometer and places it in the baby's armpit. While waiting for the temperature reading she tells me that she is not happy with the baby"s heart rhythm as she fixes a temperature sensor on the baby's right hand. Sinee this morning baby Mark is given extra potassium, because the levels in his blood were low. If the potassium-balance is not right the patient may get an irregular heart rhythm. Nurse A has noticed irregularities in the ECG and is keeping an eye on the monitor. The combination of the cold extremities and the irregular rhythm are worrying her, and she paces around the bed, looking at the baby and the monitor, occasionally feeling if the feet are any warmer. The extra temperature sensor and thermometer the nurse A applied, confirm that Mark's central temperature is much higher than his peripheral temperature. When nurse $B$. asks if nurse $A$ is ready for the coffee break, nurse A turns the offer down and asks nurse B to phone doctor $G$ instead. When doctor $G$ arrives he decides to do some blood tests and he orders an X-ray.

\section{Sketch 5.8 What is wrong, with Mark?, PICU}

Thus, the alertness of nurse $\mathrm{A}$ is provoked by her observations of the patient and the differences she perceives between her own sensory information and the machine information. She deals with the uncertainty in two ways: by applying more equipment and by asking for teamwork. Nurse A considers the possibility that the continuous temperature display is not correct. Therefore she places another thermometer for the central temperature and an additional sensor for the peripheral temperature. These extra measurements will also help her to back up her observations when she communicates with the doctor. In addition, she asks some other person, in this case the researcher, to confirm her observation that the 
hands are cold and she asks a colleague to contact a doctor. Intensive care nurses are quite confident that a crisis is preceded by small warnings. Therefore, they argue, it is possible to anticipate or even prevent a crisis by monitoring the patient carefully and taking timely action. When signs of an impending crisis are recognised, the nurse starts thinking about possible actions. Sketch 5.9 illustrates the important role of experience in an uncertain situation. In this case there is little technology involved in monitoring the patient. Also, there are no obvious signs that the patient's condition is deteriorating, but the nurse picks up a small clue and follows it up.

In this evening shift I meet a patient who has had his jaw reconstructed. These patients spend their first night after the operation on the ICU because they are breathing through a tube while the jaw is in a fixed position. Nurse D looks after this 18-year old who has his walkman on in bed. His face is swollen and he feels nauseous. While nurse D clears up some saliva that has dribbled onto his chest she notices some redness. She points the rash out to me and says: "I don't trust this. He could be allergic to these antibiotics." She asks the patient if he has allergies, and he scribbles on some paper that he used to be allergic to cats. Nurse D asks again if he has had allergic reactions from medication in the past, and how he normally reacts to antibiotics. He does not know and is more worried about his nausea. Nurse $D$ promises to ask for medication to take that feeling away. She approaches nurse J and asks him to take a look at the redness. He thinks it's nothing and she thanks him for his opinion. Nurse D walks over to the desk and phones the responsible ear-nose-throat doctor at home. She asks him about the nausea and about the redness, and makes it clear that she fears an allergic reaction. The doctor tells her which medication to use for the stomach, and which alternative antibiotics she can give the patient. Nurse D looks at me when she puts the phone down. I say: "So you still do not trust it?" She replies: "No, I think we should be very carefull. I've seen one patient go into an anaphylactic shock and II don't want to experience that again".

\section{Sketch 5.9 Suspected allergic reaction, GICU}

Thus, past experience is applied to the present situation, and the opinion of a second nurse is sought. Finally, the nurse presents her ideas to the doctor, who makes a decision. In this example, nurse $D$ is not reassured by the fact that her colleague sees no reason for alarm. Nurse D follows her own ideas, and it turns out that she has had a particular experience that makes her more anxious to recognise an allergic reaction early. Both examples address the desire of nurses in a vigilance phase to share their ideas with others. This use of teamwork has the same function as the enrolment of more equipment that we saw in Sketch 5.8 , namely to spread the information over more sources, so that the value of each piece of information can be assessed. The emphasis in this process is typically on the information that can be directly observed on the patient. The data that are obtained from machines can be distorted as the result of some technical failure or in-built limitation of the equipment that makes it unsuitable for use in the current situation. We also saw that the vigilance phase provides a situation in which the instruction that is given has some special characteristics. The instruction typically refers to the knowledge and experience that the nurse has built up over the years and demonstrates how a nurse selects the salient aspects of a complex situation. Thus, the vigilance phase is especially valuable for the communication of insights into the relationships between the elements of a 
situation and the ways to set priorities. It follows that other activities such as administration and provision of supplies are done insofar as they are relevant at the time and, as Sketch 5.8 illustrates, there is no time to relax.

\subsection{Conclusions}

Work in intensive care is unpredictable, but we argue that the work process is structured nevertheless. In this chapter we have presented a model of the work process that in which seven activities are identified that assume various levels of importance in the four phases of the process. Thus, while the activities of the staff are prompted by the condition of the patient, these activities form a pattern in each phase of the process. In the hands-on routine phase work is pre-structured and there is no particular activity that is pivotal. However, in the hands-on emergency phase the activity Work on equipment is dominant and this phase has special learning opportunities. The most important feature of the hands-off phase is that it allows the supply of teamwork to other nurses, while in each other phase teamwork is received. The activity Work on patient dominates in the vigilance phase, which offers an occasion for special learning. Thus, two central themes emerge from our discussion of the patterns of activities in the work process: the situational redefinition of the role of technology and the enabling character of teamwork. As we have seen, there are instances when the technology is used without hesitation. In fact, the role of the technology is unproblematic in most phases of the work process. Only in the vigilance phase the value of the information from the equipment is openly doubted. In keeping with our discussion in Sections 5.1 and 5.2, we suggest that when the image of the patient is not clear because the information from different sources does not converge, the role of the technology is called into question. The information that is observed directly on the patient is thus judged as more reliable. This set of priorities emphasises that the patient is central to the care process and that the technology is an aid. The negotiations that are involved in the process of establishing the reliability and effectiveness of the equipment are further explored in Chapter 6. The crucial role of teamwork in intensive care nursing is also taken up in Chapter 6. We argue that teamwork is an enabling activity in the work process on ICUs. The need for teamwork may arise at any time and the continuity of the care process depends to a large extent on the timely availlability of teamwork. Not all teamwork is necessarily of the life-saving kind as in the hands-on emergency phase, but there may also be organisational arrangements that require teamwork as a safety precaution as in the hands-on routine phase or uncertainties regarding the patient situation that can benefit greatly from teamwork as in the vigilance phase. Thus, the effectiveness as well as the quality of care are affected by teamwork. 


\section{Chapter 6}

\section{Working and learning}

This chapter explores the ways in which nurses learn and make decisions. These processes require the handling of information. Following the Dreyfus model of skill acquisition that was introduced in Chapter 2, we see that the practice of the individual nurse changes as the nurse gains experience as he or she progresses from "novice" to "expert". This career model provides the framework for our investigation of information handling at the bedside. As the basis for the individual decision-making process we use Argyris' model of single-loop and double-loop decision-making. This model allows us to describe the decisions made by 'novices' and 'experts' as qualitatively different processes. Thus, while the skillacquisition model describes career development and the ways of information handling that go with each stage of the learning process, the decision-making model deals with the mechanisms that govern each decision. The models thus complement each other, and they are applied to the data found in the present study in order to explore the use of technology in intensive care in greater depth. It is argued that technology can play several roles, depending on the situation as perceived by the nurse, while the nurse's assessment is influenced by his or her level of experience.

The discussion in the first half of the chapter concerns the individual nurse, as is outlined above. In the latter sections of this chapter the analysis addresses the level of the group or team of nurses. It is argued that the team as a whole has two central responsibilities: assuring the quality of patient care and providing education for nurses and junior doctors. Teamwork in the process of patient care is discussed in Section 6.5 with regard to the mechanisms that coordinate the work on an ICU. The umpredictable nature of the work and the different levels of experience within the staff are considered as complicating the coordination process. The process of education that pervades the work process in intensive care nursing is addressed in Section 6.6. Here, we first discuss the unusual position of junior doctors on an ICU and then we describe how new skills are taught to trainee nurses. This is followed by a discussion of the introduction of new technology in intensive care which presents the need for the entire team of nurses to acquire new skills. It is found that the assimilation of technology into work practice follows the learning process as described in the model. 


\subsection{From novice to expert}

'From novice to expert' succinctly summarises the model of skill acquisition that was developed by Dreyfus and Dreyfus. The model describes five stages of skill development: novice, advanced beginner, competent, proficient and expert. Table 6.1 below summarises the characteristics of each stage.

\section{Level. I: Novice}

Beginners who, because they have no experience of the situations in which they are expected to perform, must depend on rules to guide their actions. Following rules, however, has limits. No rule can tell nowices which tasks are most relevant in real situations or when to make exceptions.

\section{Level II: Advanced beginner}

One who has coped with enough real situations to note (or to have them pointed out by a mentor) the recurrent meaningful aspects of situations. An advanced beginner needs help setting priorities since she/he operates on general guidelines and is only beginning to perceive recurrent meaningful patterns. The advanced beginner cannot reliablly sort out what is most important in complex situations.

\section{Level III: Competent}

Typically, the competent nurse has been in practice two to three years. This nurse can rely on long-range goals and plans to determine which aspects of a situation are important and which can be ignored. The competent nurse lacks the speed and flexibility of the nurse who has reached the proficient level, but competence is characterized by a feeling of mastery and the ability to cope with and manage many contingencies of clinical nursing.

\section{Level IV: Proficient}

One who perceives situations as wholes, rather than in terms of aspects. With holistic understanding, decision-making is less labored since the nurse has a perspective on which of the many attributes and aspects present are the important ones. The proficient performer considers fewer options and homes in on an accurate region of the problem.

\section{Level V: Expert}

The nurse who no longer relies on an analytical principle (rule, guideline, maxim) to connect an understanding of the situation to an appropriate action. The expert nurse, with an enormous background of experience, has an intuitive grasp of the situation and zeros in on the accurate region of the problem without wasteful consideration of a large range of unfruitful possibilities.

Table 6.1 From novice to expert, as summarised in Benner and Tanuer (1987) p. 28

Originally developed in the study of aircraft pilots and chess players, this model was applied to the study of nurses by Patricia Benner. She found "much confirming and no disconfirming evidence" for applicability of the Dreyfus model of skill acquisition to clinical nursing practice (Benner, 1982). As the summary in Table 6.1 shows, the practice of nursing changes as the nurse gains more experience and knowledge. Experience, in this model, is not the mere passage of time, but is defined as "the refinement of preconceived notions and theory by 
encountering many actual practical situations that add nuances or shades of differences to theory" (Benner, 1982, p. 407). Similarly, knowledge has a particular meaning in this model, as it does not focus on theoretical knowledge, but on practical knowledge instead (Benner, 1984; Dreyfus and Dreyfus, 1986). As Patricia Benner and Christine Tanner wrote in 1987: "This study takes a practicalist tum in that what is learned in the practice by the practitioner is considered knowledge even though it contains puzzles and cannot always be fully located in the currently explicated science." (p. 14). This opens up the possibility to explore the kind of knowledge that is used when rules are not followed. When knowledge is embedded in practice and can hardly be separated from that practice, it is referred to as tacit knowledge. What the Dreyfus model and Benner"s research show, is that the expert uses tacit knowledge and intuition to assess a situation. In Table 6.2 we see that the expert has two unique characteristics: the expert takes decisions on the basis of intuition and the expert is fully involved in the situation. Thus, in the process of becoming an expert, the learner moves from analytical, rule-based thinking to intuition, and from detachment to involvement. Concurrent changes take place as the learner moves from reliance on abstract rules to use of concrete experience, and moves from perceiving the situation as a compilation of equally relevant parts to seeing the situation as a complex whole in which certain parts are relevant (Benner, 1984; Benner, Tanner and Chesla, 1992).

\begin{tabular}{|c|c|c|c|c|}
\hline Skill level & Components & Perspective & Decision & Commitment \\
\hline Novice & context-free & no & analytical & detached \\
\hline $\begin{array}{l}\text { Advanced } \\
\text { beginner }\end{array}$ & $\begin{array}{l}\text { context-free } \\
\text { and situational }\end{array}$ & no & analytical & detached \\
\hline Competent & $\begin{array}{l}\text { context-free } \\
\text { and situational }\end{array}$ & chosen & analytical & $\begin{array}{l}\text { detached understanding } \\
\text { and deciding; } \\
\text { involved in outcome }\end{array}$ \\
\hline Proficient & $\begin{array}{l}\text { context-free } \\
\text { and situational }\end{array}$ & experienced & analytical & $\begin{array}{l}\text { involved } \\
\text { understanding: } \\
\text { detached deciding }\end{array}$ \\
\hline Expert & $\begin{array}{l}\text { context-free } \\
\text { and situational }\end{array}$ & experienced & intuitive & involved \\
\hline
\end{tabular}

Table 6.2 Five stages of skill acquisition, as summarised in Dreyfus and Dreyfus (1986) Mind aver machine, p. 50

Recently, Benner and Tanner (1987) have paid special attention to the role of intuition in expert practice. They define intuition as "understanding without a rationale" and argue that intuition "appears to be a legitimate and essential aspect of clinical judgment" (Benner and Tanner, 1987, p. 23). Following the Dreyfus model, they investigate six key aspects of intuitive judgment: pattern recognition, similarity recognition, common-sense understanding, skilled know-how, sense of salience and deliberative rationality (see Table 6.3). These aspects are not separable 
in practice, but together make up the conditions for expert judgment. Expert judgment relies heavily on past experience, but this does not mean that those rules are forgotten. Benner and Tanner (1987) conclude that "intuitive knowledge and analytical reasoning are not in either/or opposition", but that they often work together.

\section{Pattern recognition:}

Similarity recognition:

\section{Common-sense understanding:}

Skilled know-how:

Sense of salience:

Deliberative rationality: a perceptual ability to recognise relationships without prespecifying the components of the situation.

the capacity to recognise 'fuzzy" resemblances despite marked differences in the objective features of past and current situations.

a deep grasp of the culture and language, so that flexible understanding in diverse situations is possible.

advanced levels of knowing how are based on embodied intelligence. The body 'ttakes over' a skill.

when one operates in a fully differentiated world where: events stand out as more important or less important, complete with nuances.

a way to clarify one's current perspective by considering how one's interpretation of a situation would change if one's perspective were changed.

Table 6.3 Aspects of intuition, after Benner and Tanner (1987)

In a study of nurses in intensive care, Benner, Tanner and Chesla (1992) found that beginners and experts "live in different clinical worlds". They relate two aspects to these clinical worlds: how the nurse deals with a particular situation and to what extent the nurse shows responsibility for the patient. "The world of the expert in this context is described as follows:

"The expert is at home managing rapidly changing situations and is able to attend to many other aspects of care that go unnoticed by the less experienced clinician."

The expert shows "a sense of agency and responsibility for the patient"s wellbeing", which is noticeable "in three major areas:

1) negotiating and managing physicians' responses to the patient situation;

2) keeping track of what's going on with the patients of less experienced nurses and augmenting the less experienced nurses' clinical assessments;

3) being responsive to and advocating for the patient and family concerns in ways that more closely match the actual needs and concerns."

Benner, Tanner and Chesla (1992) p. 26

Thus, Benner and her colleagues have described how nurses gain experience and move from one level of skill to the next. Central to this model is a particular way of learning, namely learning from experience. In this learning process the rules 
and the theoretical basis for action are formative, but their importance diminishes as the learner gains more experience. One could say that the rules have only limited value since in each situation one has to decide which rules apply, if any. Thus, there are two levels of learning: one to learn the rules, and the other to decide which rule applies under the circumstances. This is the central idea in Argyris" model of single-loop and double-loop decision-making, to which we now turn.

\subsection{Single-loop and double-loop models of decision-making}

In 1976, Argyris published an article in Administrative Science Quarterly under the title: "Single-loop and double-loop models in research on decision-making". In this article he explored the role of learning processes in problem-solving and decision-making. For Argyris, decision-making and learning are very closely related. He argues that decisions are made on the basis of information that is necessarily incomplete, and therefore feedback is needed to evaluate the effectiveness of decisions. In this feedback process, errors are detected and corrected, and this constitutes learning in Argyris' model. In fact, the feedback process to evaluate a decision is called single-loop learning. If the feedback process is extended to include not only the decision itself but also the circumstances under which the decision is taken, we speak of double-loop learning. According to Argyris, the effectiveness of learning can be increased by improving the quality of the information and by improving the participant's receptivity to feedback. In a later publication this model is extended to include a third loop that helps the participant to learn how to learn. This is called deutero-learning (Argyris and Schön, 1978). From their research Argyris and Schön conclude that single-loop learning is the most common form of learning in organisations. Since doubleloop learning involves questioning fundamental aspects of the organisation, this type of learning is not very frequent and is also not encouraged in organisations, precisely because it challenges the current situation. Consequently, deuterolearning very rarely occurs in organisations.

Looking at single-loop learning in more detail we wind that it applies to those situations where a participant works according to a rule and evaluates if the rule has been followed correctly. This does not necessarily mean that the desired outcome has been achieved, it only implies that the participant is satisfied that the procedure was done correctly and the result is as expected. If the result is not as expected, the participant will assume that the rule was not applied properly and will improve on the performance of the procedure. A totally new problem emerges when the participant cannot find anything wrong with the procedure, but has not achieved the desired outcome. This is the kind of problem that cannot be solved in a single loop, but requires double-loop learning. The participant who can initiate the second loop will ask if perhaps this particular procedure is not appropriate under the given circumstances. This requires the participant to have insight into the circumstances and to be committed to solving the problem. Thus, if the participants operate in an uncertain environment, we see that they will need the skill of double-loop learning, because the circumstances are changing frequently. This is the case in intensive care nursing, to which we now turn in order to compare the skill-acquisition model and the learning model with the data 
that were gathered in this study. Taking the above into account, the following analysis approaches the work of nurses and the role of technology in intensive care in terms of information-handling and learning.

\subsection{Information handling and learning}

In intensive care it is the staff who have the overview of the process of patient care. As we saw in in Section 5.2, nurses use direct and indirect sources of information in order to construct an image of the patient. The patient and the equipment provide direct data, whereas the information from the changeover meeting, as well as reports and charts, is indirect. These sources can produce quantitative data, such as machine readings and laboratory results, and qualitative data such as personal observations on the appearance and behaviour of the patient. Based on this information, staff must decide how to administer patient care. To do so, nurses have developed strategies in which they combine the information from several sources to make an assessment of the patient. This assessment is always temporary, and it can change easily. It guides the selection of which technologies will be used in the care of the patient.

Intensive care is characterised by complexity and unpredictability. In this kind of environment, rules and standard procedures have only limited value. In fact, professional judgment is necessary, following the arguments developed in Section 6.2 , to determine whether or not the rules are applicable. This paradoxical situation presents a problem for the training and education of newcomers to this field: while beginners need clear rules to structure their actions, they are not in a position to reflect on these rules. Also, the beginner has to learn how to make a selection from the vast amount of information that is available. Within this context, nurses have to learn to identify the relevant characteristics of the specific situation they are dealing with, taking into account the characteristics of the individual patient. At the same time they are under pressure to take timely and appropriate actions because of the critical condition of the patients.

Two abilities that are crucial to deal with the complexities and pressure of intensive care are the ability to recognise pertinent information and the ability to gain and maintain overview. Figure 6.1 shows how novices move from a situation where both recognition and overview are lacking, to the position of expert where they have both recognition and overview. Here, we follow Benner, Tanner and Chesla (1992) who, in their study of intensive care nurses, drop the category of 'novice' and assign the term "beginner' to the first group. They do so because when nurses start working in intensive care they have already qualified as general nurses and therefore it would not be realistic to refer to them as 'novices'. 


$\begin{array}{lll}\text { No recognition } & \begin{array}{ll}\text { Beginner } \\ \text { Competent }\end{array} & \text { No overview } \\ \downarrow & \text { Proficient } & \\ & \text { Expert } & \text { Overview }\end{array}$

Figure 6.1 Development of recognition and overview

In the present study a four-stage model was developed to illustrate how the capacity to handle information changes as the learner progresses from beginner to expert. This model is presented in Figure 6.2 below.

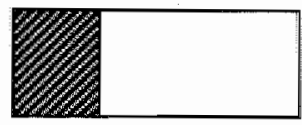

Beginner

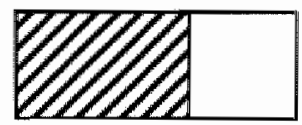

Competent:

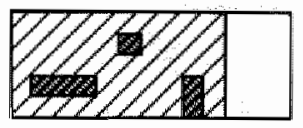

Proficient

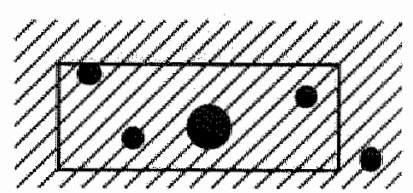

Expert

Figure 6.2 Information-handling and the learning process

In each of the four stages the box represents the information available and the shaded area indicates how much of the information the learner can handle. The density of the shading indicates how much attention is paid to each unit of information: the dense shading represents a high level of attention and the lighter shading represents a lower level of attention. We discuss each stage in turn.

Figure 6.3 Beginner

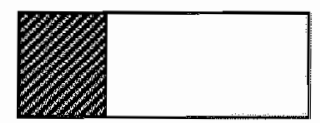

The beginner can only handle a small percentage of the information, and only in the particular order that the rules prescribe. The separate bits of information are treated as being equally important as the beginner has no insight to distinguish between more or less important information. In Figure 6.3 this situation is represented by a densely shaded area that covers only a small area of the total information box. Following the rules is an aim in itself, and the beginner concentrates on one patient and one task at a time. Regardless of changes in the circumstances, the beginner sticks to the protocols and believes that these provide the guidance for action. Benner quotes an expert nurse in an intensive care nursery who describes a beginner at work: "If I said, you have to do these eight things ... they did those eight things, and they didn't care if their other kid was screaming its head off. When they did realize, they would be like a mule between two piles of hay" (Benner, 1984, p. 24). In terms of the learning model, a beginner can only handle feedback that applies directly to the protocol that is being followed. 
Figure 6.4 Competent

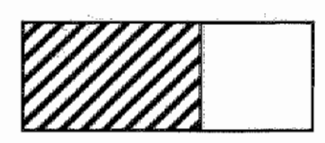

The competent nurse is trying to achieve goals. As Figure 6.4 shows, the competent learner can handle a larger portion of the available information than the beginner and does so in a qualitatively different manner, as is indicated by the less dense type of shading. Information is gathered as part of a plan, so that information directly related to the plan has higher priority than other information. The plan can be adjusted, and then a new assessment will have to be made of the information needed. The challenge is to make a plan that will take care of the unexpected. Further protection against surprises can be organised by collecting large amounts of data and frequent checking of the situation. Thus, feedback takes place mainly within the context of the plan, but the plan itself can also change.

Figure 6.5 Proficient

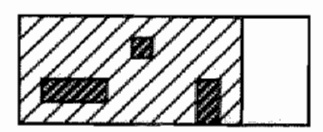

The proficient nurse utilises most of the available information and has the ability to focus on important areas, as is indicated by the darker areas within the shaded area in Figure 6.5. What the image cannot show, is that a change in circumstances is recognised quickly by the proficient nurse and this is accompanied by a shift in priorities. Rather than relying on a plan or checklist, the proficient nurse reads the situation and takes this reading as the starting point for action. Thus, the priorities are not directly guided by a plan, but they are considered more relevant in the given situation. At this stage, the nurse uses double-loop learning as he or she evaluates both the actions and the situation, and a change in situation leads to a change in action.

Figure 6.6 Expert

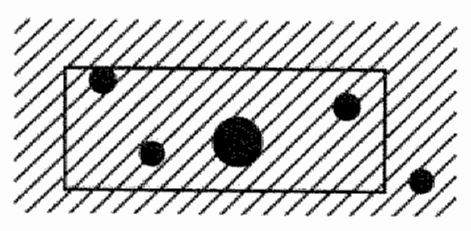

The expert is aware of the potential information about more than one patient situation. From this position of overview he or she can zoom in on pertinent aspects. This is illustrated in Figure 6.6, where the shaded area exceeds the initial box of available information and the black dots represent the salient information. As Benner et al. put it: "Important aspects of the situation simply stand out as salient, while less important aspects stay in the background." (Benner, Tanner and Chesla, 1992, p. 25). It is typical for an expert to monitor all these important aspects, thereby also keeping an eye on the work of less experienced nurses. This characteristic has already been noted in chapter four: "Experienced and critical nurses construct a comprehensive image of the circumstances (..). They make a 
quantitative and a qualitative assessment about the patients and about the staff." The expert is working on three levels: performing patient-care actions, assessing the patient situation and assessing how other nurses cope. Thus, the expert uses a form of deutero-learning as he or she uses knowledge about the levels of learning and experience of other members of the team. Essential in this process is that the expert nurse has acquired tacit knowledge from years of experience and learning. In this position the expert can quickly grasp a complex situation and oversee the possible consequences. This is illustrated in Sketch 6.1 below.

The expert has a feel for the problem and is confident that her interpretation of the situation is based on the relevant aspects. In addition, the expert sees the problem as part of the patient. This is how an expert described what her considerations were when she saw a particular baby for the first time in the medium care unit:

"I saw this baby and he was very pale and lying very still on his side. I felt his arms and legs and they were very cold and looked marbled. The body felt warm. I offered the child a dummy, but he had no interest in it. I asked the other nurses if this child was always so still and they said he was a very quiet child. When I asked about the cold extremities they said the child had never been very warm, but today he seemed colder than normal. I took his temperature and it was 39.8. I had enough clues to suspect that the child was going into shock and I made sure that a blood test was done. It showed that the blood was going sour.

In putting together a picture of the situation, the nurse sees something that is not right: a pale and still baby. Yet, she asks around to find out if this is normal for this particular child. Upon closer inspection she decides that the condition of the child is outside the normal range altogether, regardless of the peculiarities of the behaviour of this child. She switches from foreground to background and uses various levels of consideration, and decides further tests are needed to confirm her diagnosis and to support the treatment. In her story she skips over the negotiations that must have taken place with the doctors in order to get a blood test performed, but she mentions the confirmative result and moves on to her next worry.

"My next concern was to find a place for this baby on the high care unit where we would have the possibility to ventilate it. I was anticipating that if the antibiotics that we had just started did not catch on very quickly, this child would be so busy fighting the infection that he might well forget to breathe. He would just be too tired and he could do with the support from the ventilator."

The nurse stresses that anticipation is crucial to good patient care. She has seen situations like this many times before and knows how quickly this situation can turn into a crisis. The way she tells the story reflects her concern for the patient and she describes how the body of the patient will deal with the challenges of fighting the infection. While she could have said "I expected the patient to develop a respiratory deficiency" she says instead that the child "might well forget to breathe" and be "too tired" so that help should be offered by means of the ventilator.

\section{Sketch 6.1 Expert practice}

What this illustration makes clear above all is the involved and intuitive nature of the expert's decision-making. The head nurse tells her story in a way that makes her feelings explicit. These feelings are not of an emotional nature, but are in the 
first place professional as they refer to the responsibility of the nurse to achieve the best possible outcome for the patient. There are clearly some rules involved in her decisions, but it is largely on the basis of experience that the head nurse decides that a crisis is imminent. In order to make this decision, the nurse only needs a few clues that she reads directly from the patient. Yet, before she decides, she considers if the patient's behaviour is different from his normal behaviour. Although the other nurses confirm that this patient is not behaving out of character, the head nurse decides to check the temperature. She follows her hunch and finds her premonition confirmed. Thus, rather than following the rules or detailing a plan, the expert nurse uses her intuition and collects the salient information on that basis. The same situation would have been treated differently by a beginner, a competent or a proficient intensive care nurse. We will explore this idea further with regard to the four phases of the work process that we discussed in Chapter 5. These phases are: hands-on routine, hands-on emergency, hands-off and vigilance. As we have seen, the phases hands-on routine and hands-on emergency as well as hands-off apply to situations that are clear and predictable. Hands-on refers to those situations in which the nurse has to act or intervene. Whether this intervention has a routine character or an emergency character, it is quite clear for the staff what should be done. In the hands-off phase it is clear that there is no reason for interventions and that other tasks can be done while the equipment monitors the patient. The vigilance phase is fundamentally different from the previous two phases as it is characterised by uncertainty and heightened alertness. There are no explicit rules to guide the action in this phase.

As we have seen, nurses act in ways that are related to the level of skill they have achieved. Thus, a beginner can only deal with clear rules and is thus unable to perform well in a situation where the rules are not clear, or where rules are necessarily absent. Because the beginner both lacks insight and overview, he or she will be comfortable in a routine hands-on or hands-off situation and will be inclined to define each situation as a routine situation. The competent nurse will try to achieve the goals of the plan. This takes up most of their attention, and since the nurse has little experience of different situations, he or she is not in a position to recognise where vigilance applies. The proficient nurse is more at ease with the changing demands of the situations and uses past experience to assess the changes. At this level, the nurse has enough overview to recognise when a situation is changing from an unambiguous one to one characterised by uncertainty and can thus can recognise when the vigilance phase is at hand. The expert is capable of handling ambiguous and unambiguous situations and has the ability to recognise early signs of change. This is essential since the Vigilance phase often has the character of searching for a problem before it arises. The expert needs a few clues and can decide that 'something is not right' on the basis that 'it does not look right'. In other words, the expert may recognise an imminent problem when other nurses would not. Thus, the level of skill indicates the range of options a nurse has to assess a situation.

In Section 6.5 we discuss the consequences that the differences in levels of skill have for the functioning of a team of nurses in intensive care. However, we first take a closer look at uncertainty in the intensive care unit. In particular, we discuss how nurses deal with uncertainty and what the role of technology is in this process. Does the use of technology reduce uncertainty, and how? Or can the use of technology add to uncertainty, and how do nurses then deal with the extra 
uncertainty? These questions are discussed in the context of the models of the work process and levels of skill.

\subsection{Roles of technology}

In Chapter 5 we have seen that the medical equipment at the bedside performs a function and monitors its own performance, but cannot intervene when it detects an error. Moreover, there is always the possibility that a machine will produce unreliable information or that it will perform its function in an ineffective way. When this is the case, the machine adds to the uncertainty of the situation. Working with technology thus requires scepticism and alertness at all times. It is a task of the medical and nursing staff to assess the value of the machine information and to decide how this affects the definition of the situation. We can say that in the hands-off phase the technology is trusted to perform its functions while supervised from a distance. The nurse expects to be alerted to problems by the alarm of the machine. In a hands-on routine situation a similar expectation exists, but in the hands-on emergency the perspective is different as the appropriateness of the machines in use is re-assessed. A similar situation with regard to the degree of trust that is placed in the machines and the choice of the most suitable piece of equipment exists in the vigilance phase. During this phase a search is under way to determine what problems exist and what their origins are. In this situation, the nurses' distrust of the bedside equipment becomes explicit. In this study, two strategies have been identified that nurses use to deal with the uncertainties that are related to the use of technology. The first strategy is to question the reliability of machine measurements. This strategy is illustrated below with the example of the electronic monitor. The second strategy is to question the effectiveness of the machine action. The example that is used here to illustrate the second strategy is the ventilator. For each strategy it is essential that an alternative technology exists which can help to confirm or refute the impression of the nurse and which can replace the machine function, at least temporarily. The substitution of one technology for another is the main issue in the following examples.

\section{Questioning machine reliability: the case of the monitor}

The machine central to automated patient monitoring is the electronic monitor which measures and displays continuous quantitative information about the patient. It is connected to the patient by means of cables. This cable transfers signals that are measured on the patient's body to the screen where they are displayed. The signals from the patient are picked up by a number of sensors that have been positioned on the skin and fixed with adhesive labels. The monitor provides continuous data about the situation of the patient, displayed in graphical and numerical form. The electronic monitor measures and displays relevant parameters such as the frequency of breathing, the electrical activity of the heart, the heart rate, oxygen levels in the blood, blood pressure and temperature. The doctor decides on the acceptable levels of these parameters, and the monitor is set up in such a way that the alarm is triggered when the measurements for one or more parameters exceed the limits. Several of the parameters that are measured continuously by the monitor can also be measured by hand, using a stethoscope, a 
blood pressure gauge or a thermometer, or, in the case of breathing, by watching, counting and timing.

The graphs and numbers generated by the monitor are considered very important in intensive care. The monitors are positioned in such a way that the screens can be seen from many angles on the ward. This information is, however, treated with great caution. For an outsider it is difficult to make sense of the reactions of the nurses upon changes in the parameters on the screen. Sometimes alarms are not considered important and are silenced by the nurse, sometimes only a small change in one of the parameters causes the nurse to be more alert. How much value is attributed to the machine information is the outcome of a process of negotiation between the nurse or doctor and the equipment. We will concentrate on these negotiations and refer to this particular strategy as questioning the reliability of the machine information.

The first reaction of a nurse when an alarm signal sounds from the monitor is to establish what kind of alarm it is. Most monitors have two or more alarm signals; one is moderate and the other is loud and irritating. The moderate alarm indicates that the machine has detected a problem with its own operation, for example a measurement problem because one of the sensors is disconnected. The loud alarm indicates that a measurement has been received from the patient that is outside the acceptable range. Even then the nurse has to make sure that the reading was correct. If the graph appears unreliable, then the numerical values for that parameter are disregarded.

This first check is done very quickly and practically at the same time as the second check, which is to look at the patient for signs that confirm or deny the reading on the screen. There are many parameters that can be read directly off the patient, albeit with less accuracy than when it is displayed by the machine. Blood pressure is one such parameter that can be read off the patient. The quantitative information from the machine is checked against qualitative information from the patient. The nurse makes an assessment of the colour of the patient's skin and can thus discriminate between an extremely high or low pressure, or a fairly normal one, depending on whether the patient looks red, pale or pink respectively.

Almost simultaneously, the nurse combines the machine reading with other data about the patient, to see if it fits the general image. For each patient the staff have an idea of what the likely and unlikely developments are. The individual characteristics of the patient are taken into account, for example what the normal appearance is and what medication the patient is on. By comparison with the data from other sources, the machine measurement can be labelled as more or less likely to be reliable. If doubts persist on the reliability of a machine measurement, it can be repeated by a manual method.

An example of a machine measurement that is often unreliable is the frequency of breathing. This has to do with the way in which the machine measures. Because the readings are taken from electrodes on the skin, all that is measured are the movements of the chest. This means that the location of the sensors can be such that they do not register abdominal breathing. Often the machine will indicate that breathing has stopped, when it is clear from direct observation that the patient is breathing. A simple solution is to relocate the sensors. In situations where it is particularly important to establish an accurate frequency of breathing, we see that the nurse counts the breaths while looking at the patient and using a watch. This 
method can also provide additional information that the machine cannot produce, as the nurse can distinguish between shallow and deep breathing and whether it is comfortable or distressed, adequate or not.

With blood pressure the situation is slightly different. When the pressure is measured in an artery, there are many technical reasons why the result could be unreliable. If the probe is, for example, located against the wall of the artery, it cannot measure properly. Often, it helps to change the position of the limb in which the probe is inserted. The colour of the skin and the behaviour of the patient can indicate that the blood pressure is extremely high or low. A measurement can also be taken by the nurse using a "conventional" blood pressure gauge, with an inflatable band around the arm of the patient. Even then, the first reading is usually disregarded and the second one is used for the record.

Thus, the information offered by the machine is perceived to be of only limited value and has to be interpreted and checked against other sources of information. Indeed, the information that nurses get from the monitor is partial at best. The nurses use their knowledge and experience to determine when to act on a machine measurement, when to ignore it, and when to confirm it with a manual method.

\section{Questioning machine effectiveness: the case of the ventilator}

The second strategy employed by the nurses to deal with uncertainties that are related to the use of technology focuses on the effectiveness of machine action. To illustrate this strategy we will explore the alternative technologies for positive pressure ventilation and their use in the practice of intensive care nursing. On the ward, ventilation is normally carried out by computerised ventilators, working 24 hours a day for the patient. The alternative technology is the manually operated balloon, which is also known by the trade names Ambu bag, Jackson-Reese or Waterset. The strategy of questioning machine effectiveness is illustrated by the decisions and considerations involved in the temporary replacement of machine ventilation by manual ventilation.

Ventilators are machines that are used to assist, regulate or take over the breathing activity of the patient. The present-day computerised ventilating equipment can be operated in several ways and enables the staff to ventilate the patient in an effective and comfortable manner, while reducing the risk of damaging the lungs. In the Netherlands the ventilators are operated by intensive care nurses. It is the responsibility of the doctor to prescribe the type of ventilation and the settings of the machine. The nurses check the machines and monitor how the patient is doing, looking for signs of distress. Patients generally receive mechanical ventilation via the machine, but there are occasions when the staff performs the ventilation function by hand. For every ventilator there is also a manual set ready for use at the bedside. This raises the question why a manual method would be used when a sophisticated machine is available.

While the ventilator is a complicated (and often computerised) piece of automated equipment, the manual set consists of a black balloon on a tube, with a connection for the gas outlet and a connection to the patient. The function of both technologies is to bring oxygen into the lungs of the patient. The pressure and the frequency with which this ventilation should take place is determined by the situation of the patient. A number of parameters must be monitored during the ventilation, most notably volume, oxygen levels, flow, pressure, inspiration and 
expiration times. The automated ventilator measures and displays these parameters, often in graphical form. The ventilator, like the monitor, works with acceptable parameter levels, and the machine gives an alarm signal when the measured levels are outside the set range. The manual alternative technology, the balloon, has none of these options, and the monitoring is done by the nurse or doctor operating the balloon. In this process the operator relies on direct observations of the patient and combines these with the information on the screen of the electronic monitor.

To begin the manual ventilation, the automatic ventilator is disconnected from the patient and replaced by the balloon. The balloon is inflated with oxygen from the gas outlet and this is squeezed out of the balloon and into the patient. This requires considerable skill and practice, as the nurse has to make an estimate of the frequency and the pressure he or she is delivering to the patient. The airflow and the percentage of oxygen are regulated at the gas outlet. The air pressure that is delivered to the patient is determined in part by a valve on the balloon and in part by the way in which the balloon is squeezed. A squeeze can be quick or slow, delivering the contents of the balloon rapidly or gradually. In addition, the balloon can be filled partly or fully. The frequency is thus regulated by the nurse and appears on the electronic monitor.

There are several reasons for applying manual ventilation. It is often done as an intervention, or it is initiated as a diagnostic procedure, or it can be initiated when a machine is temporarily unavailable. In general, machine ventilation is replaced by manual ventilation when there are signs that the patient is not doing well on the machine. At such times the patient is restless and often working against the machine instead of cooperating. This situation is often characterised by alarm signals from the automated ventilator and from the electronic monitor.

The principal reason for applying manual ventilation is to bring the blood oxygen levels up to normal. This is the intervention aspect of manual ventilation. It raises the question why the nurse is or would appear to be more effective at doing this than the automated ventilator. Part of the answer to this question lies in the way in which the nurse delivers the air. One factor is that usually $100 \%$ oxygen is delivered with the balloon, a percentage that is hardly ever given by the machine. Also, the pressure with which the air is moved is usually higher with the balloon than with the machine. So, the higher oxygen level and the greater pressure account for part of the effect. In addition to this, the nurse observes the patient and can time the delivery of oxygen according to the patient's need. By looking at the patient, the nurse sees when the patient wants to take the next breath and acts accordingly. In this way a joint effort of breathing and support is achieved, whereas the machine is less effective at delivering on demand. Modlern machines do have a 'trigger' option that gives the patient a flow of air when he or she starts to breathe in, but this option is far less flexible than the manual method.

Manual ventilation is also used when the breathing effort has to be synchronised with some other activity. This is essential in acute situations, when the resuscitation is performed by two members of staff. One staff member is in charge of the cardiac resuscitation, while the other is in charge of the oxygen supply to the lungs. A less dramatic situation where synchronisation is important is when serious blockage of the lungs is removed by the nurses through compression and suction. In this case the inspiration is assisted by the balloon and the expiration is assisted by external compression of the lungs. 
The second most common reason for applying manual ventilation is to help the patient to feel more comfortable. During this procedure the nurse gets information about the patient. This is the diagnostic aspect of manual ventilation. By taking over the machine ventilation, the nurse can often find out why the ventilation was not effective. The nurse gathers information about the patient using all possible means. When squeezing the balloon, the nurse can feel the resistance that has to be overcome to get air into the lungs and can see how the lungs respond to the intervention by watching how the chest moves and if both sides react in the same way with each inspiration and expiration. Listening is also important, as the balloon amplifies the sounds from the lungs: a distinct rumbling can be heard when a blockage is present. Another nurse can be asked to listen with a stethoscope to the sounds of each lung separately. Smell can also be brought into the assessment. In other words, the manual ventilation allows the nurse or doctor to develop a feel for the respiratory problems of the patient. By gathering information in a direct manner, the clinician is in a position to construct an image of the breathing problem and can picture the scope and the location of the problem inside the patient.

Thus, we have seen that the technology is limited, as the machine monitors its own operation but does not monitor its effect on the patient. The nurses are in charge of ensuring effective operation of the machine, and this may result in them temporarily taking over the ventilation by hand. They can respond to the patient's needs better in this way, because they can see the reactions of the patient and adjust their actions immediately. While doing this, they are reading the relevant information directly from the patient, making little use of the surrounding equipment. In this way they gather the diagnostic information they need to find out why the mechanical ventilation was not effective. Similarly, in the case of the monitor, nurses gather information from different sources and will enrol alternative technologies in order to get a reliable picture of the situation. Thus we can conclude that both strategies are based on the same method, namely triangulation. This involves the combination of information from different sources to reduce the level of error that can be inherent to the use of a single source. When in doubt, the nurse relies on observations that result from direct contact with the patient and will try to draw upon other information in accordance with these observations. Sources of error are eliminated by a process of comparisons between different sources of information. One piece of equipment is replaced by another to see if the readings are the same, one type of measurement is replaced by another to compare the outcomes. In this way, errors can be traced and recognised as being caused either by failure of the equipment or by the wrong choice of method.

\subsection{Teamwork in patient care}

So far in this chapter we have explored the behaviour of individual nurses in relation to individual levels of skill and levels of uncertainty in the work process. Now we turn to the dynamics that are at work at the level of the group. Here we distinguish two types of collective responsibility: to assure the quality of patient care and to educate nurses and junior doctors. As we have seen, the work practices of nurses can differ, and this work takes place in an environment that is 
inherently complex and unpredictable. It is therefore all the more interesting to analyse how a whole group dealls with this. First, we look at cooperation and coordination with respect to quality and continuity in patient care using cardiopulmonary resuscitation (CPR) to illustrate cooperation in an emergency situation. This is followed by a discussion of models for group learning and team building. The issue of learning in groups is further explored in Section 6.6, where an analysis is presented of the process by which a trainee nurse is taught a new skill, in this case manual ventilation. Section 6.6 also addresses the introduction of two new technologies on an ICU: mechanical ventilation in the 1960s and ECMO in the early 1990 s.

\section{Cardio-pulmonary resuscitation}

Cardio-pulmonary resuscitation (CPR) is always a team effort. It is also a multidisciplinary effort, in which often a medical doctor and an anaesthetist are in charge. When a patient on the intensive care unit enters a crisis, the nurses are the first ones to start the resuscitation procedure. During this procedure they work closely together on the patient. This is illustrated in Sketch 6.2.

The patient has a very low blood pressure and an irregular and ineffective heart action. One nurse removes the headboard of the bed so that he can stand behind the patient's head to provide manual ventilation. The ventilator is disconnected and the balloon is put in place. The ventilator starts beeping and is switched off. The nurse fills the balloon with oxygen and starts squeezing it. Meanwhile the other nurse stands next to the bed and measures where to apply the pressure for heart massage. When he starts pressing on the chest of the patient, we see on the monitor how the blood pressure responds. A beautiful curve appears on the screen, but when the nurse stops pressing the curve disappears again. The patient is not responding. They keep trying: ventilation and massage in synchronisation. Separate activities that can only produce a positive outcome if they are coordinated and supplement each other. Communication is minimal as each knows the routine and each can see how the patient responds.

\section{Sketch $6.2 \mathrm{CPR}$ on the GICU}

Neither of the nurses can leave the patient, and so the resuscitation involves a third nurse to fetch medication, draw up syringes, connect IV drips and phone for the doctor. Doctors can play either active or passive roles in resuscitation situations, depending on how they see their role and how experienced they are. Since the doctor is in charge of the resuscitation effort, he or she has to decide on the interventions that are required, which medication is appropriate, how it should be administered, if the effort is effective and when the effort can be terminated. During the CPR, other nurses on the ward are extra alert to calls for assistance. They will also attempt to minimise the distress of other patients who may be aware of what is going on, and often they will ask visitors to leave the ward.

Thus, a resuscitation effort requires at least two people at the bedside who are synchronising their actions, but it also requires the support and cooperation of the other staff. We have stressed the need for teamwork in Chapter 5 and here we review two theoretical models that address group dynamics and cooperation to see how they fit the situation of intensive care nursing. 


\section{Learning in groups}

In the literature on group effectiveness (see for example Tyson, 1989; Johnson and Johnson, 1991) it is assumed that a group as a whole goes through a learning cycle. One widely used model of learning in groups is the 'experiential' learning cycle developed by David Kolb which uses the principles that were put forward by Kurt Lewin in the 1940s. The Kolb model consists of a cycle with four steps. The first step is concrete experience (CE), which is followed by reflective observation $(\mathbb{R O})$. The third step is abstract conceptualisation (AC), leading to the final step known as active experimentation (AE) or active programming (AP). After the last step, the group can move on to a new round of the cycle based on concrete experience.

It is difficult to see how this model fits the groups of nurses in intensive care. Teams of nurses change. Their composition is not stable over time, and in addition the composition of the groups that work the same shift are changing all the time. This means that there is little opportunity to develop one method of working for the whole team. Mintzberg (1979) offers a different model of coordination mechanisms in organisations. The simplest and most direct coordinating mechanism, according to Mintzberg, is mutual adjustment, which relies on informal communication. Because it is the most direct form, Mintzberg claims that it is also "the only one that works under extremely difficult circumstances" (Mintzberg, 1979, p. 3). Indeed, in this study we have seen that this mechanism is crucial to the effectiveness of an ICU, where details of the situation are exchanged between the actors and where uncertainties are discussed. In Mintzberg's analysis 'direct supervision' is the second coordinating mechanism and refers to the structure that gives one person the responsibility for the work of others. This mechanism has little relevance for intensive care, as we have seen. The remaining three mechanisms of coordination in Mintzberg's theory are all forms of standardisation: standardisation of work processes, standardisation of outputs and standardisation of skills. Mintzberg (1979) argues that in some situations the work or the output cannot be standardised, so instead the worker is standardised. The 'standardisation of skills' happens largely before the worker joins the organisation in the process of training and education. The combination of 'mutual adjustment' and 'standardisation of skills' appears to apply to intensive care nursing.

In the case of intensive care nursing, much of the training takes place in the work setting. This means that the practising nurses have direct influence on the skill-acquisition process and can thus shape the ideas and attitudes of starting nurses. 'Standardisation of skills' thus controls and coordinates the work indirectly by implanting skills, norms and values into the new workers, so that they know what is expected of them and what they can expect of others. An important insight that is communicated to beginner intensive care nurses is that in this setting great dependency exists, so that nobody can successfully work alone. Therefore, nurses are socialised into working together and into feeling responsible for the quality of patient care in general and not just for their own patient. This is not to say that nurses are stimulated to become emotionally involved in the patient situations. Rather, the development of a professional attitude involves learning detachment so that a distance is maintained that allows the nurse to work effectively. The emphasis is on maintaining a constant high quality of care 
for all patients. Deep personal involvement in one patient situation is considered counter-productive in two ways: it puts emotional strain on the nurse in his or her private life and it can diminish or even threaten the care for other patients.

Thus, work in intensive care is indirectly coordinated through the standardisation of skills and through mutual adjustment. Since beginners learn their intenisive care skills in the work environment, they are also immersed in the norms and values of the seting. This training system requires that experienced nurses educate beginners at work, thus combining patient care with communication of knowledge. We will investigate this process in the following section.

It is characteristic of the intensive care environment that these situations occur frequently and that it is impossible to predict when. On the other hand, the planning of the roster should ensure that emergencies can be dealt with, and that a certain level of staffing is assured. Thus, emergencies are unpredictable, yet they are planned for. In Chapter 5 we already mentioned the qualitative and quantitative aspects of the staff roster. As we have seen in that chapter, one of the skills that is developed over time is the capacity to gain and maintain overview and to recognise pertinent information. Utilising many sources to compose and adjust an image of the patients and of the situation on the ward, the expert can anticipate problems. By implication it is the responsibility of the more experienced nurses to use this capacity and anticipate where problems are likely to arise. While less experienced nurses are absorbed in performing the tasks that have been given to them, the expert can assess where this is not adequate. When the beginner cannot cope with a patient situation, the expert will see this and intervene. Thus, it is often the case that a beginner does not even have to ask for help. On the whole, it seems that little verbal communication is needed in order to get the work done. For the team to perform effectively, the actions of the nurses have to be coordinated. This need for coordination is complicated, however, by the highly individual ways of working and the complex and changeable nature of the environment. We have seen that nurses develop a way of working and reasoning in which each situation is perceived as a whole, and in which some aspects are of crucial importance.

Yet, the images that individual nurses have of the situation can differ. With regard to the discussion about learning in loops, it is difficult to see how nurses can question the relevance of a set of norms and values in a particular situation, and yet without much discussion reach the same conclusions.

\subsection{Education at work}

Learning a craft such as intensive care nursing requires a considerable amount of practice and watching other people at work. Since the learning opportunities are provided by the qualified intensive care nurses who work on the ward, education is an important part of the work of experienced nurses. They provide this instruction as a separate activity through explicit guidance and explanation, but also as an integrated part of their work by providing a running commentary on what is happening. When trainees are present on the ward, we often see the experienced nurses explaining during the course of an activity what they are doing, what the problem is, what it normally looks like, which signals and 
reactions are important, how it can go wrong and how to remedy it, in which order to do it or what to prepare for it. Thus, the experienced nurses combine the rules and the practical aspects of actions in their explanation. Gradually, the learner will become able to answer questions about the procedures and demonstrate the skill in an uncomplicated setting, and ultimately the learner is expected to perform and explain the action. Thus, the interaction with the learners on the ward keeps the experienced nurses informed about the progress of the learners. Therefore, the experienced nurses are in a position in which they understand the learning process and they are aware of the way in which the learner perceives the situation.

\section{Educating doctors and nurses}

In the practice of intensive care, trainee nurses and junior doctors (interns) are in a similar position to the extent that they both lack the skills and the insights to operate effectively in this environment. The experienced nurses are instrumental in the education of interns as well as nurses. For junior doctors this is a difficult situation because they carry formal responsibility for their decisions and can give orders to the nurses. The trainee nurses are under less pressure as they have the status of learners and are exempt from a number of responsibilities. Although this chapter deals primarily with the education of nurses, we will briefly look at the relationship between doctors and expert nurses. We have already seen that expert practice is characterised by "a sense of agency and responsibility for the patient's well being" (Benner, Tanner and Chesla, 1992, p. 26). This means that the expert nurse will use his or her image of the patient situation to assess new actions. There are numerous examples of situations where nurses have told junior doctors that a planned course of action would be harmful for the patient. On the whole, the relations between the senior medical staff and the experienced nurses is such that the judgment of an experienced nurse is trusted by the senior staff. Often junior doctors are told that they can learn a lot from listening to the expert nurses. Both the expert nurses and the senior doctors share a concern for the patient that is stronger than their urge to follow the rules. In this situation the nurse has an effective method to guide a junior doctor to a better decision. In cases of disagreement, the junior doctor is usually referred to his or her boss to get support for the suggestion. This has the important consequence that the responsibility for the decision is acknowledged by a more senior doctor. Of course, doctors can make mistakes, and especially doctors who are not familiar with a particular group of patients may overlook aspects that are obvious to the experienced nurse. A nurse in neonatal intensive care told me:

"We had this new doctor and she had no idea about premature babies. She prescribed this dosage of morphine that was ten times too high. I refused to carry out her request. She got mad and started shouting that she was a PhD and I was only a nurse. I told her that if we gave this dosage to the child it would be dead before I could withdraw the needle. I urged her to consult a senior neonatologist first, but if she insisted in giving this dosage she would have to do it herself. She was outraged."

It is not uncommon for nurses to offer the mistaken doctor a choice: "Either you phone your boss or I'll do it for you." Putting the interest of the patient first may require the nurse to enter into a conflict situation. However, there are many 
instances where junior doctors acknowledge that they can learn a lot from experienced nurses and attentively listen to their advice. Other authors have also reported this phenomenon. Berner (1975), Strauss (1975), Marcus (1989), Zussman (1992) and Wolf (1989) all provide examples of situations in which nurses coach, explain or teach junior physicians the practical skills they need in an ICU. Calculating IV drips and prescribing medication are among the skills that nurses train doctors in. This is ironic since nurses are not authorised to prescribe medication themselves. However, since the nurses monitor the overall condition of the patient, they are the ones who have to deal with medication errors. Wolf (1989) found that nurses "seemed to value their role in medication administration above other responsibilities" (p. 162).

\section{Elements of learning}

Practical and technical skills are essential to everyday work in intensive care. In this section we analyse how a trainee learns a new practical skill: manual ventilation. On the basis of my observations and interviews I suggest that five elements are important in the process of learning this skill: basic principles, "dry runs', watching others, instruction at the bedside and practice at the bedside under supervision. The basic principles of mechanical and manual ventilation are taught in the classroom during the periods of theoretical instruction. Here, the nurses learn about the breathing process and its complications, about calculations for parameters such as volumes, flows and pressures and about different modes of ventilation. On the ward, a learner is initiated in the practical side of ventilation, and this is done gradually. The first step is the 'dry run' and is illustrated in Sketch 6.3 below.

A trainee practices the manual ventilation technique when the ward is quiet. She prepares a Jackson-Reese and connects a disposable glove to the outlet that normally leads to the patient. To this system she connects a pressure gauge. Each time she squeezes the balloon, the pressure gauge shows how the pressure inside the glove changes. In this way it is easy to see how with a slow squeeze the pressure builds up slowly and can be maintained for a while, whereas the same volume can be given quickly, with one fast squeeze, and then causes a quick peak in the pressure.

\section{Sketch 6.3 'Dry run'}

As we have seen, manual ventilation can be applied for a number of reasons. It is often required in intensive care and thus there are many opportunities for the trainee nurse to observe the procedure without getting involved. Watching others perform the procedure is an element in the process of learning to deal with manual ventilation. A further step in the learning process is instruction at the bedside with the experienced nurse manually ventilating the patient while providing a running commentary for the trainee. Sketch 6.4 describes how the more experienced nurse introduces the aspects that must be monitored during manual ventilation.

More experienced nurses were sometimes seen on the ward explaining the different methods of manual ventilation, describing the different effects and the circumstances under which each method was more appropriate. This explanation would be continued at the bedside, where the more experienced nurse would disconnect the 
patient from the ventilator and explain how she established the most suitable method of manual ventilation. The trainee would be invited to listen carefully to the noises that were produced during the manual session; an aspect of feedback that the gloveand-gauge method could not provide. Other technologies would be involved, most notably the monitor where the frequency of breathing as well as the llevel of blood oxygenation and the heart action could be seen. The most important contribution of the bedside instruction was the opportunity to study the reactions of the patient. The more experienced nurse would point out that the pattent is the best source of information when you want to judge the effects of manual ventilation. The principal clues to look for are the colour of the skin and the movements of the body, especially the chest, and facial expressions. When a more experienced nurse ventilated a patient, she provided a running commentary of her findings for the trainee, explaining what she expected to find and why, and how that differed from the actual findings.

\section{Sketch 6.4 Explaining manual ventilation}

The last step in the learning process involves the trainee applying the knowledge about manual ventilation to the patient, under supervision of an experienced nurse. The trainee then has to combine his or her theoretical knowledge of the basic principles with his or her practical knowledge of how it feels to deliver a certain pressure, what it sounds like when the lungs are clear, how the chest of the patient moves and what that means, what the reactions of the patient indicate and what the monitor adds to that. The presence of a more experienced nurse ensures that the patient will receive the necessary care as the expert will intervene to prevent a dangerous situation arising. The trainee is thus reassured that he or she is not alone and responsible for the patient, but can instead concentrate on this specific procedure. Gradually, the proximity of the experienced nurse is decreased and the learner's responsibility increases. The process of learning a new procedure is concluded with a demonstration by the trainee, who then receives a note on the list of required procedures to the effect that he or she has mastered this procedure and can be considered capable of performing this procedure unsupervised. Of course, learning continues after this, as only the basic form of the skill has been acquired, and a process of further refinement begins.

Thus, in the learning process several elements can be distinguished. While the basic principles are initially taught in the classroom, the rest of the learning takes place on the ward. Instruction involves the use of artificial situations such as the plastic glove and the pressure gauge, but also takes place in real patient situations. We have noted that the context in which instruction takes place, the ward, provides the learner with impressions of the procedure in use. The fact that the trainee sees other nurses using the procedure is of help in the learning process. On the one hand it is reassuring for the trainee to see that other nurses are performing the procedure without many problems, while on the other hand the trainee gets more insight into the contexts in which the procedure is used. Thus, familiarity with the procedure is enhanced by indirect contact, by watching others use it. In the next section we see that a similar mechanism applies to the introduction of new technologies.

\section{Dealing with new technology}

As we have seen in Chapter 5, nurses find the rate of change in intensive care attractive and they mention the opportunities to learn as an appealing 
characteristic of intensive care nursing. The introduction of new technology offers such an opportunity for learning. Here, we look at two technologies that at the time of their introduction were new to the nurses in the group: the introduction of mechanical ventilation in the 1960 s and the introduction of extra-corporal membrane oxygenation (ECMO) in the 1990s. Information regarding the introduction of these technologies was collected in the interviews and during my observations of how nurses work with these technologies. Both are complex, lifesaving technologies that are invasive and can temporarily take over the supply of oxygen to the blood. The mechanical ventilator performs this function by pumping oxygen into the lungs of the patient. At present, mechanical and computerised ventilators are standard equipment for every intensive care unit. ECMO is a system that pumps the blood around the body and performs the exchange of gasses through a membrane outside the body of the patient. It thus replaces the heart as well as the lungs. At the time of this research ECMO was available in three centres in the Netherlands. The system is not used frequently, because it is seen as the last resort for those patients who cannot be helped in any other way. I visited two of the three units where ECMO is available: one is a NICU and the other is a surgical PICU. At each unit I had the opportunity to see the system in operation.

\section{Introduction of mechanical ventilators in the $1960 \mathrm{~s}$}

In the Netherlands, mechanical ventilators were introduced in intensive care in the 1960s and 1970s. Prior to the 1960s, ventilators had been in use in the operating theatre. As we described in Section 2.2, the application of positive pressure on the wards was stimulated by the polio epidemics in the 1950s and 1960s. However, the polio victims were a specific group that required a particular form of ventilation and cannot be compared with the intensive care patients of today. Automated mechanical ventilators became available for continuous positive-pressure ventilation in the $1960 \mathrm{~s}$ and were initially operated by a doctor. Since the equipment was unreliable, it was considered necessary to have a person sitting next to it to monitor its operations. These so-called 'watchers' ('wakers' in Dutch) were often medical students. This situation persisted until the mid-1970s and involved the presence of the watcher for the machine and the nurse for the patient. However, not all hospitals operated in this way. One nurse recalls:

"I remember when we got the first ventilator on this ward (neonatology). It must have been 1975, we were quite late I believe. The doctor was operating the wentilator, but when he needed a break for some sleep he asked me to watch the machine. This was during a night shift in which I was the only qualified nurse. He told me all I had to do was to sit in front of the machine and look at the dials. If they were moving between this point and that one and if the green light was on, everything was fine."

This nurse recollects how she spent the whole night anxiously looking at the dials, not leaving the machine. She was terrified that something would go wrong because she had no idea what to do. Since mechanical ventilation was new for everybody, the situation was fraught with uncertainty. The nurse did not know what the dials represented or how the machine worked. She had never seen one before. Other nurses report: 
"The doctors were really hogging the new equipment. None of us were allowed near the ventilator. Only the head nurse knew something about it. When they had finished exploring it, it was not so interesting to them anymore and the nurses got to operate it."

Topman (1993) describes a similar process for the Swan-Ganz catheter, where, after a period of doctors-only, the equipment is now operated exclusively by nurses and is in widespread use on GICUs. Increasingly, attention is paid to the training of nurses in the use of new technologies before these technologies become operational on the ward. As we have seen in the discussion of the trainee nurse who learns the skill of manual ventilation, learning is facilitated by seeing others using the technology even if this is not part of an explicit training session. Both in the case of the introduction of mechanical ventilation and in the case of the introduction of ECMO, this possibility to watch others was not available because the technology itself was new to the whole team. The introduction of ECMO provides an example of a carefully planned and thoroughly prepared innovation process and it illustrates how learning becomes easier when the technology has been in use for a while.

\section{Introduction of ECMO 1990-1993}

ECMO was used on two of the units that I visited. My first observations of ECMO were done in 1991 on a NICU that had just set up an ECMO programme. During my visit to this ward, I observed how an ECMO patient was treated. Complex calculations were made by the doctor who was constantly present, while two nurses were in charge of the patient and the pump. It was clear that the nurses had to concentrate on this work, and there was a noticeable tension around the ECMO set up. For the NICU, this was the third patient who was treated with ECMO. I visited the second unit in 1993, and they had been doing ECMO for two years by that time. The atmosphere was very different as there was only one nurse monitoring the system and no doctor at the bedside. I was very surprised to find that the nurses were not at all nervous and that they did not regard 'ECMO-duty' as particularly exciting or stressful. Their story went as follows:

"When we started with ECMO, the first group received a five-day training programme, including a simulation with a pig. We went to look at another unit where they were already using it, and it was all wery exciting. We started with two nurses and two separate administrations: one for the patient and one for the machine. "The doctor was always present and had to take all decisions. After we had treated a few patients we realised that one nurse could do it all, and we designed one administration form. Also, a protocol was developed, according to which we can change the speed of the pump ourselves, depending on a number of parameters. Now, groups for the ECMO training only get one day at the machine."

In both units, nurses mentioned differences between the first group to be trained for ECMO and the later groups. The ECMO pioneers, one on each unit, had visited the United States in order to see the system in operation in a hospital where this technology had been used for a while. They mentioned how strange it was to see the technology at work for the first time, and that it was surprisingly calm. They described how the training for ECMO has two major parts: the 'priming' of the system and 'trouble shooting'. These two areas are the most demanding and 
difficult ones. During the priming or setting, up many tests are performed to ensure that all connections are correct. For this purpose the system is initially filled with a watery solution known as Ringer"s lactate. This testing sometimes results in wet uniforms as an indication that the system has a leak. Once the system is set up and the patient has been connected, there are usually few surprises. Although the trouble-shooting skills must be kept up-to-date, they are hardly ever needed. On the whole, the operation of ECMO is heavily routinised and guided by protocols. Nurses admit that they sometimes find it hard to stay awake during the night shift on ECMO. Nevertheless, ECMO remains a complex, invasive technology with high risks. As we have seen, the potential problems were perceived as far more urgent in the first stages of the introduction process. As the nurses involved gained more experience, their confidence grew, as did their knowledge of using the system. This has been translated into a new organisational arrangement which requires one nurse instead of two to operate the system and in which certain decisions are standardised to the extent that the nurses can take these decisions on the basis of a protocol. At the same time, the operation of the ECMO system on the ward provided the other nurses with indirect experience. It has become easier to learn how to operate $\mathrm{ECMO}$, as is indicated by the reduction of the time spent on training.

\subsection{Conclusions}

Working and learning are interwoven in intensive care. Learning is a continuous process in which direct and indirect experiences are integrated in the knowledge base. By this process, nurses increase their proficiency gradually and become capable of handling more information and achieving overview. The inherent uncertainties of the intensive care setting require the kind of decision-making that can deal with rapid shifts between foreground and background and takes into account the specific aspects of each situation.

The use of a wide variety of equipment does not have a unidirectional effect on the decision-making process. The use of technology can reduce uncertainty, but it can also increase uncertainty. Dealing with technology is an important aspect of the work of intensive care nurses and requires the development of relevant skills. These skills are related to the operation of the equipment and the assessment of the reliability and effectiveness of the equipment. Direct observation and manual methods are indispensable in intensive care, both to recognise machine failure and to intervene when desirable in order to remedy the patient situation.

Coordination and cooperation are essential in intensive care. Both processes are linked to the way in which a trainee is educated and socialised. Coordination is achieved mainly through standardisation of skills, i.e. by education in the practices and professional values of the group. Cooperation is a central value in the group, and the trainee experiences this, even though he or she is not always in a position to offer effective cooperation.

This chapter has taken the analysis of the learning process, as described in Chapter 5, a step further by describing the elements in the learning process of a trainee nurse who is taught the skill of manual ventilation. It was found that watching others using a technology facilitates the learning process. We then looked at two situations where, initially, the possibility of seeing others at work 
was not available. Here also, it was found that operating the technology as well as training others in these skills becomes easier when the technology has been in use for a while. It can be said that the process by which new technology is assimilated into working practice, is very similar to the learning process that we described in Chapter 5 . In both cases we see that the ability to recognise pertinent information and the ability to gain and maintain overview improves with experience. The manner in which information from the new technology is handled changes over time as the skill of handling the technology is gradually acquired. 
: 


\section{Chapter 7}

\section{Discussion}

This study examines the role of technology in the nursing process on ICUs. It provides an exploration of the relationships between technology, work and organisation at the level of the workplace. It analyses the work process within its organisational context on the basis of data that has been gathered on site by means of interviews and observations during extended visits. This approach has allowed an investigation of the practice of intensive care nursing that focuses on what nurses actually do and what they think about what they are doing. The contribution of this research to the study of technology, work and organisation is that it provides insight into the everyday practice of work that involves extensive use of technology. In this concluding chapter we summarise the findings of the present study with regard to the three research questions that were presented in Chapter 3:

How do IC nurses use and perceive technology in their work?

How do male and female nurses differ in their use and perception of technology?

How do organisational arrangements influence the work process?

Thus, we address the themes of work and technology, gender issues and organisation and work on the basis of our study of the work process. We then compare these findings with the outcomes of the literature review that we presented in Chapter 2 and we offer some explanations for the differences that appear as a result of this comparison. The chapter concludes with recommendations for policy and suggestions for further research, for which a revision of the initial conceptual framework is proposed.

\subsection{Work and technology}

In the practice of intensive care nursing the relationship between work and technology has a number of aspects. As we have seen in Chapter 4 , intensive care nurses expressed the view that it is not technology per se, but rather the combination of critically ill patients, complex care and technology that makes the ICU an attractive workplace. Nurses indicate that the work would be far less 
attractive to them if one of the elements were removed. They do not consider it to be fulfilling to work with technology but without patients. Moreover, none of the nurses envisage returning to general nursing which offers work with patients but does not offer the level of complexity or the technology that they appreciate in the ICU. Thus we have seen that the nurses perceive the role of technology as complementary to the work process in the sense that technology is part of the complex care that the patient requires. Technology is judged with regard to its contribution to the delivery of care, both in terms of the actions it performs and the information it provides. Furthermore we have seen that nurses feel that they must treat the machines with caution, never accepting the machine readings as being absolutely true. In addition, no major differences were found in the ways the role of technology is perceived by nurses on GICUs, PICUs or NICUs. It was found that the decision to specialise in a particular type of ICU is strongly influenced by the preference of the nurse for working with children or adults.

In Chapter 5 the functions of technology in the nursing process have been discussed and four phases of the work process described. In each phase the role of technology was discussed. A distinction is made between equipment that performs a monitoring function and equipment that is used for treatment or support. Many of the advanced technologies perform some kind of self-monitoring, but it is really the responsibility of the staff to ensure that the circumstances are right for the equipment to function properly. Staff on an ICU must spend time setting up the equipment, adjusting it, cleaning it, calibrating it, and dealing with its alarms. We refer to these actions as the activity work on equipment. This activity has been qualified as a 'background' activity in the hands-on routine phase, indicating that in this phase some standard checks are performed on the equipment "Work on equipment has been qualified as 'dominant' in the hands-on emergency phase because the interventions in an emergency often require the use of more technology and in addition the role of the monitoring equipment is more prominent as it is usied to establish the effects of the interventions. In the handsoff phase the work on equipment has been qualified as 'from a distance' since the nurses do not watch the machines closely but do, to a large extent, rely on the monitoring equipment for signals if there are changes in the condition of the patient. In these phases of the work process the role of the technology has been shown to be unproblematic. The one phase in the work process that is characterised by "doubt' with regard to the technology is the vigilance phase. In this phase uncertainties exist concerning the situation of the patient. The information from different sources does not converge to form a clear image, and therefore the nurses call the reliability of the equipment into question and concentrate instead on the information that can be observed directly from the patient. Chapter 5 has thus shown how the relationships between technology and the work process are borne out in practice. We have seen that the work process is focused on the patient and that the technology is used and perceived as an aid.

The role of technology in the work process was explored further in Chapter 6 . It was argued that working and learning are interwoven in the ICU and that the manner in which nurses handle information changes as they become more experienced in their work. The way in which nurses handle technology also changes as they attain higher levels of proficiency. In addition to knowing how to operate the equipment, it is of vital importance that nurses are able to assess the reliability and effectiveness of the equipment in a patient situation. Dealing with 
the complexities of intensive care nursing requires nurses to be able to handle information as well as uncertainty. Technology contributes to the amount and the quality of the information available, but since the reliability of this information cannot be assumed, the use of technology also contributes to the uncertainty the nurse has to deal with. We have seen in Chapter 6 that a number of alternative technologies are available in the ICU for the performance of particular functions and that nurses choose the technology that is most appropriate in a particular situation. Two strategies were identified that are used by nurses in their negotiations with the technology in the work process. The first strategy was to question the reliability of machine measurements, and this was illustrated for the case of the monitor. The second strategy was to question the effectiveness of the machine action, which we illustrated for the ventilator. In both examples the limitations of the technology are compensated for by interventions of the nurse with the assistance of an alternative technology.

This review has shown that the relations between work and technology in the $\mathbb{I C U}$ are complex and that the use and perception of technology by nurses has a number of aspects. Firstly, technology is perceived as an aid in the work process and is therefore judged by the contribution it makes to that process. The aim of the work is to achieve results for the patient, and the use of technology is only justified if it supports this aim. Secondly, technology is not considered to be replacing tasks or skills. Instead, technology requires skilful use and assessment. Thirdly, the use of technology is an additional source of information and at the same time an additional source of uncertainty in the work process. Therefore machine-generated information is treated with caution and is assessed against information that is directly observed from the patient. On the basis of these findings we can conclude that the perspective on the relations between work and technology that was introduced in Chapter 1 has been shown to apply to the practice of intensive care nursing.

\subsection{Gender issues}

The present study has addressed differences between male and female nurses both at the level of career choice and at the level of the work process in the ICU. The data of the small-scale survey on careers in nursing were used to compare the career choices and motivations of male and female respondents. This analysis showed that the choice to work with adults or work with children strongly influenced further career choices. Two patterns stood out: those who had specialised as paediatric nurses had practically all become PIC/NIC nurses, and although nurses moved from GIC into PIC/NIC, no flow from PIC/NIC to GIC was found. Since a non-representative sampling method was used it is not possible to apply the gender distribution within the group of respondents to the wider population of intensive care nurses. On the basis of the distribution of male and female nurses on the ICUs, we can, however, give an indication of the differences between GICUs, PICUs and NICUs. On the three GICUs that participated in the study an average of $40 \%$ male nurses and $60 \%$ female nurses were employed. On the two PICUs in this study the average percentage of male nurses was $9 \%$, and on the three NICUs men accounted for on average $6 \%$ of the nursing staff. Thus, in relative terms, more men are working with adults than 
working with children: There is, however, remarkable agreement among men and women about the reasons for choosing intensive care as a workplace and about its attractive features.

At the level of the work process we paid special attention to the possible presence of a division of labour along gender lines. We observed men and women at work and asked them to explain their actions. We observed the changeover meetings in which the patients were allocated. We observed nurses who needed assistance with a particular task and nurses who provided assistance. Many other situations were observed and no pattern appeared that suggested that men were doing different tasks from women or that they perceived their work differently.

Thus, whereas men and women show different preferences at the aggregate level of career choice, they do not differ in the ways they use and perceive technology at the level of the work process.

\subsection{Organisation and work}

The work process in intensive care nursing is unpredictable, and thus the work organisation must allow for rapid changes. A number of aspects of the organisation of the ICUs under study are important in this respect. The system of patient assignment provides a structure in which one nurse is the key figure in the care for a particular patient. Thus, the nurse monitors both the details and the overview of the patient situation and is in a position to form an informed opinion of this situation. The relations between doctors and nurses in intensive care are usually more open and appreciative than in general nursing. Nurses feel that their work is rewarding and they enjoy being in a position where they can apply their skills and insights.

The analysis of the work process in Chapter 5 has shown that teamwork plays a crucial role in the realisation of a continuous level of high-quality intensive care. We have seen that the activity teamwork can be supplied by nurses who are in a hands-off phase with regard to the work for their "own' patient. In all other phases of the work process nurses may need to receive teamwork primarily because they cannot provide the necessary level of care alone. We have, however, distinguished three types of reasons why teamwork can be requested. In the handson emergency phase teamwork can be required for an intervention that is intended to be life-saving and demands the physical presence of two nurses. For routine procedures in the hands-on routine phase the presence of more than one nurse may be required as a safety precaution, whereas in the vigilance phase a nurse may decide that a second opinion is desirable in an uncertain situation.

The team operates as one, since the individual members monitor the work process and act when they identify occasions that require teamwork. We argue on the basis of the discussion in Chapter 5 that the organisational arrangements of the ICUs we studied provide the conditions that are crucial to the efficient operation of the units. First of all, there is a minimal nursing hierarchy. The ward hierarchy is limited to two managerial levels, and all other qualified nurses are therefore operating at the same hierarchical level, bearing the same level of responsibility. This facilitates teamwork since a minimum level of skills and knowledge can be expected from each of the nurses. In addition, the system of patient assignment requires that all nurses involved in bedside nursing are capable of performing a 
wide range of tasks. These tasks are performed primarily for the patient to whom the nurse is assigned, but they can also be performed for other patients. Furthermore, since there are no separate tasks in direct patient care assigned to technicians, the necessary assistance is provided by the team itself and the dependency on specialised technicians is kept to a minimum. Thus, since every member of the team is capable of performing the full range of tasks that is required in the process of patient care, the team as a whole is flexible, and this contributes to the continuity and quality of patient care.

The issue of teamwork was further explored in Chapter 6, where we analysed learning processes in the practice of intensive care nursing. We have argued that the intricate and continuous relationship between working and learning has important implications for the coordination of work in the ICU. We found that mutual adjustment and standardisation of skills are the most important coordinating mechanisms in intensive care nursing. This means that coordination is achieved through direct contacts between members of the team which take place against a background of shared professional norms and values that have been transferred to new staff during their training. Trainees learn technical skills, information-handling skills and social skills simultaneously. By experiencing the work process in practice, they begin to understand the way we do things around here". During their training on the ward the trainees become aware of the vital importance of teamwork and are directly involved in situations that highlight the need for cooperation. They are facing the complexities of the work and learn how priorities are set to achieve an overview of the situation at hand. As we have seen, this learning process continues after nurses have formally qualified as intensive care nurses. Years of working and learning contribute to the acquisition of experience that is necessary to progress from the stage of beginner, through the stages of competent and proficient, to expert. It was shown that expert practice is qualitatively different from the other stages in the skill-acquisition process as the expert handles information in a different way. The expert gains a wider overview than less experienced nurses, but more importantly, the expert is capable of setting priorities and of almost instantly recognising pertinent information. Experts are important to the smooth functioning of an ICU, because they contribute in two ways to the continuity and quality of the patient care. Firstly, the expert approaches a patient situation in a different manner and has developed an intuitive understanding of the situation through years of experience. Secondly, the expert is in a position to assess how the team as a whole is coping with the situation as he or she is aware of the potential and actual problems and can combine this information with his or her insight into the capabilities of the other team members. Experts, then, oversee what goes on and give direction to the work process in an informal and 'natural' manner.

We have identified coordination and cooperation as essential characteristics of the work process that takes place in an unpredictable environment. Both coordination and cooperation rely on particular skills and attitudes of the members of the team, and we have argued that these skills and attitudes are transferred to trainees during their education on the ward. An important aspect of education is thus to initiate a process of socialisation into the values and norms that prevail in intensive care nursing. 


\subsection{Reflections on findings of current literature}

The results of the present study are discussed here with regard to their contribution to current insights regarding the role of technology in the nursing process on ICUs. We first give a summary of the characteristics of intensive care nursing, based on the review of current literature as described in Chapter 2. From the wide range of issues that are discussed from a number of disciplinary backgrounds the impression emerges of intensive care as an environment where technology and care present conflicting demands to the staff. The use of technology has increased over time, according to the historical account, and nurses have become more involved in the operation of bedside equipment. The role of the nurse in intensive care has been characterised as 'extended' in the sociological studies we reviewed, meaning that nurses perform a range of tasks that are not nursing tasks in the traditional sense. The ICU is regarded as a stressful workplace, and psychologists have found personality characteristics as well as organisational arrangements to be of influence on the development of burnout in intensive care nurses. From an ethical perspective the ICU is a setting where the technical possibilities contribute to the complexity of moral problems. The work of nurses, as seen from the symbolic interactionist perspective, involves the development of strategies in order to cope with the extreme situations in the ICU. With regard to the future of intensive care nursing, we have seen that from a philosophical point of view it is argued that people will not be replaced by machines, but that within the nursing community fears exist that nurses' work will be determined by machines.

The present study has contributed to this general picture of intensive care nursing by providing an analysis of the work process based on field work, as summarised before. However, when the literature review and the results of this study were compared in more detail, two themes were identified that require further exploration. One theme addresses the conflict that is suggested in much of the literature between 'technology' and 'care', but for which no evidence is found in the present study. The second theme concerns the organisational context of the work process which, in our opinion, is undervalued in the research so far. Each theme is discussed in turn.

In the literature that we reviewed in Chapter 2 the role of the nurse is predominantly discussed with regard to the values that underlie the practice of nursing. In much of the literature a division between 'technology" and 'care' is assumed and it is effectively suggested that these represent opposite values. A number of studies use this polarisation as the basis for the normative statement that 'care' should be the most important consideration in nursing, and consequently declare "technology" a threat to what ought to be the core value in nursing practice. This is the case in the articles by Ashworth (1990) and Carnevale (1991) who juxtapose "technology" and 'humanity', and Hudson (1993) who contrasts 'technology' with "empathy'. In addition, it is argued that intensive care nurses are more interested in the technical aspects than in the social/emotional aspects of their work. Zussman (1992) argues this point on the basis of his observations in intensive care in which he finds little evidence of the nurses" role as 'the patient's advocate'. He notes that the nurses are keen to adopt those values that will give them status in the eyes of the medical staff and that these values are technical rather than social. McKerron (1991) also finds that prestige is important 
to intensive care nurses and that prestige is connected with a particular type of patient. She writes: "To the nurses involved, the technical skills associated with nursing a patient just after an operation were far more prestigious than the skills involved in caring for the longer-term patients" (p. 226). The accounts by Henderson (1980), Parfitt (1988) and Fairman (1992) address the changes in the values of nursing and argue that efforts must be made to redirect the main interest of the nurse away from the technology and back to the patient. This call for more 'humanity' in intensive care is echoed by Jablonski (1994) who reports on the experiences of ICU patients and finds that they feel ignored, neglected and unsafe.

By contrast, in the present study it was found that intensive care nurses hold a concept of 'care' in which 'technology' is incorporated. Although the study initially looked for situations and perceptions of conflict between 'care' and 'teclunology' in the practice of intensive care nursing, this proved to be an unproductive line of enquiry. Both in the interviews and in the observations there was no indication of a tension between 'care' and 'technology'. The complementary nature of the roles that the various pieces of equipment fulfil in the care process is a central feature in the analysis of the work process as described in Chapters 5 and 6 . Nurses are comfortable in the high-technology environment of the ICU and they feel that they can achieve better results for the patient if they know how to negotiate with the technology.

A possible explanation for the lack of evidence of a conflict between technology and care is sought in the different purposes of the present study and the studies that were reviewed. In the present study the phenomenon of intensive care nursing is explored in order to contribute to the state of knowledge regarding the relationships between technology, work and organisation. To this end, a number of ICUs have provided the material for the case studies upon which an analysis of the work process was conducted. However, most of the studies that we reviewed are explicitly commenting on intensive care nursing in a normative way. For these authors, intensive care nursing provides a setting where the contrasts between the values of nursing can be illustrated in an extreme way. It is our opinion that these studies use the two extremes of 'technology' and 'care' as a device in the larger debate on 'distance' and 'involvement'. 'Technology' is then used as a metaphor for an attitude of distance and lack of emotion towards the patient, while 'care' denotes warmth and personal interest. The researchers then argue in favour of more "care" and therefore less 'technology' and adopt the cause of 'humanising the ICU' (Parfitt, 1988; Camevale, 1991; Hudson, 1993; Henderson, 1980; Fairman, 1992). An important underlying thought is that the dominant values of nursing are shifting away from 'involvement' and towards 'distance'. If we accept this and if we intend to relate this development to the increasing use of technology in nursing, then the next and necessary step is to establish if technology is a cause or a symptom of this process, or if technology is really neither. In Section 7.4 we will elaborate our suggestions for further research on this question.

Another possible explanation can be found in the intention and approach of the present study in comparison with the studies reviewed. The present study intended to analyse intensive care nursing from the perspective of the nurses involved. Checks and evaluations were built into the research methodology to help the researcher separate her personal impression and opinion from the opinions and explanations that were offered by the respondents. The 
phenomenon under study (the ICU) was approached with curiosity and respect for the rules that applied in this setting. In this conceptual approach the researcher accepts that within the ICU other rules may apply than outside the ICU. As is shown by Hirschauer (1991) with regard to the work of surgeons and anaesthetists in the operating theatre and by Rhodes (1992) for the case of an emergency psychiatric unit, there are situations within health care where the patient is treated and approached in ways that would be unacceptable in ordinary life. On the other hand, these accounts make it clear that much of what goes on in these special locations is very close to everyday life and that the participants are aware of the special situation they are in. It could be argued that patients during an operation and patients in a state of serious mental disturbance are incapable of ordinary social interaction and that therefore the medical staff merely adapt their approach to the situation at hand. However, Fox (1993) finds in his analysis of the surgical ward round that the encounter between a surgeon and a patient on the hospital ward is used by the surgeon to emphasise his or her authority and skill. These conversations are controlled by the surgeon and leave the patient little opportunity to pursue his or her own questions and worries. In the three studies mentioned here the researchers do not see it as their task to comment on the desirability of the situations they studied. They accept that social relations can differ in different environments and they set out to explore these relations. The present study follows this logic and perceives the ICU as yet another environment where actions are taken and relations are accepted that may differ from the generally accepted forms of interaction in everyday life. We propose that the ICU is an environment in which the staff genuinely feels that patients can benefit more from technical interventions than from social interaction. This is not to say that no improvements can be made on the social-emotional attendance of patients. We feel, however, that being a patient in an ICU is a dramatic and frightening experience at the best of times, given the nature of the care that is provided there and the reasons why patients are admitted to the ICU. Whereas Parfitt (1988) argues that the dehumanising effects of the ICU are "compounded when the individual is from a cultural background that differs from the rest of the unit", we propose that in fact all patients are from a cultural background that differs from the ICU. We agree with Parfitt that the values of society are to a large extent not reflected in the ICU, but we are not convinced that it is desirable to give priority to the convergence of these values.

The second theme we identified in the comparison of literature and practice concerns the importance of the organisational context of the work process. Perhaps the main contribution of the present study to the understanding of the role of technology in ICUs is that it perceives the work process in its organisational context. In this way the structure of the work process can be understood in connection with the structural and procedural factors that provide the environment within which the process takes place. The focus on the work process allowed us to establish the vital importance of teamwork in the ICU. We were therefore in a position to recognise which organisational factors were facilitating the process. Why this kind of analysis is lacking in the current literature is an open question, although it may be related to the goals of the studies that we discussed before. We suggest that national differences concerning the organisation of ICUs can influence the way in which ICUs are studied. The literature that we reviewed is based on studies in the USA and in the United Kingdom, whereas the 
present study was carried out in the Netherlands. Although we do not have comparative data on the organisational context or the structure of the work process, these could be influential factors. In ICUs in the Netherlands all of the work on and around the patient is done by the nurses, including the handling of all bedside equipment. This is in contrast to ICUs in other countries, most notably the UK and the USA, where responsibilities in patient care are distributed over nurses at several hierarchical levels in the organisation and technicians who each have their own specialisation. Thus, teamwork would be more difficult to organise in this context. We further suggest that a different organisational context can influence nurses' perception of technology, which would help to explain the concerns regarding 'technology' and 'care'. A recent study in the United Kingdont concluded that while "the presence of technicians to undertake routine but technical tasks, allows nurses to concentrate on nursing tasks", a disadvantage of the employment of technicians in ICUs is that "the presence of technicians is said to prevent the nurses from acquiring necessary technical knowledge" (Stock and Ball, 1993). The suggested self-reinforcing nature of this phenomenon also illustrates that specialisation reduces efficiency by decreasing levels of self-reliance and flexibility. We return to this point when we discuss the characteristics of selfregulating work groups and their relevance to the organisation of ICUs.

In addition to teamwork, we identified learning as an important element in the organisation of the ICU. We have seen that the learning process influences the work process in two ways. On the one hand it is one of the responsibilities of the qualified nurses to provide instruction to the trainees on the ward. Thus, during the work process opportunities for learning are identified and trainees are taught the practical skills. On the other hand we noticed that the learning process continues after nurses have obtained their official qualification, and this means that the qualified nurses in a team can operate on different levels of experience or proficiency. Since the different levels of proficiency are related to different ways of handling information and assessing the situation, we concluded that there are qualitative differences within a team. We have shown how the specific approach of the expert fulfils a number of functions in the team, most notably with regard to organising teamwork and sensing vigilance situations.

Teamwork and learning are identified in the present study as important factors in the organisational context of the work process. The role of technology in the work process is also affected by these factors. Our position regarding research on the use of equipment in ICUs is thus different from the studies that we reviewed. We argue on the basis of this research that 'technology' should not be treated as a separate entity because it forms an integral and inseparable part of the ICU. This also implies that a study of the ICU which neglects technological aspects is incomplete. Analogous to the 'technological culture' which is put forward by Bijker (1995) as the unit of analysis in the study of technology and society, we can see in the present study an attempt to come to terms with the "technological organisation' or the 'technological workplace'.

It has been shown in this study that the use of technology in the ICU is integrated in the work process and that different roles of technology can be distinguished. Technology is perceived by its users as an aid in the care for those patients who require complex care and continuous monitoring. Nurses appreciate much of the technology they work with, and they perceive it as a virtual extension of their own body, as was suggested by Ashworth (1990). Moreover, nurses indicate 
that during their daily activities they do not even consider the fact that they are using technology. We argue that watchful vigilance has not been replaced by medical machines, as Fairman (1992) has claimed, but that it has remained the chief characteristic of intensive care nursing and that it is supported by advanced medical equipment.

\subsection{Policy conclusions and further research}

The findings of this study have some important implications for the management and planning of ICUs. In our view, there are two main issues that deserve attention in this respect: teamwork and learning. As we have seen, these are crucial issues in the work process as they directly pertain to the way in which patient care is provided. Teamwork and learning provide the basis for the required continunity and flexibility of the care process in a complex and unpredictable environment. Factors that contribute to teamwork and learning are found in the organisational context and include a low degree of hierarchy, a low degree of specialisation, patient assignment and interdisciplinary relations. Therefore, we propose that no changes be made to the organisation of ICU that will threaten these factors. In particular at the present time when hospital budgets are under severe strain, we consider it inadvisable to seek to achieve cost reductions by introducing more hierarchical levels or more specialisation. In many areas of health care new practices have been introduced that divide the direct patient care into two or more levels so that the more routine tasks can be done by less highly educated and therefore cheaper labour. Handwork and supervision are separated in a Tayloristic manner, and yet it is claimed that a system of tailor-made patient care will emerge. In our opinion this development should be resisted in ICUs for the simple reason that teamwork as well as learning will be adversely affected by a further division of labour. Coordination and cooperation are achieved effectively in the ICU in the organisational context that we described. It should be noted that this form of organisation is rare and in fact incorporates most elements of the whole task groups that are designed in attempts to organise the work process according to the socio-technical paradigm (See, for example, Haak, 1994; Eijnatten, 1993; Dankbaar and Den Hertog, 1990). Socio-technical designs are considered to be more efficient than others because they make the team less dependent on specialists and thus more self-reliant and flexible. Thus, the time that would normally be spent waiting for a specialist from inside or outside the team is now used by the team members to deal with the problem themselves. It proves very difficult to design and implement an effective organisation on socio-technical principles, based on so-called 'self-regulating work groups' (van Ewijk-Hoevenaars et al., 1995; Grayson, 1991). Therefore we argue that ICUs should be very reluctant to give up their unique organisational arrangements.

It would be very interesting to make a more systematic comparison of selfregulating work groups and ICU teams that takes into account the organisational performance as well as the quality of working life. Across ICUs comparisons could be made on these same criteria, comparing units that are organised along the lines presented in this study and units that are organised in different ways, especially with regard to hierarchy and specialisation. If we can combine insights pertaining 
to organisation, performance and work satisfaction we can create powerful tools for analysis and intervention.

Does the role of technology deserve a special place in organisational studies? We suggest that technology is only one of a number of elements that shape the workplace. As this research has shown, the study of technology and work benefits greatly from an approach that addresses the wider organisational context. Recently, some inspiring studies on technology in organisations have provided evidence that challenges some long-standing perceptions in this area. A study into the use of computer technology in organisations (Den Hertog and Wielinga, 1992) has the captivating sub-title: "the computer as an ink blot". The study finds that the impact of computer systems on an organisation is heavily dependent on the way in which the organisation decides to use that technology. A similar computer technology is shown to have been implemented in different ways in a number of engineering workshops. Thus, rather than influence the organisation, the technology is used by the organisation in such a way that it fits and reflects the organisation's needs and preferences. Webster (1990) focused on administrative work, which is generally done by women, and found that the quality of working life is not necessarily altered by the introduction of word-processing equipment. The new technology does not challenge the organisational arrangement, but again is implemented in such a way that the existing relations are confirmed. Another study (Daniel and Hogarth, 1990) found evidence that suggests that employees are on the whole not negative about technical change, and concludes that, in fact, they are more inclined to support technical change than organisational change. These results come from a revised version of the Workplace Industrial Relations Survey that was carried out by the authors and revealed a number of reasons why employees as well as their trade union representatives find technical change intrinsically more attractive than other kinds of change. The findings of these two studies match what is argued in the present study and is summarised succinctly by De Sitter (1993) who says: "the very concept of the technical and social system is obsolete". He continues: "In human interaction (social) goals and (technical) means are always intertwined as complementary functional components in the course of selective interaction" (1993, p. 165). We argued above that technology must be studied in its context, and we suggested that the 'technological organisation' or the 'technological workplace' are relevant concepts in this endeavour. Here we add that the focus of such a study should be on the process or the 'flow' in the organisation in order to capture the dynamics in the relations of the aspects that can be analytically separated, but that only acquire meaning in interaction.

A crucial consideration before we undertake further research concerns the choice of an appropriate conceptual framework. On the basis of the findings of the present research and the arguments outlined above, the initial conceptual framework that was presented in Chapter 3 requires revision. We discard the suggested separation of technology and care and instead emphasise the central importance of the relationship between the group of patients and the group of nurses, as is shown in Figure 7.1. The work process is portrayed as the link between the two groups, and the activities that constitute the work process are listed. Thus, the work process is pivotal and is embedded in the organisational context that is represented by the inner circle. The outer circle represents the general environment of the ICU, and this is the area where a wide variety of 
issues reside, including debates on the values of nursing practice, hospital budgets and gender issues. Thus, a major difference from the initial framework is that in the revised version the organisational factors are considered of central importance and the gender issues are considered of peripheral importance, whereas initially both these aspects were seen as external.

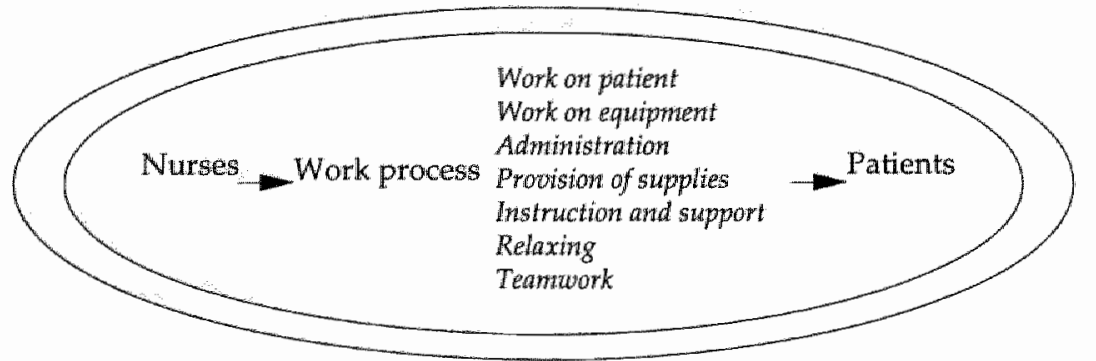

Figure 7.1 Revised conceptual framework

Some specific projects that we propose to increase our understanding of the relations between technology, work and organisation would compare the introduction and use of technology in different kinds of service organisations. The vast majority of studies have addressed cases in industry and manufacturing organisations, and we are not convinced that the results can be applied to service organsations. In order to do justice to the variety within the service sector we propose to look at commercial as well as non-profit and government organisations. Within hospitals the radiology and clinical chemistry departments provide interesting case studies as they are not directly involved in bedside care. A very different approach would be to look at banks, insurance companies, tax offices and various levels of government. We suggest that future research attempts to make connections between the organisation of work and the use and perception of technology, while paying special attention to learning and gender issues.

Another area of further research needs to address the empirical basis for the normative debate on values in nursing. It is our opinion that the problem of disctance and involvement requires a more sophisticated analysis, in which technology is not a priori cast as a negative force. Comparative studies of 'hightechnology" and 'low-technology' areas of nursing can begin to unveil the relationships between lack of involvement or increasing distance in the provision of care and the level of technology that is used. Some 'high-technology' areas are the operating theatre, coronary care units (CCUs) and other specialised ICUs as well as accident and emergency (A\&E) departments. At the 'low-technology' end of the spectrum we find neurology wards, nursing homes and psychiatric units. Studies of distance and involvement have been conducted in nursing homes by Boeije (1994) and in an emergency psychiatric unit by Rhodes (1992). Some of the symbolic interactionist studies in intensive care nursing (Hutchinson, 1984; Swanson, 1990; Marcus, 1989) also address this issue. On the basis of these studies there is little evidence that the debate on values and the problems of distance and involvement are related to the level of technology that is used in patient care. More systematic research is, however, needed to analyse the complexities and to tackle the convenient myths that surround this issue. 


\section{Bibliography}

Agar, M.H. (1986) Speaking of ethnography. Newbury Park, Sage Publications.

Anspach, R.R. (1993) Deciding who lives: fateful choices in the Intensive Care Nursery. Berkeley, University of California Press.

Argyris, C. (1976) "Single-loop and double-loop models in research on decision making", Administrative Science Quarterly, Vol. 21, pp. 363-375.

Argyris, C. and D.A. Schön (1978) Organizational learning: a theory of action perspective. Reading, Addison-Wesley Publishing Company.

Argyris. C. (1977) "Double-loop learning in organizations", Harvard Business Review, Vol. 55, September-October, pp. 115-131.

Ashworth, P. (1990) "High technology and humanity for intensive care", Intensive Care Nursing, Vol. 6, pp. 150-160.

Banta, H.D. (1984) "Embracing or rejecting innovations: clinical diffusion of health care technology" in: S.J. Reiser and M. Anbar (eds) The machine at the bedside. Cambridge, Cambridge University Press.

Banta, H.D. and B.R. Luce (1993) Health care technology and its assessment: an international perspective. Oxford, Oxford University Press.

Barley, S.R. (1986) "Technology as an occasion for structuring: evidence from observations of CT scanners and the social order of radiology departments ${ }^{\prime \prime}$, Administrative Science Quarterly, Vol. 31, pp. 78-108.

Barley, S.R. (1990a) "Images of imaging: notes on doing longitudinal fieldwork", Organization Science, Vol. 1, No. 3, pp. 220-247.

Barley, S.R. (1990b) "The alignment of technology and structure through roles and networks", Administrative Science Quarterly, Vol. 35, pp 61-103.

Becker, P.H. (1993) "Common pitfalls in published grounded theory research" in: Qualitative Health Research, 3, 2, pp. 254-260.

Benner, P. (1975) "Nurses in the intensive care unit" in: M.Z. Davis, M. Kramer and A.L. Strauss (eds) Nurses in practice: a perspective on work environments. Saint Louis, The C.V. Mosby Company.

Benner, P. (1982) "From novice to expert", American Journal of Nursing, March, pp. 402-407.

Benner, P. (1984) From novice to expert: excellence and power in clinical nursing practice. Menlo Park, Addison-Wesley.

Benner, P. and C. Tanner (1987) "How expert nurses use intuition", American Journal of Nursing, January, pp. 23-31.

Benner, P., C. Tanner and C. Chesla (1992) "From beginner to expert: gaining a differentiated clinical world in critical care nursing", Advances in Nursing Science, Vol. 14, No. 3, pp. 13-28.

Bergsma, J. (1979) "De arts als verlengstuk van de techniek en de steeds meer afhankelijke patiënt", TNO-Project, Vol. 11, pp. 384-391.

Bijker, W., T.P. Hughes and T.Pinch (eds) (1987) The social construction of technological systems: new directions in the sociology and history of technology. Cambridge, MIT Press. 
Bijker, W.E. (1995) Democratie van de technologische cultuwr. (inaugurele rede) Maastricht, Rijksuniversiteit Limburg.

Blackburn, S. (1982) "The neonatal ICU: a high-risk environment" American Journal of Nursing, November, pp. 1708-1712.

Blanck, P.D. and A.N. Turner (1987) "Gestalt research: clinical-field-research approaches to studying organizations" in: J.W. Lorsch (ed.) Handbook of organizational behavior. Englewood Cliffs, Prentice Hall.

Blume, S. (1992) Insight and industry: on the dynamics of technological change in medicine. Cambridge, Mass., MIT Press.

BMJ (1991) "Winning over women", British Medical Journal, Vol 303, p. 10-11

Boeije (1994) Kualiteit van zorg in werpleeghuizen. een onderzoek naar problemen en strategieën van verzorgenden. (Proefschrift, Erasmus Universiteit Rotterdam) Utrecht, Uitgeverij De Tijdstroom.

Boxsel, J. van (1992) The relewance of technology dynamics for the practice of constructive technology assessment. Research Memorandum 91-030, Maastricht Economic Research Institute on Innovation and Technology.

Boyle, A, M.J. Grap, J. Younger and D. Thornby (1991) "Personality hardiness, ways of coping, social support and burnout in critical care nurses", Journal of Advanced Nursing,Vol. 16, pp. 850-857.

Briggs, D. (1991) "Critical care nurses" roles - traditional or expanded/extended", Intensive Care Nursing, Vol. 7, pp. 223-229.

Bruns, W.J. (1989) "Case study research: design and methods" (book review), Journal of Management Accounting Research, Vol. 1, pp. 157-163.

Bryman, A. (ed.) (1988) Doing research in organizations. London, Routledge.

Campbell, M. (1990) "Systemating nursing and the promise of computers: a new phase in nurses" struggle for control of their practice?", in: E. Dimitz (ed.) Computers in hospital care. Proceedings of an international colloquium held in Vienna, Austria, June 8-9.

Carnevale, F.A. (1991) "High technology and humanity in intensive care: finding a balance $^{* \prime}$, Intensive Care Nursing, Vol. 7, pp. 23-27.

Chenitz, W.C. (1986) "The informal interview" in: W.C. Chenitz and J.M. Swanson From practice to grounded theory. Menlo Park, Addison-Wesley Publishing Company.

Chenitz, W.C. and J.M. Swanson (1986) From practice to grounded theory. Menlo Park, Addison-Wesley Publishing Company.

Cockburn, C. and S. Ormrod (1994) Gender and technology in the making. London, SAGE Publications.

Collins, H.M. (1990) Artificial experts: social knowledge and intelligent machines. Cambridge, MA, The MIT Press.

Coombs, R., P. Saviotti and V. Walsh (1987) Economics and technological change. Basingstoke, MacMillan.

Corbin, J. (1986) "Qualitative data analysis for grounded theory" in: W.C. Chenitz and J.M. Swanson From practice to grounded theory. Menlo Park, AddisonWesley Publishing Company.

Corbin, I. and A. Strauss (1990) "Grounded theory research: procedures, canons, and evaluative criteria" Qualitative Sociology, Vol. 13, No. 1, pp. 3-21.

Cowan, R.S. (1989) More work for mother: the ironies of household technology from the open hearth to the microwave. London, Free Association Books. 
Daniel, W.W. and T. Hogarth (1990) "Worker support for technical change", New Technology, Work and Employment, Vol. 5, No. 2, pp. 122-134.

Dankbaar, B and J.F. den Hertog (1990) "Labour process analysis and sociotechnical design: living apart together? ${ }^{n}$, New Technology, Work and Employment, Vol. 5, No. 2, pp. 122-134.

Dassen, T.W.N., F.J.N. Nijhuis and H. Philipsen (1990a) "Carrièreperspectieven bij mannelijke en vrouwelijke intensive care verpleegkundigen", Gedrag en Organisatie, Vol. 3, No. 1, pp. 32-47.

Dassen, T.W.N., F.J.N. Nijhuis and H. Philipsen (1990b) "Male and female nurses in intensive care wards in the Netherlands", Joumal of Advanced Nursing, Vol. 15, pp. 387-393.

Dassen, Th., H. Topman, F. Theunissen and F. Nijhuis (1987) "Technisch handelen op de intensive care; taak van de verpleegkundige?" Tijdschrift voor Ziekenverpleging, Vol. 41, Nr. 17, pp. 529-535. Discussie in Tijdschrift voor Ziekenverpleging, Vol. 41, No. 19, pp. 602-605.

Davis, M.Z., M. Kramer and A.L. Strauss (eds) (1975) Nurses in practice: a perspective on work environments. Saint Louis, The C.V. Mosby Company.

Davis-Martin, S. (1984) "Research on males in nursing", Journal of Nursing Education, Vol. 23, No. 4, pp. 162-164.

Dreyfus, H.L. and S.E. Dreyfus (1986) Mind over machine: the power of human intuition and expertise in the era of the computer. Oxford, Basil Blackwell.

Dubbelman, K.A. and H.E.G.M. Hermans (1990) Besluttoorming in de neonatologie. 's-Gravenhage, VUGA Uitgeverij.

Egeland, J.W. and J.S. Brown (1989) "Men in nursing: their fields of employment, preferred fields of practice, and role strain", Health Services Research, Vol. 24, No. 5, pp. 693-707.

Eijnatten, F.M. van (1993) The paradigm that changed the work place. Assen, Van Gorcum.

van Ewijk-Hoevenaars, A.M., J.C.M. van Jaarsveld and J.F. den Hertog (eds)(1995) Naar eenooud in organisatie: werken met zelfsturende eenheden. Deventer, Kluwer Bedrijfswetenschappen.

Fairman, J. (1992) "Watchful vigilance: nursing care, technology, and the development of intensive care units", Nursing Research, Vol. 41, No. 1, pp. 5660.

Fetterman, D.M. (1989) Ethnography: step by step. Newbury Park, Sage Publications Field, P.A. and J.M. Morse (1985) Nursing research: the application of qualitative approaches. London, Croom Helm.

Fitter, M. (ed.) (1986) The impact of new technology on workers and patients in the health services: physical and psychological stress. The European Foundation for the Improvement of Living and Working Conditions, Loughlinstown House, Shankill, Co. Dublin, Ireland.

Fox, N.J. (1993) "Discourse, organisation and the surgical ward round", Sociology of Health and Illness, Vol. 15, No. 1, pp. 16-42.

FOZ (1995) Financieel Overzicht Zorg 1995. "s-Gravenhage, Sdu.

Frohock, F.M. (1986) Special care: medical decisions at the beginning of life. Chicago, The University of Chicago Press.

Galbraith, M. (1991) "Attracting men to nursing: what will they find important in their career?", Journal of Nursing Education, Vol. 30, No. 4, pp. 182-186. 
Gelijns, A. and N. Rosenberg (1994) "The dynamics of technological change in medicine", Health Affairs, Summer, pp. 28-46.

Glaser, B. (1978) Theoretical sensitivity. Mill Valley, CA, Sociology Press.

Glaser, B. and A. Strauss (1967) The discovery of grounded theory: strategies for qualitative research. Chicago, Aldine.

Grady, K.E and B.S. Wallston (1988) Research in health care settings. Newbury Park, Sage Publications.

Grayson, D. (1991) "Self-regulating work groups: an aspect of organisational change", International Journal of Manpower, Vol. 12, No. 1, pp. 22-29.

Greer, A.L. (1985) "Adoption of medical technology: the hospital's three decision systems", Journal of Technology and Health Care, Vol. 3, No. 3, pp. 669-680.

Groen, M.A.H. (1988) Technical innozation and clinical chemistry: a case study in automated laboratory equipment. Unpublished Master's thesis, Department of Science and Technology Policy, University of Manchester.

Haak, A.T. (1994) Dutch sociotechnical design in practice: an empirical study of the concept of the whole task group. Assen, Van Gorcum.

Hammersley, M. and P. Atkinson (1983) Ethnography: principles in practice. London, Routledge.

Harvey, J. (1985) "Living between life and death", New Society, Vol. 8, pp. 233-236

Henderson, V.A. (1980) "Preserving the essence of nursing in a technological age", Journal of Advanced Nursing. Vol. 5, pp. 245-260.

den Hertog, J.F and E. van Sluijs (1995) Onderzoek in organisaties: een methodologische reisgids. Assen, Van Gorcum.

den Hertog, J.F. and C. Wielinga (1992) "Control systems in dissonance: the computer as an ink blot", Accounting, Organizations and Society, Vol. 17, No. 2, pp. 103-127.

von Hippel, E. (1976) "The dominant role of users in the scientific instrument innovation process", Research Policy, Vol. 5, pp. 212-239.

Hirschauer, S. (1991) "The manufacture of bodies in surgery", Sacial Studies of Science, Vol. 21, pp. 279-319.

Hudson, G.R. (1993) "Empathy and technology in the coronary care unit", Intensive \& Critical Care Nursing, Vol. 9, No. 1, pp. 55-61.

Hutchinson, S.A. (1984) "Creating meaning out of horror", Nursing Outlook, Vol. 32, No. 2, pp. 86-90.

Jablonski, R.S. (1994) "The experience of being ventilated", Qualitative Health Research, Vol. 4, No. 2, pp. 186-207.

Jennett, B. (1984) High technology medicine: benefits and burders. London, the Nuffield Provincial Hospitals Trust.

Johnson, D.W. and F.P. Johnson (1991) Joining together: group theory and group skills. Einglewood Cliffs, Prentice-Hall.

Jorgensen, D.L. (1989) Participant observation: a methodology for human studies. Newbury Park, Sage Publications.

Josefson, I. (1988) "The nurse as engineer - the theory of knowledge in research in the care sector", in: B. Göranzon and I. Josefson (eds) Knowledge, skill and artificial intelligence. London, Springer-Verlag.

Josefson, I. (1990) "Language and experience", in: B. Göranzon and M. Florin (eds), Artificial intelligence, culture and language: on education and work. London, Springer-Verlag.

Kanter, R.M. (1977) Men and women of the corporation. New York, Basic Books. 
Kanter, R.M. (1984) The change masters. New York, Simon \& Schuster.

Kaplan, A. (1964) The conduct of inquiry: methodology for behavioral science. Aylesbury, International Textbook Company Limited.

Kidder, J.T. (1981) The soul of a new machine. Boston, Little, Brown and Company.

Kidder, L.H. and C.M. Judd (1986) Research methods in social relations. (Fifth edition), New York, CBS Publishing Japan Ltd.

Kirk, J. and M.L. Miller (1986) Reliability and validity in qualitative research. Newbury Park, Sage Publications.

Leonard-Barton, D. (1990) "A dual methodology for case studies: synergistic use of a longitudinal single site with replicated multiple sites", Organization Science, Vol. 1, No. 3, p. 248-266.

Levine, C.D., S.P. Wilson and G.W. Guido (1988) "Personality factors of critical care nurses", Heart \& Lung, Vol. 17, No. 4, pp. 392-398.

MacKenzie, D. (1990) Inventing accuracy: a historical sociology of nuclear missile guidance. Cambridge, Mass., MIT Press.

MacKenzie, D. and J. Wajcman (eds) (1985) The social shaping of technology. Milton Keynes, Open University Press.

Marcus, M.T. (1989) Surgical intensive care mursing work: a phenomenological study. (Dissertation) University of Houston.

Marshall, C. and G.B. Rossman (1989) Designing qualitative research. Newbury Park, Sage Publications.

McKerron, L.C. (1991) "Dealing with stress of caring for the dying in intensive care units: an overview", Intensive Care Nursing. Vol. 7, pp. 219-222.

Melia, K.M. (1987) Learning and working: the occupational socialization of nurses. London, Tavistock Publications.

Mesman, J. (1992) Machines en moraal, Krisis, Vol, 48, pp. 5-18.

Miles, M.B. and A.M. Huberman (1984) Qualitative data analysis: a source book of new methods. Newbury Park, Sage Publications.

Miles, M.B. and A.M. Huberman (1994) Qualitative data analysis: an expanded sourcebook. Thousand Oaks, Sage Publications.

Mintzberg, $H$. (1979) The structuring of organizations. Englewood Cliffs, PrenticeHall.

Miranda, D.R. and J.F.A. Spangenberg (1992) Kwaliteit, doelmatigheid en organisatie van intersive care units in Nederland. Groningen, Foundation for Research on Intensive Care in Europe.

Moustakas, C. (1990) Heuristic research: design, methodology and applications. Newbury Park, Sage Publications.

Mumford, E. and MacDonald, W.B. (1989) Exsel's progress: the continuing journey of an expert systert. Chichester, Wiley.

NZi (1988) Vrouwen in de intramurale gezondheidszorg. Utrecht, Nationaal Ziekenhuisinstituut.

NZi (1992) Productie statistiek 1992: soort en onvang van functies, faciliteiten en producties. Publicatie 193.925 (algemene ziekenhuizen) en 193.926 (academische ziekenhuizen). Utrecht, Nationaai Ziekenhuisinstituut.

OTA (1976) Development of medical technology: opportunities for assessment. United States Congress, Office of Technology Assessment.

Ott, M. (1983) Assepoesters en kroonprinsen: een onderzoek naar de minderheidspositie van agentes en verplegers. (Proefschrift), Universiteit van Amsterdam. 
Parfitt, B.A. (1988) "Cultural assessment in the Intensive Care Unit", Intensive Care Nursing, Vol. 2, pp. 124-127.

Reid, B. (1991) "Developing and documenting a qualitative methodology", Journal of Advanced Nursing, Vol. 16, pp. 544-551.

Reiser and Anbar (eds) (1984) The machine at the bedside: strategies for using technology in patient care. Cambridge, Cambridge University Press.

Reiser, S.J (1984) "The machine at the bedside: technological transformations of practices and values" in: S.J. Reiser and M. Anbar (eds), The machine at the bedside. Cambridge, Cambridge University Press.

Reiser, S.J. (1978) Medicine and the reign of technology. Cambridge, Cambridge University Press.

Rhodes, L.A. (1992) Emptying beds: the work of an emergency psychiatric unit. Berkeley, University of California Press.

Roberts, H.J.E. (1993) Accountability and responsibility: the influence of organisation design on management accounting. (Proefschrift) Universitaire Pers Maastricht.

Robson, C. (1993) Real world research: a resource for social scientists and practitioner-researchers. Oxford, Blackwell Publishers.

Romano, C.A. (1990) "Diffusion of technology innovation", Advances in Nursing Science, Vol. 13, No. 2, pp. 11-21.

Rosen, M. (1991) "Coming to terms with the field: understanding and doing organizational ethnography", Journal of Management Studies, Vol. 28, No. 1, pp. 1-24.

Rossum, W. van (1989) Besluitoorming en medisch technologisch aspectenonderzoek: een analyse van de gebruikswaarde van T.A.-studies naar hart- en levertransplantaties en in vitro fertilisatie. Faculteit Bedrijfskunde, Rijksuniversiteit Groningen.

Rossum, W. van (1990) "Medisch-technologisch aspectenonderzoek", Medisch Contact, Vol. 45, No. 16, pp. 509-511.

Russell, L.B. (1979) Technology in hospitals: medical advances and their diffusion. Washington, Brookings Institution.

Sanday, P.R. (1983) "The ethnographic paradigm(s)" in: J. Van Maanen (ed.) Qualitative methodology. Beverly Hills, Sage Publications.

Seymour, E. and J.R. Buscherhof (1991) "Sources and consequences of satisfaction and dissatisfaction in nursing: findings from a national sample", International Journal of Nursing Studies, Vol. 28, No. 2, pp. 109-124.

Shaffir, W.B. and R.A. Stebbins (eds.) (1991) Experiencing fieldwork: an inside view of qualitative research. Newbury Park, Sage Publications.

Shaw, B. (1991) "Developing technological innovations within networks" Entrepreneurship \& Regional Development, Vol. 3, pp. 111-128.

Shuldham, C. (1986) "The nurse on the intensive care unit", Intensive Care Nursing, Vol. 1, pp. 181-186.

Sibbes, J.L.H. (1989) "Extra aandacht voor loopbaanbeleid voor/van vrouwen?" in: J. van Dooren (ed.) symposiumbundel Vrouwen voor het voetlicht. Utrecht.

Sitter, L.U. de (1993) "A socio-technical perspective" in: F.M. van Eijnatten, The paradigm that changed the work place. Assen, Van Gorcum.

Skillman, J.J. (1975) Intensive care, Boston, Little, Brown and Company. 
Spangenberg, J.F.A., J.H.R van de Poel, J. Winter et al. (1989) "Technical efficiency of high technology medicine", Techmology Analysis \& Strategic Management, Vol. 1, No. 4, pp. 367-391.

Stock, J. and J. Ball (1993) "The roles of nurses and technicians in intensive care", Intensive and Critical Care Nursing, Vol. 9, pp. 67-69.

Straten, G. and T. Weijers (1991) Consensus-conferenties: medische technologie ter discussie. TNO-rapport. Apeldoorn, Studiecentrum voor Technologie en Beleid TNO (STB).

Strauss, A. (1985) "Work and the division of labor", The Sociological Quarterly, Vol. 26, No. 1, pp. 1-19.

Strauss, A. and J. Corbin (1990) Basics of qualitative research: grounded theory procedures and techniques. Sage Publications, Newbury Park.

Strauss, A., S. Fagerhaugh, B. Suczek and C. Wiener (1985) Social organization of medical work. Chicago, The University of Chicago Press.

Strauss, A.L. (1975) "Work in the premature nursery" in: M.Z. Davis, M. Kramer and A.L. Strauss (eds) Nurses in practice: a perspective on work environments. Saint Louis, The C.V. Mosby Company.

Swanborn (1984) Methoden van sociaal-wetenschappelijk onderzoek: inleiding tot ontwerpstrategieën. Amsterdam, Boom.

Swanson, J.M. (1986) "The formal qualitative interview for grounded theory" in: W.C. Chenitz and J.M. Swanson From practice to grounded theory. Menlo Park, Addison-Wesley Publishing Company.

Swanson, K.M. (1990) "Providing care in the NICU: Sometimes an act of love", Advances in Nursing Science, Vol. 13, No. 1, pp. 60-73.

Thomas, L. (1974) The lives of a cell: notes of a biology watcher. New York, Bantam Books.

Topman, H. (1987) "De IC-verpleegkundige en het medisch handelen binnen de verlengde-arm-theorie" ${ }^{\prime \prime}$ Tijdschrift voor Ziekenverpleging, Vol. 41, No. 19, pp. 615-624.

Topman, H. (1993) "De rol van de verpleegkundige in zorgprocessen, waarin medische technologie een grote rol speelt". Lecture for students of nursing, Amsterdam.

Turner, B.A. (1983) "The use of grounded theory for the qualitative analysis of organizational behaviour" ,Journal of Management Studies, Vol. 20, No.3, pp. 333-348.

Turner, B.A. (1988) "Connoisseurship in the study of organizational cultures" in: A. Bryman (ed.) Doing research in organizations. London, Routledge.

Tyson, T. (1989) Working with groups. Melbourne, MacMillan Australia.

Van Maanen, J. (ed.) (1983) Qualitative methodology. Beverly Hills, Sage Publications.

Visser, H.K.A. (1991) "Intensive care voor pasgeborenen: een behoefteraming", Nederlands Tijdschrift der Geneeskunde, Vol. 135, No. 28, pp. 1259-1261.

de Vries, A.H.G, S.H. Schmidt, C. van Ekeren and T.F. Meijman (1987) Techniek en patiëntenzorg: een arbeidspsychologische studie naar de invioed van nieuwe technologieën op de inhoud van het verpleegkundig werk in ziekenhuizen. Rijksuniversiteit Groningen.

Vrolijk, H., G-J Straten and T. Weijers (1991) Neonatologie: technologie voor de toekomst. NOTA Werkdocument W22. 
Wagner, I. (1991) "Transparenz oder Ambiguität? Kulturspezifische Formen der Aneignung von Informationstechniken im Krankenhaus", Zeitschrift für Soziologie, Vol. 20, No. 4, pp. 275-289.

Webster, J. (1990) Office automation: the labour process and women's work in Britain. Harvester Wheatsheaf.

Whyte, W.F. (1955, 2nd edition) Street corner society: the social structure of an Italian slum. Chicago, The University of Chicago Press

Wichowski, H.C. (1994) "Professional uncertainty: nurses in the technologically interise arena", Journal of Advanced Nursing, Vol. 19, pp. 1162-1167.

Wiener, C, A. Strauss, S. Fagerhaugh and B. Suczek (1979) "Trajectories, biographies and the evolving medical technology scene: labor and delivery and the intensive care nursery", Sociology of Health and Illness, Vol. 1, No. 3, pp. 261-283.

Wilde, V. (1992) "Controversial hypotheses on the relationship between researcher and informant in qualitative research", Journal of Advanced Nursing, Vol. 17, pp. 234-242.

Williams, C.L. (1992) "The glass escalator: hidden advantages for men in the 'female' professions", Social Problems, Vol. 39, No 3, pp. 253-267.

Wolf, Z.R. (1988) Nurses' work: the sacred and the profane. Philadelphia, University of Pennsylvania Press.

Yin, R.K. (1981) "The case study crisis: some answers", Administrative Science Quarterly, Vol. 26, pp. 58-65.

Yin, R.K. (1989) Case study research: design and methods. Newbury Park, Sage Publications.

Yin, R.K. (1993) Applications of case study research. Newbury Park, Sage Publications.

Zussman, R. (1992) Intensive care: medical ethics and the medical profession. Chicago, The University of Chicago Press. 
Dit proefschrift analyseert het arbeidsproces van verpleegkundigen op afdelingen voor intensive care (ICUs) in vier Nederlandse ziekenhuizen. Met betrekking tot dit arbeidsproces zijn drie onderwerpen bestudeerd. Het belangrijkste onderwerp in dit onderzoek is de rol en het gebruik van medische technologie in de patiëntenzorg. Daarnaast is aandacht besteed aan mogelijke verschillen tussen mannelijke en vrouwelijke verpleegkundigen in het gebruik en perceptie van technologie in hun werk. Tevens zijn organisatorische kenmerken van de werkplek geanalyseerd en in verband gebracht met de structuur van het arbeidsproces. Deze onderwerpen vormen de basis van het onderzoek, maar worden in het proefschrift niet apart behandeld. Ook in deze samenvatting zijn de onderwerpen geintegreerd.

De opvallendste uitkomsten zijn dat voor de betrokkenen technologie een hulpmiddel is dat onderdeel uitmaakt van het zorgproces en dat mannelijke en vrouwelijke verpleegkundigen niet verschillen in de manier waarop zij omgaan met de apparatuur op de werkplek. De rol van technologie staat echter niet vast. In het arbeidsproces moet de apparatuur steeds haar nut bewijzen en hebben verpleegkundigen bij twijfel meer vertrouwen in de signalen die ze direct van de patiënt kunnen "aflezen" dan in de gegevens die de apparatuur produceert. Het onvoorspelbare karakter van het werk op een ICU, gecombineerd met de levensbedreigende situaties die zich frequent voordoen, stelt hoge eisen aan de samenwerking van verpleegkundigen onderling en met andere disciplines. $\mathrm{Om}$ de noodzakelijke flexibiliteit te realiseren, zijn de diensten zo georganiseerd dat elke verpleegkundige verantwoordelijk is voor de zorg voor een klein aantal patiënten en, als dat nodig is, hulp geeft aan of ontvangt van collega's.

\section{Methode en theorie}

Het voornaamste doel van dit onderzoek is het formuleren van een theorie betreffende de rol van technologie in de praktijk van intensive care verpleging. Een dergelijke theorie die op basis van praktijkobservaties wordt opgebouwd, heet in het Nederlandse taalgebied een 'gefundeerde theorie' en is elders bekend als 'grounded theory'. Dit onderzoek maakt gebruik van de analysetechnieken van 'gefundeerde theorie', waarbij door middel van continue vergelijking van. gegevens gezocht wordt naar relevante concepten en naar patronen die deze concepten verbinden. In dit onderzoek zijn de belangrijkste gegevens verzameld door middel van participerende observaties en diepte-interviews.

De onderzoeker heeft een periode van tenminste tien dagen doorgebracht op elk van de acht bestudeerde ICUs en was aanwezig op verschillende tijdstippen (dag, avond, nacht). De observaties waren niet voorgestructureerd en werden uitgevoerd door het volgen van verpleegkundigen (en soms medewerkers uit andere disciplines) tijdens hun werkzaamheden. Door mee te lopen en mee te kijken was er ook gelegenheid om uitleg te vragen over de handelingen waar deze medewerkers mee bezig waren. Diepte-interviews werden uitgevoerd op rustige 
tijdstippen en betroffen de loopbaan, keuzes en motivatie van de verpleegkundigen. De gegevens die verzameld waren op een afdeling werden direct verwerkt en de voorlopige analyse werd voorgelegd aan de verpleegkundigen. Dit proces werd herhaald voor alle betrokken afdelingen. Nieuwe inzichten werden getoetst op een volgende afdeling, zodat theorievorming en gegevensverzameling werden geintegreerd. Deze overwegingen zijn bediscussieerd in Hoofdstuk 3 .

Uit het literatuuroverzicht in Hoofdstuk 2 blijkt dat in de huidige wetenschappelijke en vakliteratuur geen theorie met betrekking tot de rol van technologie in intensive care verpleging gevonden werd. Hierdoor was de gangbare manier van onderzoek doen, namelijk door een bestaande theorie te toetsen of te verfijnen ofwel een nieuwe theorie te formuleren als alternatief voor de bestaande, hier niet relevant. Het voornaamste probleem met de bestudeerde literatuur is dat onderzoek veelal wordt gekenmerkt door een nauwe probleemstelling die weliswaar goed binnen een bepaalde wetenschappelijke discipline past, maar aan de complexiteit van de praktijk geen recht doet. De disciplines en onderzoekstradities die besproken worden in het literatuuroverzicht zijn: (medische) technology assessment, geschiedenis van intensive care, ethiek, economie, psychologie, sociologie, en filosofie van mens-machine interactie.

\section{Resultaten}

In Hoofdstuk 4 worden de resultaten besproken van de analyse van de individuele loopbaangegevens die verkregen werden door middel van de diepte-interviews. In deze analyse is onderscheid gemaakt tussen drie soorten ICUs: de algemene ICU, waar veelal volwassenen worden verpleegd, de pediatrische of kinder-ICU voor kinderen van 0 tot 1 jaar en de neonatologische ICU waar pasgeborenen, vaak vroeggeborenen (prematuren), verpleegd worden. Uit de interviews blijkt dat een belangrijke loopbaankeuze betrekking heeft op het willen werken met kinderen of niet. De respondenten die na hun algemene opleiding de kinderaantekening behaalden, werken vrijwel allemaal op een pediatrische of neonatologische ICU en hebben hiervoor een specialisatie-cursus gevolgd. Van de verpleegkundigen die de kinderaantekening niet hebben, heeft het merendeel de algemene ICopleiding gevolgd en werkt nu op een algemene ICU. Doorstroming tussen de soorten ICUs is gering en vindt niet plaats vanuit de pediatrische of neonatologische ICU naar de algemene ICU. Andersom zijn wel een aantal verpleegkundigen overgestapt van de algemene ICU naar pediatrische of neonatologische ICU. De helft van deze groep zijn leidinggevenden. Hoewel in totaal evenveel mannen als vrouwen zijn geïnterviewd, is het opvallend dat de pediatrische en neonatologische ICUs relatief veel meer vrouwelijke verpleegkundigen in dienst hebben (tussen $84 \%$ en $99 \%$ ) dan algemene ICUs (tussen $44 \%$ en $83 \%$ ). Waar het motivatie en keuzes betreft, was het belangrijkste verschil tussen mannelijke en vrouwelijke respondenten dat vrouwen vaker voor kinderverpleging hadden gekozen.

Het arbeidsproces wordt beschreven in de hoofdstukken 5 en 6 . Hoofdstuk 5 behandelt de structuur van het arbeidsproces en beschrijft vier fasen die daarin voorkomen. Hoofdstuk 6 analyseert hoe verpleegkundigen omgaan met de verschillende soorten informatie die ze verzamelen tijdens hun werk en verbindt dit met individuele en collectieve leerprocessen. In beide hoofdstukken wordt de rol van technologie aan de orde gesteld. De rol van de technologie, en dan met 
name de waarde van de informatie die verkregen wordt door middel van de apparatuur en de effectiviteit van de handelingen die door de apparatuur ondersteund worden, wordt in elke situatie opnieuw bepaald. In de fase die "hands-off' genoemd wordt, heeft de apparatuur een betrekkelijk zelfstandige rol. in het zorgproces: de monitor, de beademingsmachine en de infuuspompen doen hun werk zonder directe supervisie van de verpleegkundige. In de hands-on routine fase wordt de apparatuur vertrouwd en worden gegevens die de appratuur produceert overgenomen in de administratie. In de 'hands-on emergency' fase heeft de apparatuur een belangrijke rol in het verschaffen van informatie waarop snel gereageerd moet worden. De rol van technologie is echter veel bescheidener in de fase van waakzaamheid, die wordt aangeduid met het begrip 'vigilance'. Hoewel continue waakzaamheid een kenmerk is van intensive care, is in dit onderzoek gevonden dat er omstandigheden zijn waarin de waakzaamheid verhoogd is. In het algemeen zijn in deze situatie de signalen van de apparatuur en de signalen van de patiënt niet met elkaar in overeenstemming. Bij twijfel wordt dan de voorkeur gegeven aan de informatie die direct van de patiënt af te lezen is en dit betekent dat de apparatuur niet vertrouwd wordt.

Het vak van intensive care verpleegkundige leert men voornamelijk in de praktijk. Tijdens de opleiding krijgen de cursisten theorie-lessen en werken ze mee op de afdeling. Daar worden ze begeleid door ervaren intensive care verpleegkundigen. Na de diplomering gaat het leerproces door en vertonen verpleegkundigen verschillende werkstijlen die samenhangen met hun ervaringsniveau. De belangrijkste verschuivingen die platsvinden in de manier waarop een verpleegkundige een situatie benadert, hebben betrekking op het herkennen van een situatie en het verkrijgen van overzicht. Naarmate men meer ervaring heeft, heeft men meer situaties meegemaakt en zal men de situatie sneller overzien. Een ervaren verpleegkundige is dus beter in staat om overzicht houden in deze onvoorspelbare omgeving. Omdat de verpleegkundigen die op het hoogste ervaringsniveau functioneren (de 'experts') zelf ook de lagere niveaus kennen, weten zij hoe de minder ervaren verpleegkundigen redeneren en kunnen zij daarom gericht sturen of ingrijpen. Het overzicht van de "experts" strekt zich verder uit dan de situatie van de patiënt waar men op dat moment mee bezig is en omvat ook andere patiënten en collega's. Daardoor vervullen de 'experts' een belangrijke rol in de coördinatie van de samenwerking. De organisatie van ICUs wordt gekenmerkt door grote individuele vrijheid van de verpleegkundige, waardoor samenwerking wordt vergemakkelijkt.

In dit onderzoek zijn twee inzichten besproken die het arbeidsproces van verpleegkundigen op ICUs mede vormgeven. Ten eerste: de rol van technologie in intensive care verpleging wordt steeds opnieuw bepaald in een proces van 'onderhandeling' waarin de verpleegkundige de verdiensten van de apparatuur afweegt tegen de directe waarneming en handeling aan de patiënt. Dit onderhandelingsproces is onderdeel van het arbeidsproces en is een van de vaardigheden die intensive care verpleegkundigen moeten leren. Ten tweede: samenwerken is van cruciaal belang in de ICU. Hoewel elke verpleegkundige in principe verantwoordelijk is voor een klein aantal patiènten, is in feite het hele team verantwoordelijk voor de hele groep patiënten. 



\section{Curriculum vitae}

Marjan Groen werd geboren op 7 oktober 1964 te Rotterdam. Zij behaalde in 1983 het atheneum-diploma aan de scholengemeenschap "Gemini" te Ridderkerk en ging aan de Erasmus universiteit te Rotterdam studeren bij de Studierichting Algemene Gezondheidszorg. Toen zij in 1989 afstudeerde was de naam van deze studie veranderd in Beleid en Management Gezondheidszorg. Tijdens haar studie verbleef zij een jaar (1987-1988) aan de University of Manchester (Verenigd Koninkrijk), waar zij de titel van Master of Science behaalde in Science and Technology Policy. Marjan werkte gedurende 1989 als "uitzend-beleidsmedewerker" voor Bureau Beleids- en Managementondersteuning in de Ouderenzorg te Den Haag. Vanaf 1 januari 1990 was zij als Assistent in Opleiding verbonden aan de Faculteit der Economische Wetenschappen van de Rijksuniversiteit Limburg. Het promotie-onderzoek voerde zij uit binnen het Maastricht Economic Research Institute on Innovation and Technology van deze universiteit. 